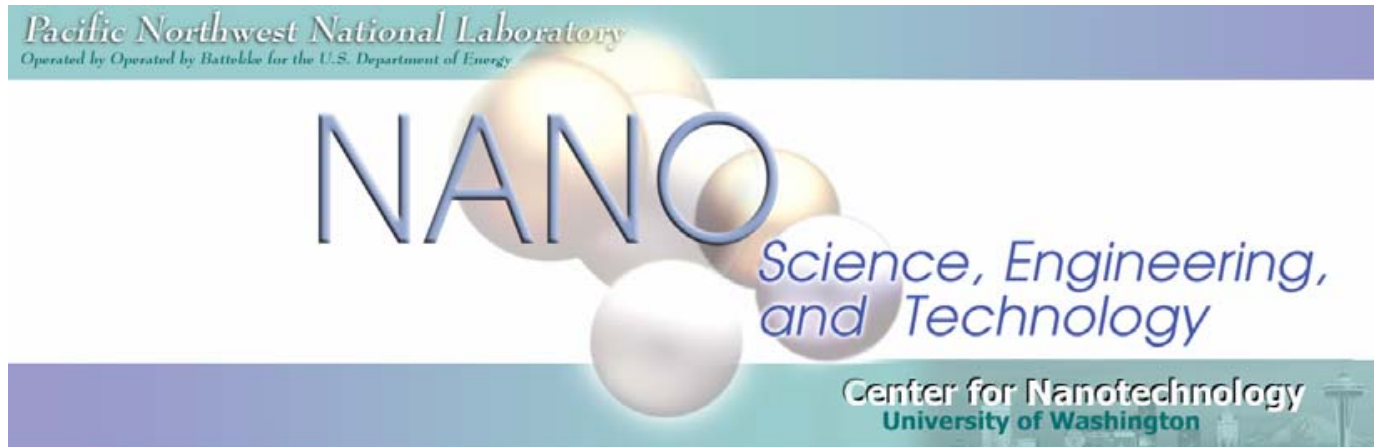

\author{
Joint Institute for Nanoscience \\ Annual Report, 2003
}




\title{
DISCLAIMER
}

This report was prepared as an account of work sponsored by an agency of the United States Government. Neither the United States Government nor any agency thereof, nor Battelle Memorial Institute, nor any of their employees, makes any warranty, express or implied, or assumes any legal liability or responsibility for the accuracy, completeness, or usefulness of any information, apparatus, product, or process disclosed, or represents that its use would not infringe privately owned rights. Reference herein to any specific commercial product, process, or service by trade name, trademark, manufacturer, or otherwise does not necessarily constitute or imply its endorsement, recommendation, or favoring by the United States Government or any agency thereof, or Battelle Memorial Institute. The views and opinions of authors expressed herein do not necessarily state or reflect those of the United States Government or any agency thereof.

\author{
PACIFIC NORTHWEST NATIONAL LABORATORY \\ operated by \\ BATTELLE \\ for the \\ UNITED STATES DEPARTMENT OF ENERGY
}

under Contract DE-AC06-76RL01830

Printed in the United States of America

Available to DOE and DOE contractors from the

Office of Scientific and Technical Information,

P.O. Box 62, Oak Ridge, TN 37831-0062;

ph: (865) 576-8401

fax: (865) 576-5728

email: reports@adonis.osti.gov

\begin{abstract}
Available to the public from the National Technical Information Service, U.S. Department of Commerce, 5285 Port Royal Rd., Springfield, VA 22161 ph: (800) 553-6847 fax: (703) 605-6900

email: orders@ntis.fedworld.gov

online ordering: http://www.ntis.gov/ordering.htm
\end{abstract}

This document was printed on recycled paper.

$(8 / 00)$ 


\section{Joint Institute for Nanoscience Annual Report, 2003}

Donald R. Baer

Charles T. Campbell

Co-Directors of the Joint Institute for Nanoscience

March 2004 


\section{Summary}

The Joint Institute for Nanoscience (JIN) is a cooperative venture of the University of Washington and Pacific Northwest National Laboratory (PNNL) to encourage and enhance highimpact and high quality nanoscience and nanotechnology of all types, and to facilitate education in these areas. This first annual report for the JIN summarizes activities beginning in 2001 and ending at the close of fiscal year 2003 and therefore represents somewhat less than two years of activities. Major portions of the JIN resources are dedicated to funding graduate students and postdoctoral research associates to perform research in collaborations jointly directed by PNNL staff scientists and University of Washington (UW) professors. These fellowships were awarded on the basis of applications that included research proposals. They have been very successful in initiating intensive research collaborations between PNNL and UW, which have led to many excellent joint publications and presentations and enhanced the competitiveness of both institutions for external grant funding. JIN co-sponsors an annual Nanoscale Science and Technology Workshop held in Seattle. In addition to involving PNNL staff in various UW nanoscience courses and seminars, a National Science Foundation grant Development of $U W$ PNL Collaborative Curriculums in Nano-Science and Technology has allowed the development of three intensive short courses that are taught by UW faculty, PNNL staff, and faculty from other institutions, including Washington State University, the University of Idaho, Stanford University, and the University of Alaska. The initial JIN agreement recognized that expansion of cooperation beyond UW and PNNL would be highly valuable. Starting in early 2003, efforts were initiated to form a regional communication link called the Northwest Nanoscience and Nanotechnology Network $\left(\mathrm{N}^{4}\right)$. In concept, $\mathrm{N}^{4}$ is a tool to encourage communication and help identify regional resources and nanoscience and technology activities.

In addition to an overview of JIN activities, this report includes summaries of individual JIN Award Projects, an assessment of the impact of the JIN, and listings of publications and presentations linked to JIN activities. 


\section{Contents}

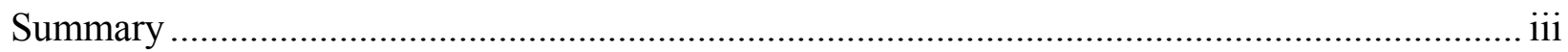

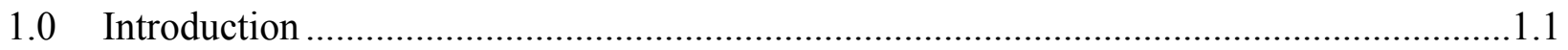

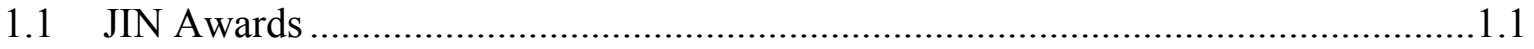

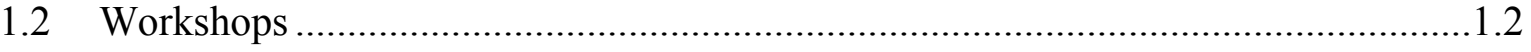

$1.3 \quad$ JIN Related Education Programs ...........................................................................1.3

1.4 Northwest Nanoscience and Nanotechnology Network ......................................1.3

$1.5 \quad$ JIN Organization......................................................................................

$2.0 \quad$ JIN Award Project Reports ……………………...............................................................

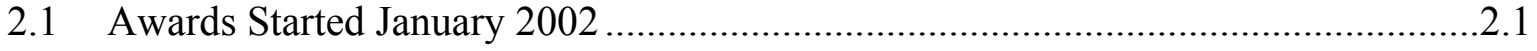

Synthesis, Magneto-Optical and Electronic Spectroscopies of Nanocrystalline Ferromagnetic

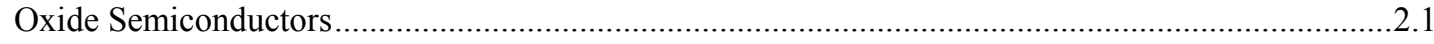

Synthesis and Characterization of Ordered Dye-Functionalized Oxide Nanostructures for Photoelectrochemical Applications .....

Fourier Transform Infrared Spectroscopy Studies (FTIR) and Temperature Programmed

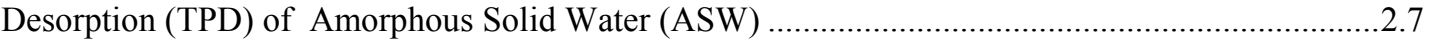

Development and Application of Interatomic Potentials for Heterogeneous Nanostructures .............2.9

Nondestructive Carbon Nanotube Modification for Tailored Functionality …….............................2.13

Fundamental Studies of Monolayer-Protected Nanoparticles by Gas Chromatography ...................2.16

Dilute Magnetic Semiconducting Oxide Thin Films and Nanostructures .......................................2.21

Interfacing Chip-Based Nanofluidic-Systems to Surface-Desorption Mass Spectrometry ..............2.24

Molecular Engineered Conjugated Polymers for High - Performance Light-Emitting Diodes

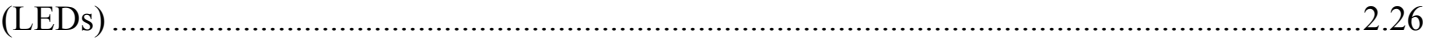

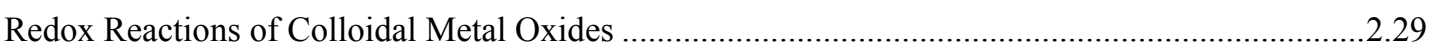

Electronic Structure of Thin Film Anatase $\mathrm{TiO}_{2}$ : A Candidate Spintronics Material.........................2.30

Surface Recognition and Incorporation of Additives into Calcium Oxalate Host Crystals..............2.33

Epitaxial Growth and Characterization of $\mathrm{Co}_{\mathrm{x}} \mathrm{Zn}_{1-\mathrm{x}} \mathrm{O}$ and $\mathrm{Co}_{\mathrm{x}} \mathrm{Ti}_{1-\mathrm{x}} \mathrm{O}_{2-\mathrm{x}}$ for Spintronic

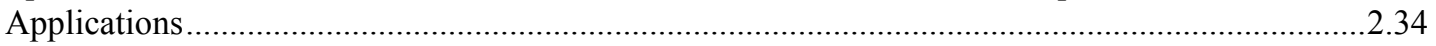

Sol-Gel Electrophoresis for the Formation of Nanosized Nanostructured Materials .......................2.37

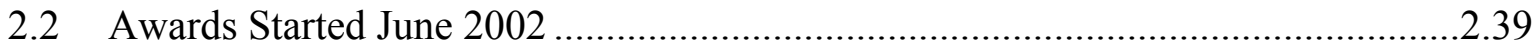

Superparamagnetic Nanoparticles for Imaging and Therapeutics ................................................2.39

Direct Simulation Approach to Multi-Phase Biomaterial Transport and Nano-Interactions in Microfluidic Systems 
Nature of Genetically Engineered Protein/Inorganic Interactions: Novel Molecular Linkers for Nanotechnology

Magnetic Nanocrystals: Synthesis and Study of $\mathrm{ZnO}$ and GaN Diluted Magnetic

Semiconductors

Materials Characterization and Magnetic Studies of Epitaxial $\mathrm{Co}_{\mathrm{x}} \mathrm{Ti}_{1-\mathrm{x}} \mathrm{O}_{2-\mathrm{x}}$ Deposited on $\mathrm{Si}(001)$

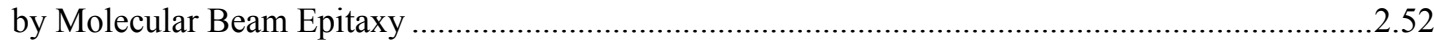

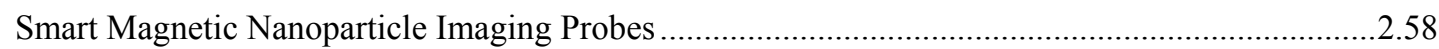

Photochemistry of Colloidal Dilute Magnetic Semiconductor Quantum Dots...................................2.59

Pd Nanoclusters Supported on $\mathrm{MgO}(100)$ : Effects of Cluster Size on Chemisorption Properties...2.61

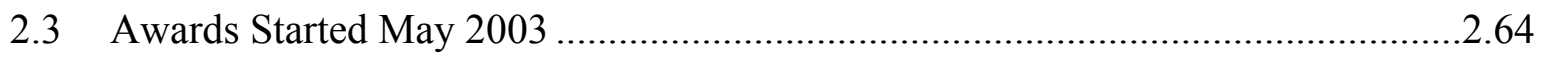

Bioaerosol Detection via Nanoparticle Surface Enhanced Raman Spectroscopy .............................2.64

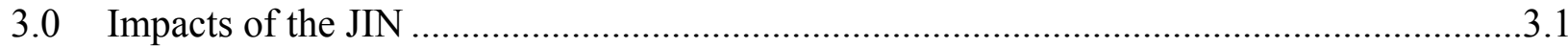

$3.1 \quad$ Summary of Impacts ......................................................................................

3.2 Papers Related to JIN Awards ………………....................................................3

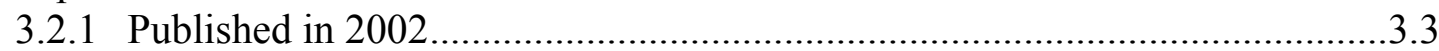

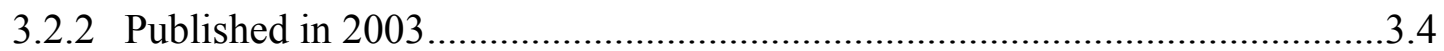

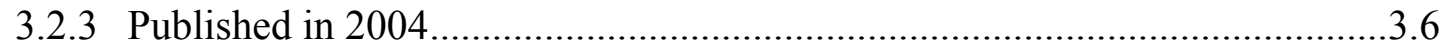

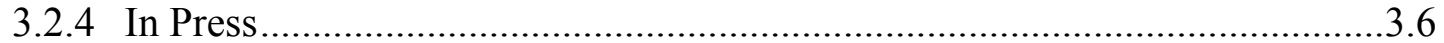

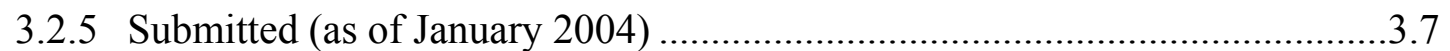

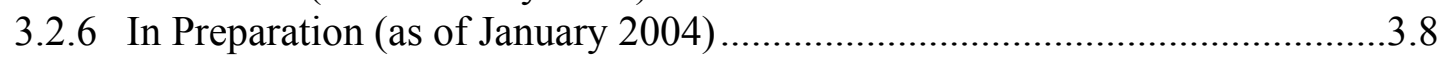

3.3 JIN Related Presentations .......................................................................................

Appendix A: List of JIN Awards by Award Dates ……………...............................................

Appendix B: JIN Related Award Winners..............................................................................

Appendix C: Programs from four Nanotech Workshops: Aug. 2001, Feb. 2002,

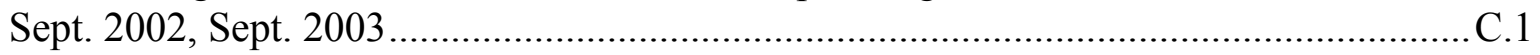

First Annual Seattle Nanotechnology Workshop, Aug. 2001 …………................................................. C.2

Business Forum Previous to Second Annual Seattle Nanotechnology Workshop, Sept. 2002 .................... C.4

Second Annual Seattle Nanotechnology Workshop, Sept. 2002 …............................................................

Third Annual Seattle Nanotechnology Workshop, Sept. 2003 ..................................................................

Richland Nanotechnology Workshop: Relating Nanoscience to Problems .................................................. 15

Appendix D: Syllabi for the Three Intensive Nanoscience Courses ........................................... 1

D.1 Nanoclusters, Nanomaterials, and Nanotechnologies .......................................................................... 1

D.2 Fabrication and Characterization of Nanomaterials .........................................................................

D.3 Fabrication and Characterization of Nanomaterials .........................................................................

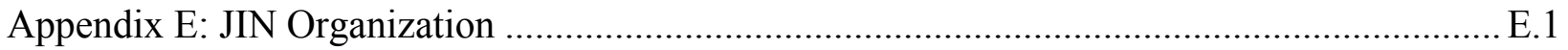




\subsection{Introduction}

The Joint Institute for Nanoscience (JIN) was established by the University of Washington and Battelle, which operates Pacific Northwest National Laboratory (PNNL), in April 2001. Both the university and laboratory provide up to $\$ 500,000$ on an annual basis for support of the JIN. Each institution offers substantial technical capability and personnel with high levels of skill and expertise in this area. By combining these institutional strengths, both nanoscience and nanotechnology research progress and educational activities are advanced. Activities undertaken include engaging in collaborative research and development (R\&D) activities, sharing facilities, conducting workshop and symposia to enhance communication and staff interactions, and working together to secure R\&D contracts for research and education.

The JIN was established in 2001, but full operation did not begin until early calendar year 2002. This report summarizes projects through the end of fiscal year 2003 and therefore represents somewhat less than two years of activity. As would be expected, the activity of the JIN has expanded, and the intensity of collaborations in nanoscience and nanotechnology R\&D and their related educational activities have increased. More specifically, we have cooperated strongly in a variety of efforts to:

- Increase the number of PNNL/UW collaborative projects

- Coordinate education and training opportunities

- Develop multi-disciplinary programs

- Offer short-courses and conferences

- Jointly host visiting scientists

- Secure private and public sector funding for research and education activities.

Those involved with the JIN have sensed a dramatic increase in the level of interactions between the two institutions in the past year which have resulted directly from JIN activities. A separate section of this report will attempt to evaluate the impact of JIN activities.

\subsection{JIN Awards}

The major part of the JIN budget is dedicated to fund graduate students and postdoctoral research associates to perform research in collaborations jointly directed by PNNL staff scientists and UW professors. These fellowships were awarded on the basis of applications which included research proposals. The JIN Steering Committee scored these proposals on the following basis:

A. Quality of proposed research and (for renewals) performance to date.

B. Expected enhancement of collaborations between PNNL and UW. 
C. Contribution toward chances for external funding of collaboration between PNNL and UW, and/or impact on other Joint Institute missions besides that in item $\mathrm{C}$ above (e.g., quick publications).

D. Relevance to nanoscience.

E. Previous academic and/or research performance of individual to be funded and/or collaborator from PNNL and UW (new applications ONLY).

F. Performance in first funded period (renewals ONLY).

Funding included the graduate student or postdoc salary, tuitions for grad students, and travel and housing expenses for time spent at PNNL. Appendix A contains a list of the awards granted through September 2003. The main body of the report is a summary from each JIN award project that outlines the research progress and the publications or external grant proposals that have so far resulted from this funding. The reports can also be found at http://www.pnl.gov/nano/institute/index.html.

The JIN seeks to encourage and enhance high-impact and high-quality nanoscience and nanotechnology of all types. However, it is also clear to the JIN Steering Committee that the maximum impact of the JIN may be best achieved if we focus some of our efforts and attention in specific areas where complementary strengths of the two institutions match scientific, technological, and funding opportunities. One of the first areas of significant overlap was associated with nano-scale magnetic materials and diluted magnetic semiconductors. Many of the early JIN awards were linked to this area, new programs were developed, and outside funding has been obtained at both UW and PNNL in this area. In January 2003, the JIN Steering Committee formally recognized that the areas of Nano-Structured Reactive Materials Systems and Nano-biological Nano-Materials Based Functional Systems impact a wide variety of technologies (including medical, environmental, national security, and energy) and will strongly benefit from differing scientific skills and technology needs of the two institutions. These represent two areas of major importance that are under-represented in many Nanoscience and Technology efforts.

\subsection{Workshops}

The JIN co-sponsors an annual Nanoscale Science and Technology Workshop held in Seattle. This workshop was started in 2001; the third workshop was held on the UW campus in Sept. 2003. Although participation of UW students, especially those with JIN awards, and faculty and PNNL staff is encouraged, participation throughout the northwest is sought. The program is found in Appendix C. The level of presentations was superb. Notable was the fact that many scientists came from across the country just to listen to the presentations, including scientists from Wright-Patterson Air Force Base and Lawrence Livermore National Laboratory. A number of scientists with world-class reputations were also invited from around the world to speak at this meeting. We instituted Outstanding Student Presentation Awards this year, with one each awarded for the best oral and poster presentations. In addition to the Seattle workshop, a special workshop focused on relating 
nanoscience to needs and technologies important to DOE was held in Richland, Washington, in February 2002.

\subsection{JIN Related Education Programs}

In addition to involving PNNL staff in various UW nanoscience courses and seminars, an NSF grant Development of UW-PNL Collaborative Curriculums in Nano-Science and Technology has allowed the development of three intensive short courses that are taught by UW faculty, PNNL staff, and faculty from other institutions, including Washington State University, the University of Idaho, Stanford University, and the University of Alaska. The three courses are 1) An introduction to nanoscience and nanotechnology, 2) Theory and Modeling of Nanoscale Material Systems, and 3) Fabrication and Characterization of Nano-materials. Various versions of these courses have been taught in Richland at PNNL and in Seattle. The introductory course was taught in Seattle during the winter quarter 2003 and in Richland the last two weeks in May 2003. The Modeling and Theory course was first offered in September 2003 in Seattle. The Fabrication and Characterization course was given for the first time in January 2004 in Richland, and the introductory course is scheduled again for May 2004 (http://www.nano.washington.edu/pnnl/courses.html). Syllabi of these courses are listed in Appendix D.

\subsection{Northwest Nanoscience and Nanotechnology Network}

The initial JIN agreement recognized that expansion of cooperation beyond UW and PNNL would be highly valuable. Starting in early 2003, efforts were initiated to form a regional communication link called the Northwest Nanoscience and Nanotechnology Network $\left(\mathrm{N}^{4}\right)$. In concept, $\mathrm{N}^{4}$ is a tool to encourage communication and help identify regional resources and nanoscience and technology activities. There is a public website offering a variety of information, including contacts and participating institutions as well as a calendar and information about research, education, and business activities. In addition to the public site, there is a secure member area where reports can be processed; members can post information or work, in a secure fashion, on proposals and publications. The public site started preliminary operation in the fall of 2003. The site is still under development, but can be examined at www.pnl.gov/nwnano. Many northwest universities and research organizations were asked to become founding $\mathrm{N}^{4}$ members, each with an institutional representative who will help chart the future of the network. Initial participants have suggested that in addition to web-based communication that $\mathrm{N}^{4}$ participants may want to be involved in an annual meeting, and the possibility of live internet of video seminars should be explored. A current list of organizations associated with $\mathrm{N}^{4}$ can be found on the website. As of December 2003, participants from Washington, Oregon, and Idaho are included. 


\subsection{JIN Organization}

The organization of the UW and PNNL agreement for the JIN gave much of the responsibility for JIN operation to a steering committee made up of five researchers each from the two institutions. It is the responsibility of the committee to work out criteria, develop and implement policy (with approval of an advisory board), and evaluate the award applications. Much of the success of the JIN builds on the hard work of the Steering Committee members (see Appendix $\mathrm{C}$ for a listing of members). The JIN is part of a more general Joint Institutes agreement between the UW and PNNL. All JIN activities have been undertaken under the guidance of a Joint Institutes Advisory Board and a Council of Fellows whose members are listed in Appendix E. 


\title{
2.0 JIN Award Project Reports
}

This section contains short reports describing JIN awards. These reports are arranged in three groups based on when the awards were initiated: January 2002, June 2002, and May 2003.

\subsection{Awards Started January 2002}

\section{Synthesis, Magneto-Optical and Electronic Spectroscopies of Nanocrystalline Ferromagnetic Oxide Semiconductors}

\author{
J. Daniel Bryan*, Daniel R. Gamelin**, Scott A. Chambers ${ }^{\&+}$ \\ ${ }^{+}$mentors; * Chemistry Dept. University of Washington; ${ }^{\&}$ Pacific Northwest National \\ Laboratory
}

\section{Project Summary}

Recent promising work in the field of spintronics has shown that internal incorporation of cobalt into $\mathrm{TiO}_{2}$ (anatase), grown by high-vacuum Oxygen Plasma Assisted Molecular Beam Epitaxy (OPA-MBE), results in a ferromagnetic dilute magnetic semiconductor (DMS) above room temperature. Such a high Curie temperature material would be quite useful for controlling the electron spin state in future generation spin dependent computation. However, solution chemistry offers a complementary technique and alternative approach to such spintronics materials. We propose developing and studying a colloidal solution chemical approach that has the added benefits of 1) dopant ion oxidative state control achieved through Sol-Gel chemical techniques, 2) accessibility of ultraviolet-visible (UV-VIS) characterization probes capable of elucidating dopant speciation, and 3) the low cost of sol-gel chemical precursors and equipment. Nanophase doped samples offer the unique processability of colloidal samples along with possessing the potential to be used as nanoscale building blocks for larger hetero-structures.

We have used Sol-Gel micellar nanoreactors to synthesize doped $\mathrm{TiO}_{2}$ colloids. Because the initial hydrolysis step of the Sol-Gel process, through the nucleophilic addition of water, is so rapid, internalization of a dopant species may only be achieved by slowing down the hydrolysis step via limiting the number and type (free or bound) of water molecules present. Pressure treatment of the doped nanoparticles yields nanocrystalline material as seen in Figure 1. Fitting the width of the (101) peak in the spectrum at $2 \theta=25.2^{\circ}$ using the scherrer relation yields an average particle diameter of $4 \mathrm{~nm}$. The crystallinity of the nanophase doped titania and the crystallite size is further verified by Transmission Electron Microscopy (TEM) (taken at PNNL) shown in Figure 2.

The magnetic properties of these nanocrystals were measured to investigate their DMS behavior. Ferromagnetism has been observed in these samples as evidenced by the room temperature hysteresis of the magnetic moment shown in Figure 3. The saturation moment of the Co is lower than that of the thin film, indicating a large concentration of paramagnetic Co ions. However, this behavior is to be expected, as the inter-granular electronic coupling between nanocrystallites is significantly weaker than the homogenous OPA-MBE grown thin films. The 
coupling can be increased by high temperature sintering of the particles into larger crystallites. This is demonstrated in Figure 3 where the saturation moment is increased by a near order of magnitude upon sintering the particles from an average $4 \mathrm{~nm}$ to an average $22 \mathrm{~nm}$. Such an electronic coupling between Co ions is thought to be necessary for the itinerant electron exchange interaction resulting in ferromagnetism. Tuning such an interaction will be important for the rational design of DMS hetero-structures. The ligand field absorption spectroscopy and magneto-optic circular dichroism spectroscopy are shown in Figure 4. The chemical doping procedure significantly changes the band structure of the $\mathrm{TiO}_{2}$, shifting the absorption bandgap edge from UV into the visible region, resulting in a light orange-brown color of the doped colloidal samples. The inflection change in the doped absorption spectra between 16000 and $24000 \mathrm{~cm}^{-1}$ are the $d-d$ or ligand-field bands of the Co dopant. These bands appear to be obscured by the bandgap absorption edge extending into the visible, likely a result of subbandgap defect states arising in the perturbed $\mathrm{TiO}_{2}$ band structure. The Magnetic Circular Dischroism (MCD) is also shown in Figure 4. These data, taken at $5 \mathrm{~K}$, verify the existence of the ligand-field bands, and the feature shows an increasing intensity with increasing field. This mixing verifies that the Sol-Gel derived $\mathrm{Co}_{0.023} \mathrm{Ti}_{0.97} \mathrm{O}_{2}$ nanocrystals are indeed dilute magnetic semiconductors. Shown in Figure 5 is the absorption and MCD spectra of $\mathrm{Zn}_{1-\mathrm{x}} \mathrm{Co}_{\mathrm{x}} \mathrm{O}$ grown by MOCVD at PNNL by A. Tuan and S. Chambers. The saturation magnetization fit inset shows the spin state $(S=3 / 2)$ and magnetization of the charge-transfer transition, illustrating magnetization of the $\mathrm{ZnO}$ band states by the dopant and therefore DMS behavior.

\section{Publications, Presentations and Proposals}

1. J. Daniel Bryan, S. Heald, S. Chambers, D. R. Gamelin, "Colloidal Cobalt Doped TiO2 nanocrystals: Nanoscale Diluted Magnetic Semiconductor Building Blocks for High-Tc ferromagnetic Materials”, submitted to Applied Physics Letters, 2003.

2. Tuan, S. Chambers, J. D. Bryan, D. R. Gamelin, et al. "Epitaxial Growth and Properties of Cobalt doped $\mathrm{ZnO}$ on Al2O3 Single Crystal Substrates," submitted to Phys Rev. B.,2003.

3. Proposal citing this work submitted to the American Chemical Society- Petroleum Research Fund-Alternative Energy Research Post-Doctoral Fellowship. - Proposal chosen for funding. 


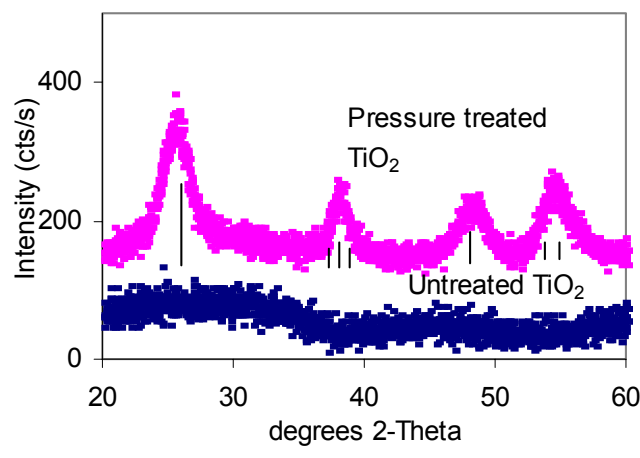

Figure 1. Powder X-Ray diffraction of untreated and pressure treated nanocrystalline $\mathrm{Co}_{0.023} \mathrm{Ti}_{0.097} \mathrm{O}_{2}$. Vertical lines represent position of bulk anatase peaks.

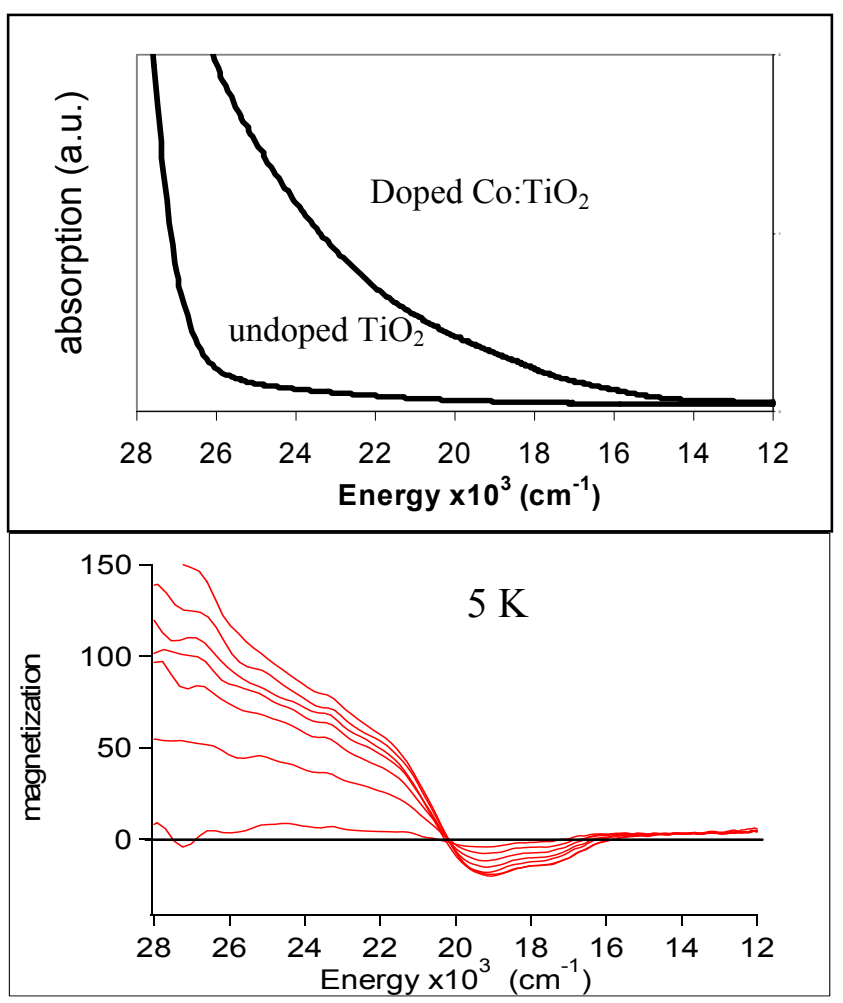

Figure 4. Electronic absorption (upper) and magnetic circular dichroism (lower) spectrum of $\mathrm{Co}_{0.023} \mathrm{Ti}_{0.97} \mathrm{O}_{2}$.

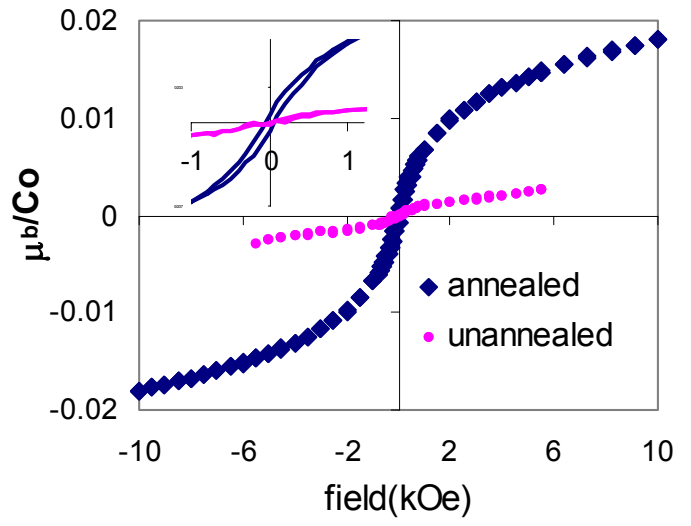

Figure 3. $300 \mathrm{~K}$ hysteresis loop for

$\mathrm{Co}_{0.023} \mathrm{Ti}_{0.097} \mathrm{O}_{2}$. The annealed sample was heat treated in air at $600 \mathrm{C}$ for $1 / 2$ hour; XRD analysis gave particle sizes $\sim 20 \mathrm{~nm}$.

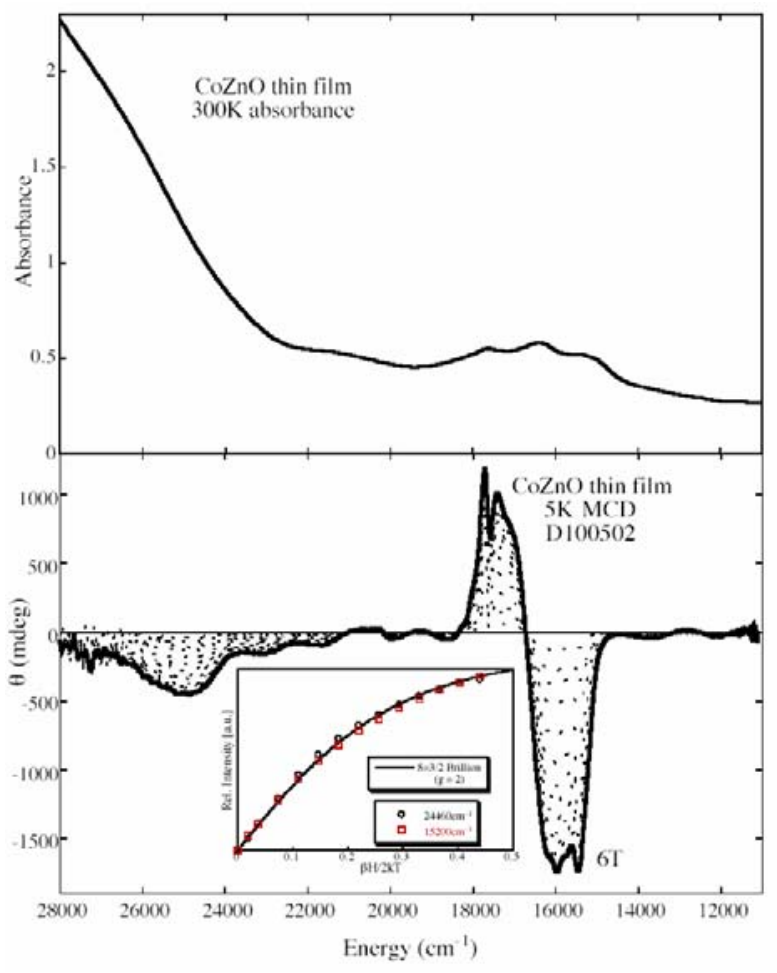

Figure 5. Absorption (upper) and MCD spectra (lower) of $\mathrm{Co}: \mathrm{ZnO}$ thin film. Inset shows magnetization saturation for $24460 \mathrm{~cm}^{-1}$ and $15200 \mathrm{~cm}^{-1}$ fit to a spin $3 / 2$ Brilluoin function. 


\section{Synthesis and Characterization of Ordered Dye-Functionalized Oxide Nanostructures for Photoelectrochemical Applications}

Awardee: Tammy Chou - UW

Mentors: Guozhong Cao - UW; Glen Fryxell and Paul Burrows - PNNL

\section{Project Summary}

Nanostructures are advantageous in solar cell devices for highly-efficient conversion of light to electric power. In particular, dye-sensitized solar cells (DSSCs) using inexpensive porous nanocrystalline titania $\left(\mathrm{TiO}_{2}\right)$ film with an interconnected network of nanometer-sized crystals in conjunction with an efficient light-absorbing dye have achieved $>10 \%$ conversion efficiency.

We are currently exploring the potential for utilizing ordered dye-functionalized oxide nanostructures, specifically $\mathrm{TiO}_{2}$ and indium-tin-oxide (ITO) materials, in solar cell devices in an attempt to simplify the electron percolation pathways during the light conversion process in order to further improve the efficiency. To examine this potential, we have successfully synthesized $\mathrm{TiO}_{2}$ and ITO nanorods with good uniformity using template-assisted sol electrophoresis, and have also managed to attach these nanorods onto conducting ITO glass using a layer of ITO sol. Figures $1 \mathrm{a}$ and $1 \mathrm{~b}$ show the SEM images of grown $\mathrm{TiO}_{2}$ and ITO nanorods attached to an ITO substrate. The nanorods are $\sim 150 \mathrm{~nm}$ in diameter for $\mathrm{TiO}_{2}$ and $\sim 140 \mathrm{~nm}$ in diameter for ITO, and $\sim 10 \mu \mathrm{m}$ in length for both materials. XRD analysis of the nanorods verified that $\mathrm{TiO}_{2}$ maintained the anatase phase and also confirmed the cubic structure of ITO. Initial solar cell analysis found that electrodes consisting of these ordered nanorod structures exhibited an overall light conversion efficiency $<0.1 \%$, and they were observed to be highly unstable with very low short-circuit current and open-circuit voltage values.

Based on these initial findings, we directed our studies to electrodes with $\mathrm{TiO}_{2}$ film prepared from the same $\mathrm{TiO}_{2}$ sol used to form the $\mathrm{TiO}_{2}$ nanorods in an effort to compare results and to determine the cause for the instability and reduced current and voltage values found for the electrodes with an ordered nanorod structure. Analysis of the $\mathrm{TiO}_{2}$ film electrode yielded an overall light conversion efficiency of $\sim 1 \%$, which is $\sim 10$ times higher than the ordered nanorod electrode. However, it was found that prolonged air and light exposure reduced the performance of the solar cell. Figure 2a compares the initial I-V curve for the solar cell with the $\mathrm{TiO}_{2}$ film immediately after dye immersion with the I-V curves obtained from the same electrode after exposure to air and light for various amounts of time. It can be seen that the I-V behavior eventually becomes unstable, and the current begins to fluctuate after extended air and light exposure. This highly unstable behavior was comparable to the behavior found in our initial findings for the electrodes with an ordered nanorod structure. Figure $2 b$ shows the decreasing trend in short-circuit current and open-circuit voltage for the $\mathrm{TiO}_{2}$ film as the amount of air and light exposure increases. It can be seen that excess air and light exposure reduced the current and voltage values, thereby decreasing the efficiency by $>50 \%$, and eventually resulted in very poor performance. Further analysis also found that the amount of surface coverage has some influence on the performance of the solar cell and that the presence of visible surface defects reduces the effectiveness of the electrode during the light conversion process. 
In general, our initial analysis of $\mathrm{TiO}_{2}$ film electrodes indicated that dye oxidation and degradation, as well as surface defects, factor into the conversion efficiency and performance of the solar cell. The very low efficiency initially obtained for the ordered nanorod structure may have been influenced by the above-mentioned factors, as evidenced by the unstable I-V behavior in Figure 2. However, the random alignment of the nanorods seen in Figure 1, where a number of nanorods are sintered together and a few are free-standing, and the possibility of incomplete nanorod adhesion to the substrate surface, where minimal contact at the nanorod-substrate interface might have reduced electrical contact and limited the electron transport process, may have also influenced the measurement. Further structural studies are currently underway to verify this, and methods to optimize the nanorod structure are being explored to further analyze the potential of these ordered nanostructures.

\section{Publications and Presentations}

1. T.P. Chou, C.M. Chung, and G.Z. Cao, "Ordered Dye-Functionalized Titania Nanorods and Their Applications as Sensors," in Nanomaterials and Their Optical Applications, SPIE Proceedings 5224, eds. G.Z. Cao, Y.N. Xia, and P. Braun, 53-61 (2003).

2. "Ordered, Dye-Functionalized Titania Nanostructures for Photoelectrochemical Applications," T.P. Chou, S.J. Limmer, and G.Z. Cao, SPIE $48^{\text {th }}$ Annual International Symposium in Optical Science and Technology, San Diego, CA, August 2003.

3. "Formation and Optical Properties of Cylindrical Gold Nanoshells on Silica and Titania," S.J. Limmer, T.P. Chou, and G.Z. Cao, in Nanoscale Optics and Applications, Proceedings of SPIE 4809, ed. G.Z. Cao and W.P. Kirk, 222-230 (2002).

4. "Functionalized, Hierarchically Structured Mesoporous Silica by Sol Electrophoresis and Self Assembly," T.P. Chou, S.J. Limmer, and G.Z. Cao, in Nanoscale Optics and Applications, Proceedings of SPIE 4809, ed. G.Z. Cao and W.P. Kirk, 239-248 (2002).

5. "Adhesion of Sol-Gel-Derived Organic-Inorganic Hybrid Coatings on Polyester," (invited), T.P. Chou and G.Z. Cao, Journal of Sol-Gel Science and Technology 27, 31-41 (2003).

6. "A study on the Growth of $\mathrm{TiO}_{2}$ Nanorods by Sol Electrophoresis," S.J. Limmer, T.P. Chou, and G.Z. Cao, Journal of Materials Science, in press (2003).

\section{Funding that has resulted from this research}

"Highly Efficient Inexpensive Solar Cells Based on Ordered Nanostructures," still under review. "Photoelectrochemical Cells Based on Nanofiber Films," still under review. 


\section{Figures}
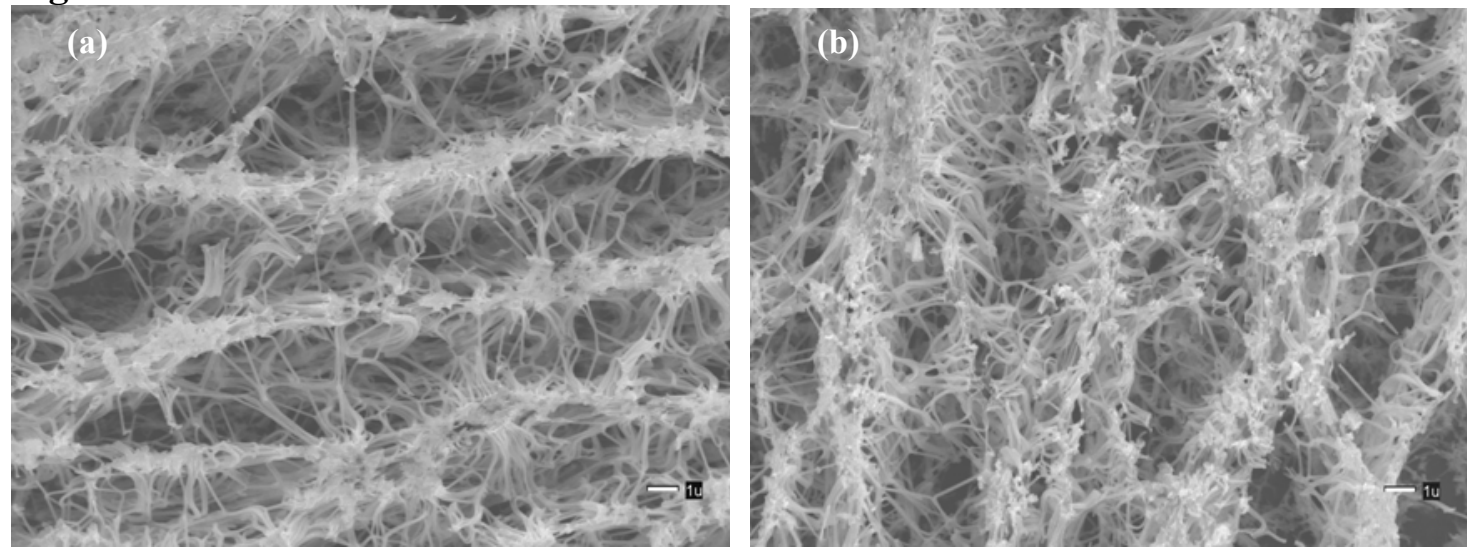

Figure 1. SEM images of an array of (a) $\mathrm{TiO}_{2}$ nanorods and (b) ITO nanorods attached to an ITO substrate using ITO sol after sintering to $500^{\circ} \mathrm{C}$ and $650^{\circ} \mathrm{C}$, respectively.
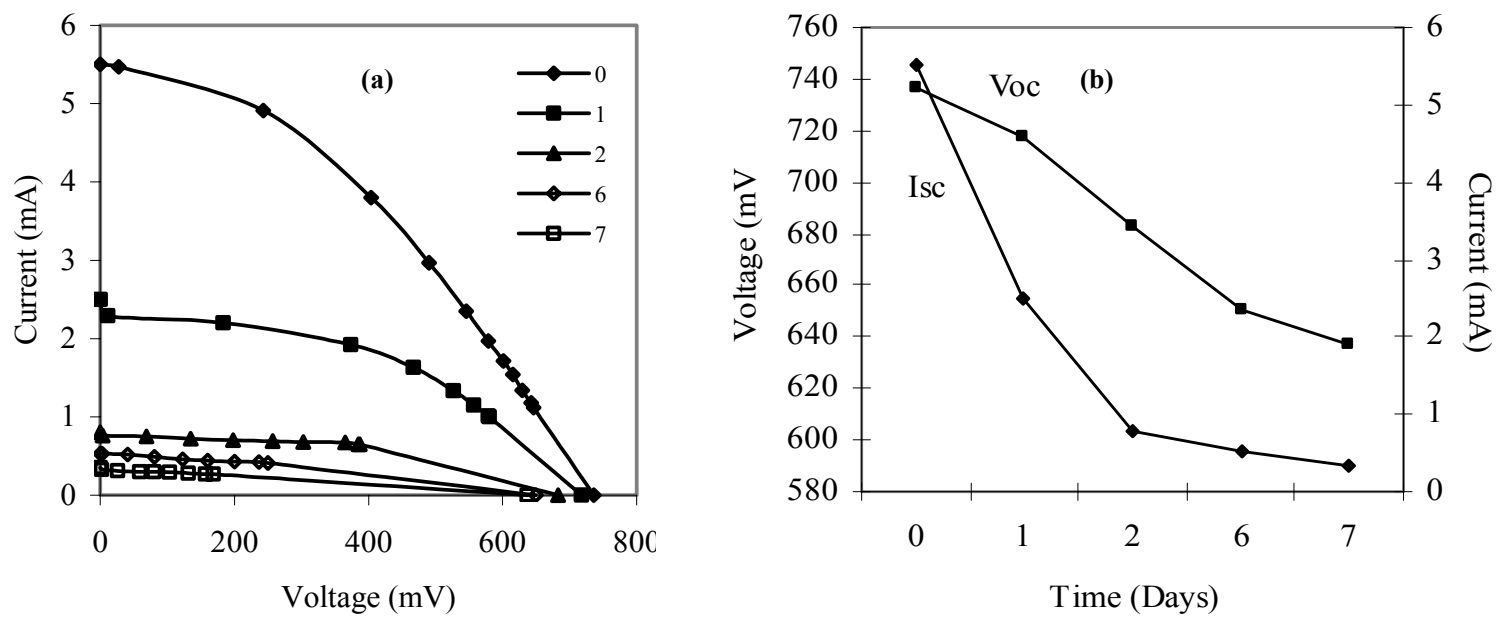

Figure 2. Plots showing (a) the current-voltage (I-V) curves of the solar cell with a $10 \mu \mathrm{m}$-thick $\mathrm{TiO}_{2}$ film electrode taken after $0,1,2,6$, and 7 days of air and light exposure to compare the effect of dye degradation by oxidation, and (b) the relative short-circuit current and open-circuit voltage trends resulting in decreased efficiency and reduced performance. 


\section{Fourier Transform Infrared Spectroscopy Studies (FTIR) and Temperature Programmed Desorption (TPD) of Amorphous Solid Water (ASW)}

Awardee: Jason Donev and Sam Fain

Mentors: Sam Fain - UW; Bruce Kay - PNNL

Fourier Transform Infrared Spectroscopy Studies (FTIR) and Temperature Programmed Desorption (TPD) measurements were used for a preliminary investigation of $\mathrm{H}_{2} 0$ water films deposited on decane-covered $\operatorname{Pt}(111)$ as a function of deposition time, temperature, and angle.

We performed isothermal sticking/condensation measurements on decane covered $\operatorname{Pt}(111)$. At temperatures above $100 \mathrm{~K}$, the initial condensation coefficient was less than 1 and decreased with increasing temperature. At a given temperature, the condensation coefficient increased monotonically with exposure reaching a temperature dependent asymptotic value. The complicated time dependence of the condensation coefficient is thought to be due to differences between water desorption from bare decane and water desorption from water clusters. The water desorption kinetics also depend on the water diffusion kinetics on the decane substrate. The topology of the water clusters/islands is not known, and therefore kinetic modeling of this data is difficult.

FTIR measurements showed that water films deposited at normal incidence at $80 \mathrm{~K}$ crystallized after annealing at $146 \mathrm{~K}$ for 20 minutes. Sticking measurements of water films prepared in the same way showed that the water films dewetted from (clustered on) the decane substrate.

TPD measurements indicated that production of crystalline nuclei is a strong function of deposition $\mathrm{T}$, becoming significant above $100 \mathrm{~K}$ for water on decane. This result supported the UW hypothesis that the number of crystalline nuclei for water films initially deposited on $\mathrm{Au}(111)$ varied with temperature for $\mathrm{T}>85 \mathrm{~K}$.

The EMSL experiments also led to the important new idea that the cantilever in the AFM measurements was redirecting water desorbed from the surface during AFM annealing experiments, an interpretation that was tentatively confirmed by further AFM measurements after the EMSL experiments.

A surprising preliminary result was that water depositions on decane plated $\operatorname{Pt}(111)$ near 120 $\mathrm{K}$ led to non-crystalline clusters.

Some of these results are very briefly described in the Ph.D. dissertation of Jason Donev. 


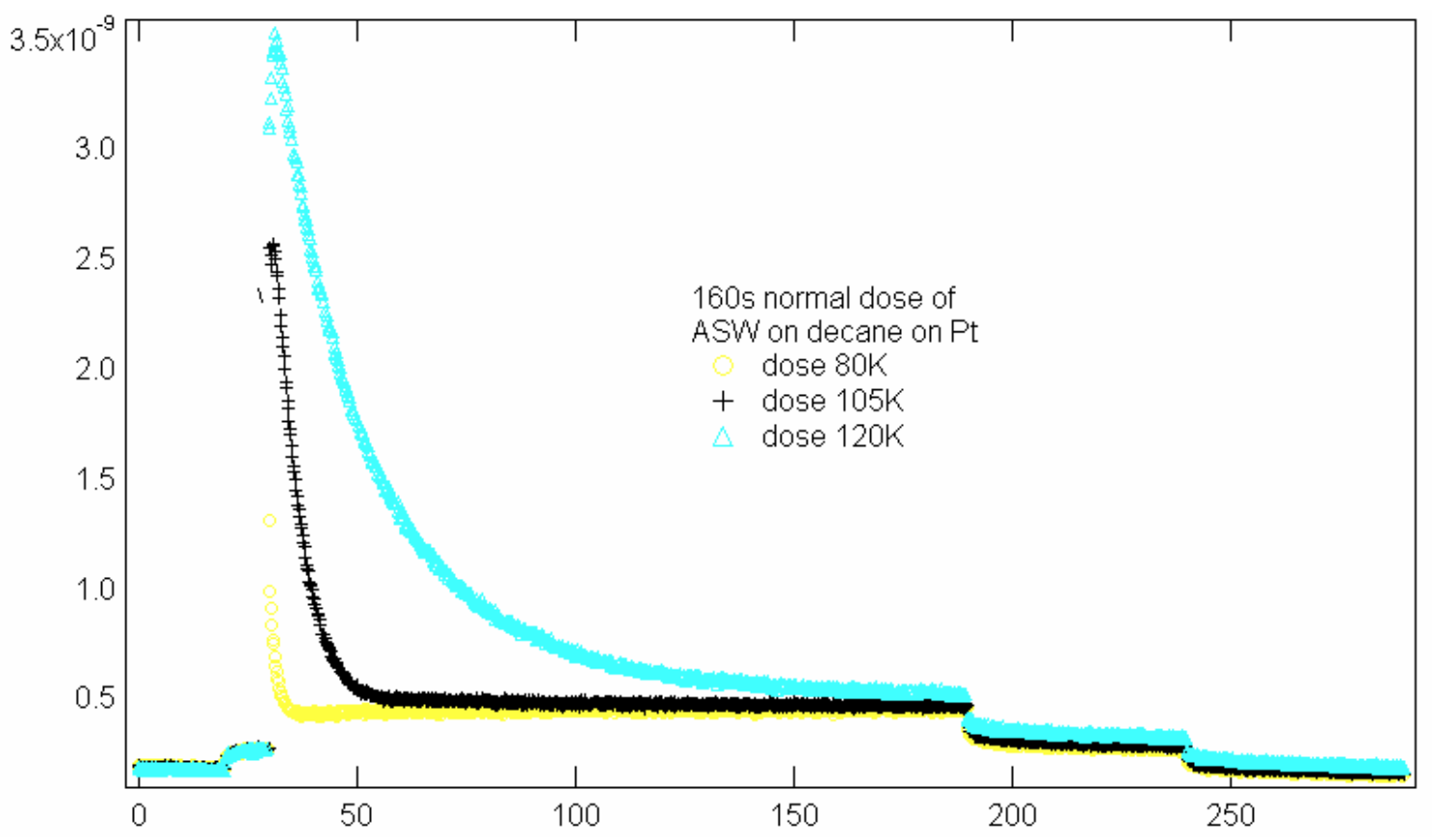

King-Wells measurements for condensation of water on decane coated $\operatorname{Pt}(111)$. Water was deposited on the decane surface at normal incidence. The axes are partial pressure of water vs. time in seconds. The initial small rise in pressure that is present for all three curves is due to the gate valve opening, which blocks off the molecular beam from the sample. A shutter with very precise timing control is moved out of the way at 30 seconds, and the pressure rises abruptly. For the bottom curve, the substrate was at $80 \mathrm{~K}$; the chamber pressure returning to equilibrium very quickly indicates that all of the water condensed on the surface. For dosing at $105 \mathrm{~K}$, the middle curve, the pressure took a longer time to return to the same equilibrium background pressure as in the dose at $80 \mathrm{~K}$. For the top curve, the pressure took much longer to reach the equilibrium pressure. From this, it is concluded that water has a non-unitary initial condensation coefficient on decane, starting around $105 \mathrm{~K}$ and decreasing with increasing temperature. 


\title{
Development and Application of Interatomic Potentials for Heterogeneous Nanostructures
}

\author{
May 2003
}

Scott Dunham, Joo Chul Yoon, Electrical Engineering, University of Washington

Anter El-Azab, Fundamental Science Directorate, Pacific Northwest National Labs

\section{Project Summary}

A key challenge in dealing with nanostructures is that system sizes are too large to deal with effectively via ab-initio approaches (a volume of $5 \mathrm{~nm}^{3}$ contains on the order of 104 atoms), but they are so small that their properties are strongly controlled by surface/interface properties and details of internal structure. Recent advances in computational power and efficient algorithms for long time scale dynamics $[1,2,3]$ have made it possible to use approaches based on molecular dynamics (MD) to analyze the behavior of nanostructures. However, a major barrier in application of these methods to systems of practical interest is the lack of efficient and accurate interatomic potentials for multi-component and multi-phase systems. The aim of this work is to develop potentials that can be successfully applied across multiple phases and (most critically) at heterogeneous materials interfaces. We will specifically explore potentials that account for charge transfer between atoms to allow the potential to span interfaces among metallic, ionic, and covalently bonded systems. The aim is to generate an approach that is applicable across a broad array of material systems.

In addition to the potential development, we used density functional theory (DFT) calculations for calibration and molecular dynamics (MD) simulations as a tool for the computational modeling of nanosystems, which in turn enables the use of these tools as a virtual laboratory for optimizing nanostructure design to meet application goals. We specifically focused on potentials for systems with multiple phases with fundamentally different bonding structures to apply them to systems of both immediate and long-range technological interest. Specifically, we are developing potentials that can be effectively used for understanding $\mathrm{metal} / \mathrm{ceramic}$, semiconductor/ceramic, and metal/semiconductor interfaces. Initial prototype systems that have been explored to date are $\mathrm{Ti} / \mathrm{TiOz}$ systems, $\mathrm{Fe} / \mathrm{Fe}$-oxide interfaces, and 8i:As. These targets are chosen to match the application areas of greatest interest to the collaborating UW and PNNL groups. In this way, it is anticipated that the research will strongly leverage ongoing research in the two groups.

\section{Research Results}

As the basis of our development of interatomic potentials, we use the Modified Embedded Atom Potential (MEAM) [6] framework combined with explicit consideration of charge transfer and Coulombic interactions via the electrostatic plus (E8+) approach pioneered by Streitz and Mintmire $(8 \mathrm{M})[4,11]$. By combining these two methods, we generate potentials that are transferable across a wide range of phases and interfaces, including metals, semiconductors, and ceramics.

The MEAM method (a generalization of the embedded atom method in which angledependent densities are included to model covalent bonding) can be considered a simplified 
version of tight-binding in which a static set of orbital basis functions is utilized. Within this system, charge transfer can be considered as variable occupation of the orbitals. The E8+ approach provides an efficient method to determine the optimum charge distribution and therefore both the electrostatic and MEAM bond energies as function of atomic structure.

Although the E8+ method has been used in dozens of published of papers over the past decade, our analysis found a critical error in 8M's approach [4]. To determine the optimum charge distribution, it is necessary to calculate the interaction energy between one orbital and an infinite periodic array of other orbitals. SM calculated this interaction via Ewald sums; however, because the periodic cells are not charge-neutral, the infinite summations diverge, and so the Ewald summation is invalid. We have developed and implemented a reformulation of the core ES+ method to use a transformed charge interaction matrix that includes only differences between the orbital-orbital interaction energies and thus results in neutral periodic cells and finite energies.

Although considering electrostatic interactions explicitly (rather than through an approximate local pair potential) allows much more accurate determination of the ionic component of bonding, it has the disadvantage of a significant computational cost associated with the longrange Coulombic potential. To overcome this issue, we have implemented the Wolf method [12], which allows the calculation of electrostatics via short-range potentials in systems with strong charge compensation (as in condensed phases). We have implemented this method and tested it against both direct summation and the Ewald method with good agreement. Previous work [13] concluded that the Wolf method does not work for the ES+ approach of SM. However, the reason for the discrepancy is the error in the SM formulation, which we have now corrected. Thus, we can include electrostatic interactions with minimal overhead compared with standard MD potentials.

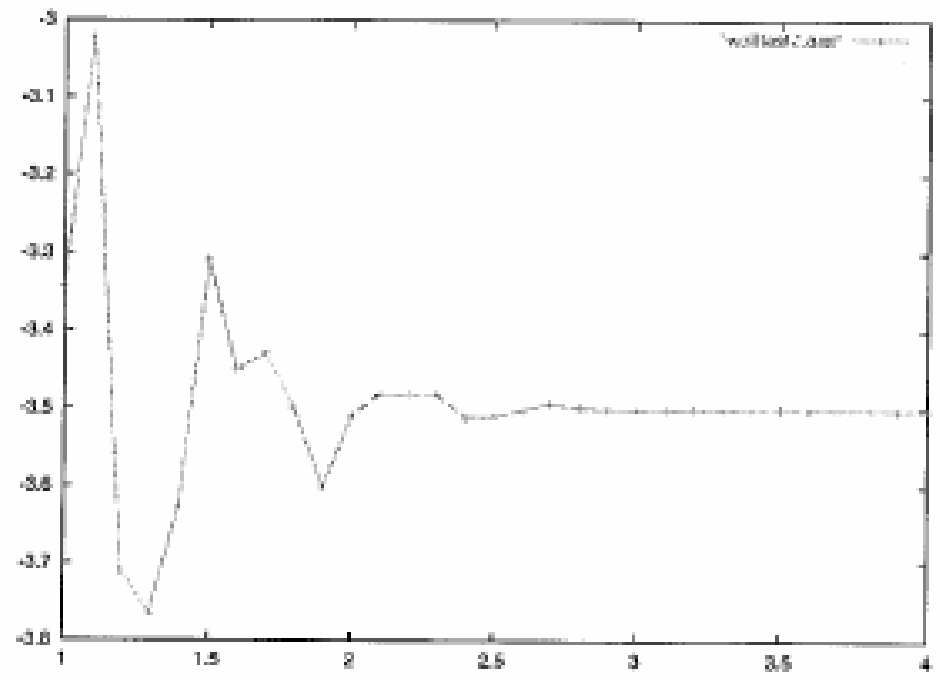

Figure 1. Convergence of Wolf method with cut-off radius demonstrating that short-range interactions are sufficient for use in ES+ models.

To quantify the large number of parameters associated with accurate empirical potentials in multi-component systems, we make use of both experimental results (e.g., mechanical 
properties, structural cohesive energies) and ab-initio calculations. We consider ab-initio calculations to be preferable in many ways due to the ability to generate large amounts of fullyconsistent data for both calibration and testing. For the ab-initio calculations, we use VASP, a state-of-the-art parallel density functional theory (DFT) code using supercells and ultra-soft pseudopotentials [10]. As part of this work, we have initiated a series of VASP calculations on the $\mathrm{Si}$ and Fe systems.

The end goal of this work is to apply the interatomic potentials developed in dynamical simulations in order to understand the formation and behavior of nanostructures. To date, we have focused on implementing the potentials developed in the parallel MD code MDCask. We have now added the original and reformulated ES+ approach, EAM and modified Si:As Tersoff potential within MDCask and have conducted a series of parallel MD simulations of system evolution.

The initial systems we have investigated are the $\mathrm{Si} / \mathrm{SiOz}, \mathrm{Ti} / \mathrm{TiOz}$, and $\mathrm{Fe} / \mathrm{Fe}$-oxide systems: silicon because it is a heavily-studied system with wide-ranging technological applications and provides an appropriate test for the generation of potentials transferable across interfaces between dissimilar materials, $\mathrm{Ti} / \mathrm{TiO}_{2}$ to compare to previous ES+ efforts [11] and $\mathrm{Fe} / \mathrm{Fe}$-oxide.

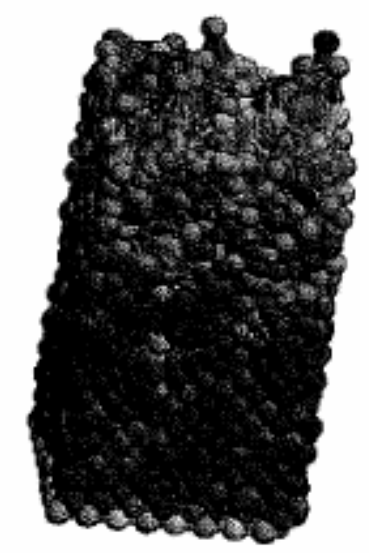

Figure 2. Atomic structure following parallel MD simulation of amorphization via $250 \mathrm{e} \mathrm{V} \mathrm{Si}$ atoms and subsequent partial regrowth at $1000^{\circ} \mathrm{C}$ of Si with $1 \%$ As using modified Tersoff potential. Note that the top is a free surface, and the bottom atoms are fixed. The color indicates atom energy as a prototype transition metal/metal-oxide interfaces because of great interest in this system for nanocatalysis. These systems will be explored both for nanoelectronics applications and functional nanostructures for catalysis and optical nanomaterials at PNNL. Our initial efforts with Si used a modified Tersoff potential for simulation of amorphization and regrowth of heavily As-doped silicon (Fig. 2).

\section{Publications, Presentations, and Proposals}

In collaboration with Fumio Ohuchi (PI) and other Nanotech/PNNL researchers (Charles Campbell, Tom Stoebe, and Don Baer), we have obtained funding of $\$ 370,000$ over three years from NSF for "Development of UW PNNL Collaborative Curriculums in Nanoscience and Technology." This grant will support the development and offering of a number of collaborative 
UW/PNNL offerings. Along with Anter EI-Ezab and Maciej Gutowski at PNNL, we are currently developing a course in "Nanotechnology Theory and Modeling" to be offered this Fall.

The work on development of transferable potentials and their application within accelerated MD tools provided a portion of the background for an additional proposal for $\$ 500 \mathrm{~K}$ over three years to the Semiconductor Research Corporation entitled "Dynamic Modeling of Disordered Materials for Nanoscale CMOS" in collaboration with Hannes Jonsson (UW Chemistry). The short proposal has been positively reviewed, and we have been invited to submit a full proposal.

\section{References}

[1] A. F. Voter, Phys. Rev. Lett. 78, 3908 (1997).

[2] M. R. Sorensen and A. F. Voter, J. Chern. Phys. 112, 9599 (2000).

[3] G. Henkelman and H. Jonsson, J. Chern. Phys. 115, 9657 (2001); Mat. Res. Soc. Symp. Proc. 677, AA8.1.1 (2001).

[4] F.H. Streitz and J.W. Mintmire, Phys. Rev. B50, 11996 (1994); J. Adhesion Sci. Tech. 8, 853 (1994); Phys. Rev. B60, 773 (1999).

[5] A.K. Rappe and W.A. Goddard, J. Phys. Chern. 95, 3358 (1991)

[6] M. Baskes, Phys. Rev. Lett. 59, 2666 (1987); Phys. Rev. B46, 2727 (1992).

[7] D. Chen, M. Yan, and Y.F. Liu, Scrip. Mat. 40, 913 (1999).

[8] A. Yamaguchi and H. Nakajima, Interfacial Engineering for Optimized Properties, (Mater. Res. Sac, Pittsburgh, PA, 1997) pp. 27-32.

[9] H. Huang, N. M. Ghoniem, J. K. Wong, and M. Baskes, Mod. Sim. Mat. Sci. Eng. 3615 (1995).

[10] G. Kresse and J. Hafner, Phys. Rev. B 47, 558 (1993); 49, 251 (1994); G. Kresse and J. Furthmiiller, Comput. Mater. Sci. 6, 15 (1996); Phys. Rev. B 55, 169 (1996).

[11] F.H. Streitz and J.W. Mintmire, Phys. Rev. B 60, 773 (1999)

[12] D. Wolf, P. Keblinski, S. R. Phillpot and J. Eggebrecht, J. Chem. Phys. 110, 8254 (1999).

[13] T. P. Swiler and R. E. Loehman, Acta Mat. 48, 4419 (2000). 


\title{
Nondestructive Carbon Nanotube Modification for Tailored Functionality
}

\author{
Leonard S. Fifield $^{*}$ and Christopher L. Aardahl ${ }^{* *}$ \\ *Department of Chemistry, University of Washington \\ ***NNL Environmental Technology Directorate
}

\section{Project Summary}

Controlled chemical modification of carbon nanotubes and other graphitic structures is highly desirable for the processing and use of these materials in practical devices. Chemical means for modifying nanotubes have existed for some time, but most involve pre-treating the tubes in strong acids to induce oxidized defects in the tube surfaces and ends at which to perform chemistry. Sidewall functionalization methods, such as those employed by James Tour and his group at Rice University, have been developed to attach desired chemical groups to nanotubes without first damaging the tubes by oxidation. This approach, however, also results in an interruption of the conjugated backbone of the carbon nanotube with a corresponding loss in mechanical and electronic properties. One strategy to limit this drawback is the use of such chemistry on multi-wall carbon nanotubes. In the case of multi-wall nanotubes, only the outer wall might be damaged in the process, leaving the inner walls intact. Unfortunately for this strategy, the larger diameter of multi-wall carbon nanotubes leads to a lower strain in the carboncarbon bonds of the tubes and a much lower reactivity compared to single wall carbon nanotubes. Chemical modification of multi-wall nanotubes is thus difficult to accomplish without cutting, opening, and oxidatively damaging the tubes to provide reaction sites.

The utilization of noncovalent means for carbon nanotube modification is preferable for applications in which the properties resulting from the conjugated backbone of the nanotubes need to be maintained. In addition, noncovalent approaches, such as the use of molecular anchors for chemical functionalization, are generally applicable to all types of graphitic surfaces. The use of organic molecular anchors is a viable way to chemically modify multi wall carbon nanotubes, which are less difficult to synthesize and less expensive to purchase than single wall nanotubes, while keeping attractive carbon nanotube properties intact.

We have developed a facile and effective method for depositing molecular anchors onto multi-wall carbon nanotubes using supercritical fluids. Characterization of the degree of loading in these nanotube-anchor structures is achieved with the use of thermal gravimetric analysis (TGA) and differential scanning calorimetry (DSC). It is our contention that employment of the described method will facilitate the use of carbon nanotubes in a variety of applications, including chemical separations and chemical sensors.

\section{Publications, Presentations, and Proposals}

"Nanostructured materials for efficient carbon dioxide separation " Leonard S. Fifield, Glen E. Fryxell, Thomas S. Zemanian, R. Shane Addleman, Feng Zheng, Larry R. Dalton, and Christopher L. Aardahl. 225th ACS National Meeting, New Orleans, LA, March 23, 2003. 
"Development of Active Nanomaterials based on Carbon Nanotubes" Leonard S. Fifield, Larry R. Dalton, Rosemary A. Golhotra, R. Shane Addleman, Glen E. Fryxell, and Christopher L. Aardahl. JINN Nano Workshop, University of Washington, Seattle, WA, September, 2003.

Proposals Submitted as a Result of this Work

“ $\mathrm{CO}_{2}$ Capture from Submarine Atmospheres" NAVSEA Philadelphia—in process

“Signature Collection” Coastal Security, United States Navy—in process

\section{Selected Figures}

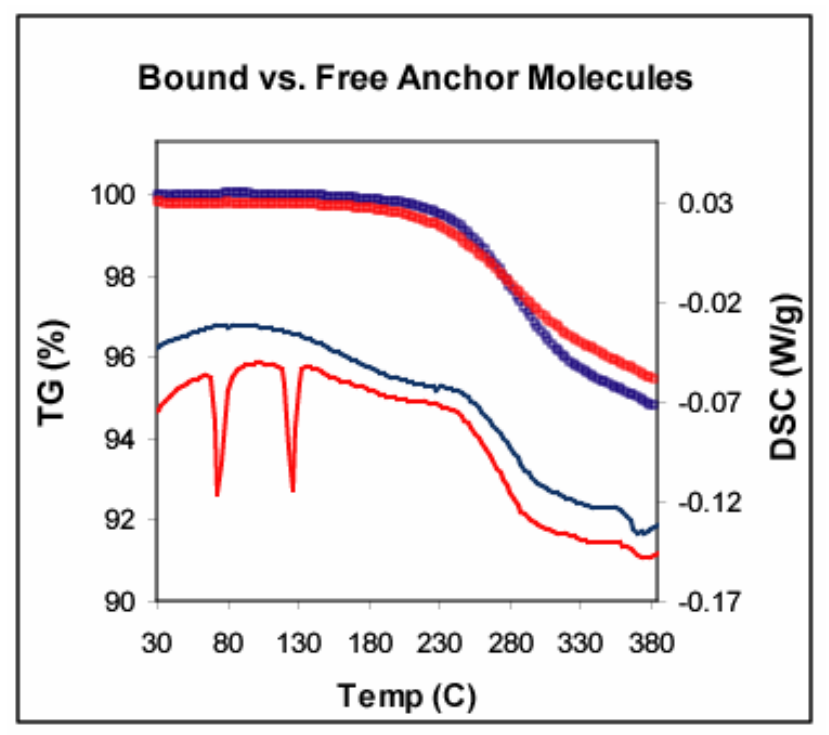

Figure 1. Plot of TGA/DSC data for anchor compound reacted (blue line) and merely mixed (red line) with MWNTs. Melting points of the unreacted anchor (dips on the red DSC curve) indicate that the molecules are not in close association with surface, while the absence of melting points for the reacted anchor indicate a close association with the nanotube surface. 


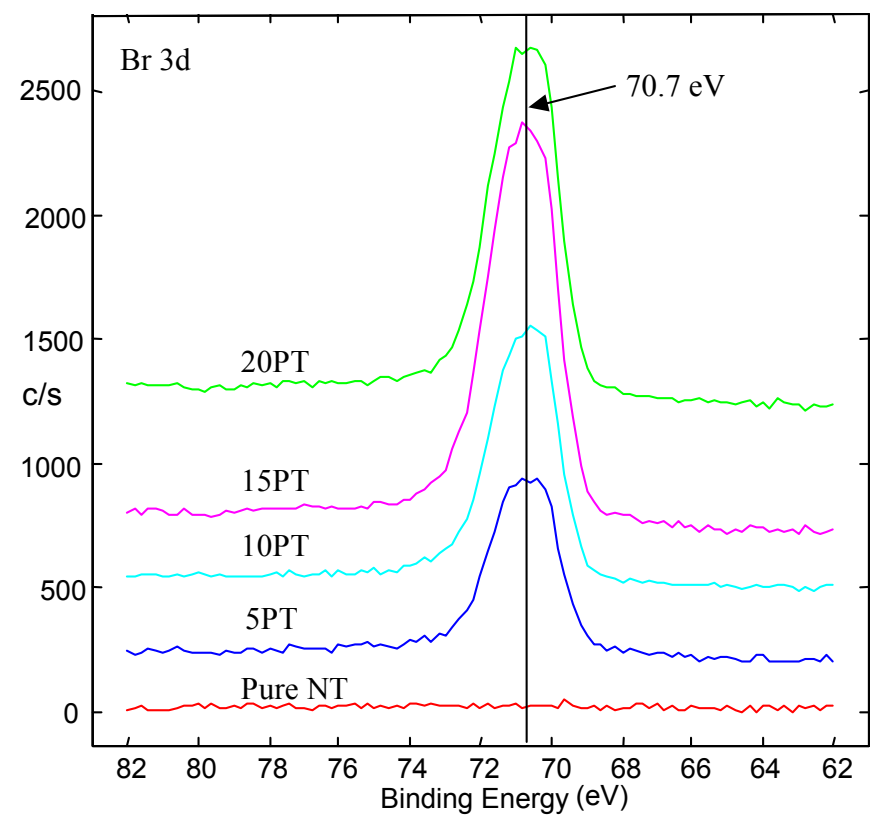

Figure 2. X-ray Photoelectron Spectroscopy Results Indicate an Increasing Br Content of Carbon Nanotubes Modified with Increasing Amounts of 1-Bromoacetyl Pyrene (BAP) Molecular Anchor (XPS results and figure credit: Mark Engelhard) 


\section{Fundamental Studies of Monolayer-Protected Nanoparticles by Gas Chromatography}

Gwen M. Gross $^{(a)}$, Jay W. Grate ${ }^{(b)}$, and Robert E. Synovec ${ }^{(a)}$

(a) Department of Chemistry, University of Washington

(b) PNNL Environmental Molecular Sciences Laboratory (EMSL)

\section{Project Summary}

Monolayer-protected nanoparticles (MPNs) are gaining considerable interest in the nanotechnology field, especially for chemical sensor and chemical separation instrumentation development. The selectivity achieved for chemical sensing with gold-centered MPNs is dominated by the chemical structure and functionality selected for the organic surface layer, which is a thiol-linked chemical functionality bound on the surface of each gold-centered nanoparticle. There is considerable interest to study MPN materials in more detail to understand their sorptive and mass transfer properties. Knowledge of the sorptive properties of MPNs would provide valuable insight into the thermodynamics and mass transfer rates of vapor sorption onto MPNs and therefore the possible applications of MPNs. In this project, gas chromatography (GC) serves as a versatile platform for the characterization of gold-centered MPNs. GC retention time data can be related to thermodynamic properties of the MPNs, while the band broadening (peak width data) observed in the GC data can be readily related to the mass transfer characteristics of the MPNs. We have continued to explore a wide range of chemical sensing layers (monolayers) on the MPNs. Ideally, each of the MPN materials will provide a different GC retention factor for the wide array of analyte vapors that are being studied. The variation in chemical selectivity, as observed through GC retention data, should engender the MPN materials useful for a broad range of either sensor array or GC stationary phase applications.

To date, this project has progressed at a steady pace with excellent results. The synthesis and characterization of three monolayer protected gold nanoparticle stationary phases has been completed. The methodology for production of a dodecanethiol MPN-based stationary phase for GC capillary columns has been established with initial chromatographic results published within the past year (Figure 1). Based upon the separation efficiencies and reduced plate height studies as a function of linear flow velocity, we concluded that a dodecanethiol MPN stationary phase operated at nearly the optimum possible performance level when compared to a commercially available polymer stationary phase. The robustness of the MPN phase has also been studied with consistent performance observed over several months. Using the same methodology, the production of multiple columns has been achieved with acceptable levels of reproducibility. This is promising for successful future studies and applications of MPN phases. One such application explored was the possible implementation of the dodecanethiol MPN stationary phase within micro-fabricated GC channels. A 100- $\mu \mathrm{m}$ square capillary was used as a model for a micro-GC system (Figure 2). The potential application of this nano-material for an emerging area of analytical measurement science is shown by the efficiency of the separations obtained (Figure 3). An example of one such separation, of particular interest to those developing microGC devices for detection of chemical warfare agents, is the separation of DMMP from common interferences found in gasoline. The separation we obtained is very similar, i.e., the same 
compounds and nearly the same resolution, to one shown by the scientists at Sandia National Laboratories with their device referred to as the $\mathrm{ChemLab}^{\mathrm{TM}}$, but our separation was achieved in 50-fold less time. Continued studies using smaller capillaries, a novel high-speed injection design (see publications list), and application of the dodecanethiol MPN within a twodimensional separation (GC x GC) format (Figure 4) are currently underway. Preliminary work on the application of other MPN materials, specifically chlorobenzenethiol MPNs and triflouromethylphenylthiol MPNs, is also progressing well. This project is a very successful application of nanoparticle technology. Actual instrumental devices have been developed, and the establishment of an efficient thin film stationary phase now allows for the thermodynamic studies of the dodecanethiol MPN nanoparticle material. However, continued development of MPN stationary phases, whether they be those previously used or ones newly developed, is needed to ensure accurate and successful characterization of the sorptive and mass transfer properties of the nanoparticles in turn to continue the implementation of the nanoparticles in cutting edge analytical instrumentation and measurement science.

\section{Publications, Presentations, and Proposals}

1. "Open Tubular Gas Chromatography using Monolayer Protected Gold Nanoparticles as the Stationary Phase." G. M. Gross, D. A. Nelson, J. W. Grate, R. E. Synovec, 26th International Symposium on Capillary Chromatography and Electrophoresis in May 2003, Las Vegas NV, invited poster presentation.

2. "Fundamental Studies of Monolayer-Protected Nanoparticles by Gas Chromatography." G.M. Gross, D.A. Nelson, J.W. Grate, R.E. Synovec, Nanoscience Workshop for the PNNL/UW Joint Institute of Nanoscience, Seattle, WA, September 2002 \& 2003, two poster presentations.

3. G.M. Gross, D.A. Nelson, J.W. Grate, R.E. Synovec "Monolayer Protected Gold Nanoparticles as a Stationary Phase for Open Tubular Gas Chromatography," Anal. Chem., 75, 2003, 4558-4564.

4. G.M. Gross, J.W. Grate, R.E. Synovec, "Monolayer-Protected Gold Nanoparticles as an Efficient Stationary Phase for Open Tubular Gas Chromatography using a Square Capillary: A Model for Chip-Based Gas Chromatography in Square Cornered Microfabricated Channels," J. Chromatogr. A, accepted and in press, December 2003.

5. J.W. Grate, D.A. Nelson, R. Skaggs, R.E. Synovec, G.M. Gross, "Metal Nanoparticles Protected with Monolayers: Applications for Chemical Vapor Sensing and Gas Chromatography," invited chapter for the Encyclopedia of Nanoscience and Nanotechnology, accepted and in press, December 2003.

6. G.M. Gross, B.J. Prazen, J.W. Grate, R.E. Synovec, "High-Speed Gas Chromatography using a Synchronized Dual-Valve Injector," Anal. Chem., submitted for publication, December 2003.

7. G.M. Gross, J.W. Grate, R.E. Synovec, "The Development of Novel Gas Chromatographic Stationary Phases Using Monolayer Protected Gold Nanoparticles for Application in MultiDimensional Gas Chromatographic Separations," J. Chromatogr. A, invited manuscript in preparation, December 2003. 


\section{Funding and Intellectual Property that has resulted from this research}

1. Record of Invention for Patent Protection: G. M. Gross, J. W. Grate, R. E. Synovec; "Monolayer Protected Gold Nanoparticles for use as a Gas Chromatographic Stationary Phase in Capillary and Microfabricated Chromatographic Systems". Date received at OTL: 10/17/2003 (3131-4038DL), Still under review.

2. DARPA micro-Gas Chromatograph Proposal: J.W. Grate (Pacific Northwest National Laboratory) and R.E. Synovec (University of Washington), and personnel from Honeywell International, Inc. - $\$ 400,000$ for 4.5 years for research in the Synovec group starting February 1, 2004. Still under review.

\section{Figures}

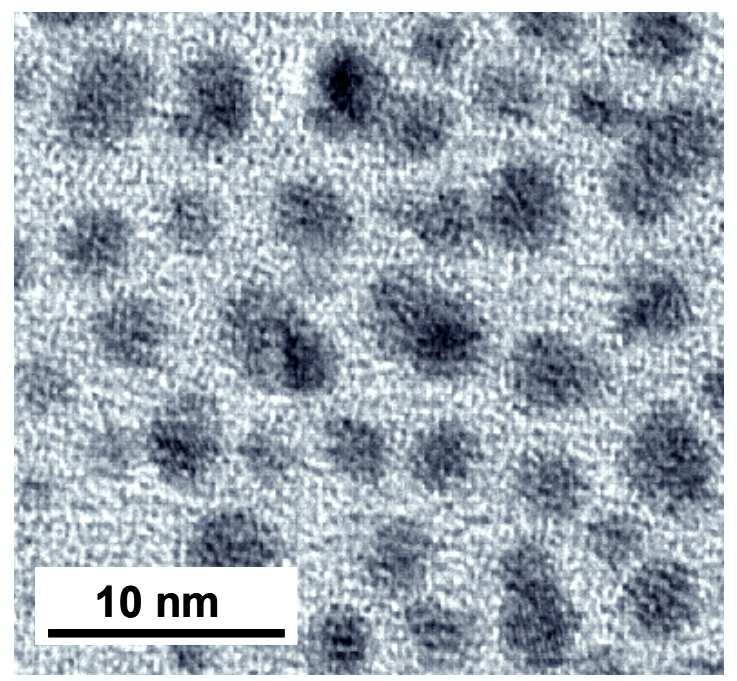

Figure 1. Transmission electron micrograph (TEM) of a thin film of dodecanethiol MPNs. The TEM image indicates the nanoparticle core size was moderately polydispersed with diameters ranging from about 1.5 to $5 \mathrm{~nm}$ with an average of $3.2 \mathrm{~nm}$.
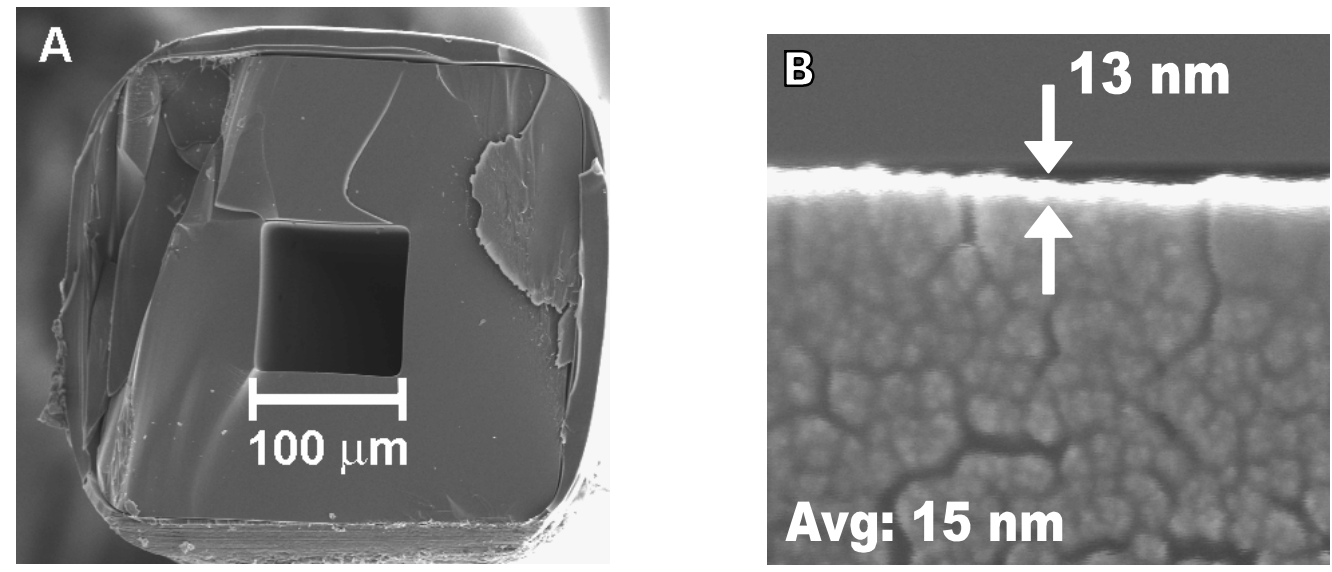

Figure 2. (A) Scanning Electron Microscope (SEM) image of the dodecanethiol MPN stationary phase within the $100 \mu \mathrm{m}$ square capillary. (B) Representative view of the MPN stationary phase 
along the capillary wall. Here, the thickness is $13 \mathrm{~nm}$. Fourteen measurements from five locations along the column resulted in an average film thickness of $15 \mathrm{~nm}(+/-4 \mathrm{~nm})$.

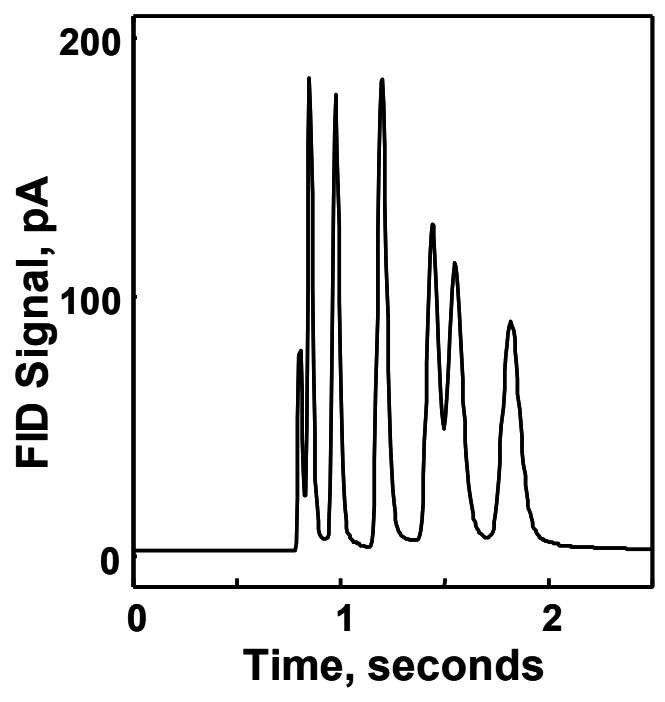

Figure 3. High-speed separation of seven components is shown using the dodecanethiol MPN stationary phase within the $100 \mu \mathrm{m}$ square capillary. The following is the retention order: methyl ethyl ketone, benzene, octane, chlorobenzene, anisole, 3-octanone, and decane. The separation was obtained using a $1.3 \mathrm{~m}$ column with the dodecanethiol MPN stationary phase at $75^{\circ} \mathrm{C}$, operated under constant pressure conditions at 170,000 $\mathrm{Pa}(\sim 200 \mathrm{~cm} / \mathrm{s}$ hydrogen gas $)$. 


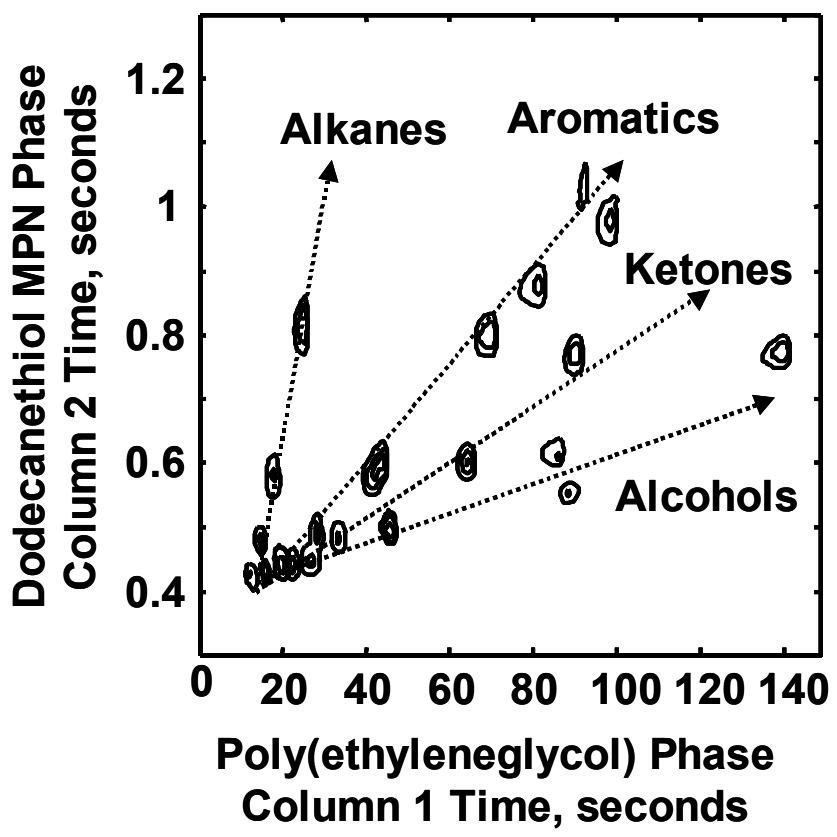

Figure 4. Two-dimensional GC separation (GC x GC) of 24 components consisting of alkanes, aromatics, ketones, and alcohols, using the dodecanethiol MPN stationary phase within a $100 \mu \mathrm{m}$ square capillary as the second dimension separation. This separation was obtained using a $4 \mathrm{~m}$ poly(ethylene glycol) column (200 $\mu \mathrm{m}$ I.D., $0.2 \mu \mathrm{m}$ film) as the first column at 34,000 Pa $(\sim 40 \mathrm{~cm} / \mathrm{sec})$ and a $0.9 \mathrm{~m}$ dodecanethiol MPN $100 \mu \mathrm{m}$ square capillary column as the second column operated at $210,000 \mathrm{~Pa}(\sim 235 \mathrm{~cm} / \mathrm{sec})$. The oven was held constant at $60^{\circ} \mathrm{C}$ with the FID and inlet temperatures at $250^{\circ} \mathrm{C}$. A $0.5 \mu \mathrm{L}$ injection was introduced with a $150: 1$ split on the inlet. The valve injection onto the second column had a 15 milliseconds wide injection pulse width, a $1.3 \mu \mathrm{L}$ loop with a one-second modulation period onto the Column 2. 


\section{Dilute Magnetic Semiconducting Oxide Thin Films and Nanostructures}

Alexandre B. Pakhomov ${ }^{1}$, Bradley Roberts ${ }^{1}$, Kannan M. Krishnan ${ }^{1} \&$ Scott Chambers $^{2}$

${ }^{1}$ Department of Materials Science and Engineering, University of Washington

${ }^{2}$ PNNL Environmental Molecular Sciences Laboratory (EMSL)

\section{Project Summary}

We have initiated a multidisciplinary project to investigate the growth, properties, and optimization of dilute magnetic semiconducting oxides for spintronics applications. Specifically, our efforts are focused on transition metal-doped $\mathrm{ZnO}$ and anatase $\left(\mathrm{TiO}_{2}\right)$ thin films and heterostructures. At the same time that our individual JIN applications were funded last year, four of the PIs involved (Krishnan, Gamelin, Olmstead, and Chambers) also submitted a coordinated proposal to the NSF in response to a national initiative on Spin Electronics. This proposal, entitled "Varied synthetic approaches to the development of room-temperature ferromagnetic and semiconducting oxide nanostructures for silicon-based spintronics," was also funded. Naturally, there is now significant synergy between the JIN activity and the NSF-funded research. However, there is one principal difference. The NSF activity will eventually focus on the integration of such oxide films with silicon whilst the JIN activity will continue to explore new methods of growing a viable room-temperature dilute magnetic semiconductor. Fundamental magnetic/transport measurements, structural characterization, and the role of dimensionality are being initially emphasized. In keeping with our educational mission, a graduate student (Brad Roberts) has been brought on board. He is being trained and will eventually take over this project as part of his doctoral dissertation in MSE.

In a search for new methods for growing diluted magnetic semiconductors (OMS), superlattices of $\mathrm{Co} / \mathrm{ZnO}$, with varying nominal thickness of metal (2-10 $)$ and semiconductor (2$20 \AA$ ), were prepared by ion beam sputtering. The films were characterized by x-ray diffraction/reflectivity, Rutherford back-scattering, and x-ray photoelectron spectroscopy. Magnetic, transport, and magneto-transport measurements were carried out over a temperature range of 2.5-300 K. With decreasing Co thickness and increasing $\mathrm{ZnO}$ thickness in the multilayer stack, the properties of the samples undergo a crossover from those of granular metallic $\mathrm{Co} / \mathrm{semiconductor} \mathrm{multilayers} \mathrm{to} \mathrm{an} \mathrm{OMS} \mathrm{superlattice.}$

RBS studies showed the $\mathrm{Co} / \mathrm{Zn}$ atomic ratio in the range from 0.1 to 1.25 , a slight excess of oxygen compared to stoichiometric $\mathrm{ZnO}$, and about $5 \%$ of aluminum (donor dopant). Fig. 1 shows an XRO pattern for a $\left(\mathrm{ZnO}_{20 \AA} \mathrm{Co}_{2 \AA}\right)_{25}$ sample on a glass substrate, which reveals the nanocrystalline structure of $\mathrm{ZnO}$ and no peaks of metallic Co. Samples with larger relative Co content indicated diffuse Co reflections. Fig. 2(a-d) shows the zero field cooled and field cooled magnetization measurements as a function of temperature in a field of 20 Oe for samples with fixed Co layer thickness and varying $\mathrm{ZnO}$ thickness. Because of the limited solubility of metal, the higher relative content of Co results in a granular multilayer structure, which demonstrates magnetic blocking phenomena and superparamagnetism. Magnetic blocking results in separation of the ZFC and FC curves, and a maximum in the ZFC susceptibility near the blocking temperature (Fig. 2a,b). The sample with the thickest $\mathrm{ZnO}$ layers behaves as a diluted 
magnetic semiconductor, i.e., its magnetization does not go to zero at high $\mathrm{T}$, and it remains approximately constant in the temperature range 40 to $300 \mathrm{~K}$ (Fig 2d). M vs H dependences for this sample are hysteretic both at $10 \mathrm{~K}$ and $300 \mathrm{~K}$ as shown in Fig. 2(e), where the slope at large fields is dominated by the substrate, while closed loops with no hysteresis, typical of superparamagnetic materials, are observed in samples a-c above the blocking temperature. Analyses of the temperature dependences of resistivity (Fig. 3 (a-d)) for these multilayers indicate a crossover from dominating 20 variable range hopping (VRH) conduction via metallic granules

(InR-1rf, $\mathrm{n}>1 / 2)$ to $30 \mathrm{VRH}(\mathrm{n}<1 / 2)$ to VRH with no single exponent in the whole temperature range, close to that of AI-doped $\mathrm{ZnO}$ film with no Co added (not shown here).

Magnetoresistance was measured with magnetic field perpendicular to the film plane. These measurements also show a crossover from negative magnetoresistance in superparamagnetic state [Fig. 4(a-b)] to a behavior typical of doped semiconductors with positive magnetoresistance [Fig. 4(d)].

In summary, we have managed to prepare $\mathrm{ZnO}$ :Co OMS films, with the Curie temperature higher than room temperature, by alternating deposition of $\mathrm{ZnO}$ and $\mathrm{Co}$ multilayers on the atomic scale. We have also studied the properties of superparamagnetic granular multilayers and observed a 20 to 30 transition in both VRH and magnetization in these films. Further studies will include modification of the films by thermal treatment in controlled atmosphere, optimization of the sputtering process, and advanced measurements (optical MCD and synchrotron radiation experiments) in collaboration with the other members of our team.

\section{Publications, Presentations and Proposals}

1. A.B. Pakhomov, Bradley Roberts, and Kannan M. Krishnan, Dimensional transitions in granular magnetic $\mathrm{Co} / \mathrm{ZnO}$ multilayers, Phys. Rev. B, in preparation

2. Diluted magnetic semiconductor $\mathrm{Zn}(\mathrm{Co}) \mathrm{O}$ superlattices by ion beam sputtering deposition, Appl. Phys. Lett., in preparation.

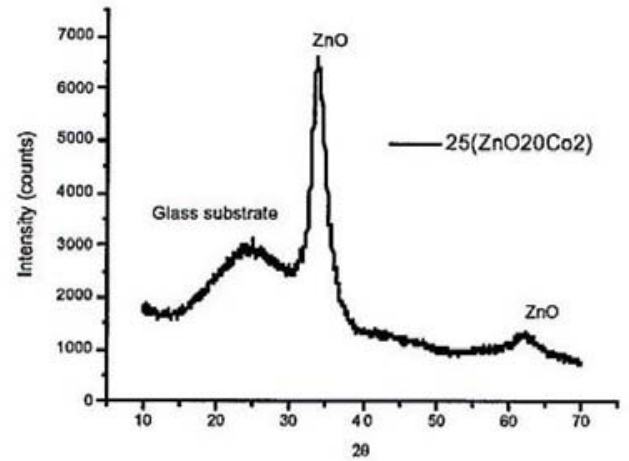

Fig. 1. XRD pattern for sample 25( $\mathrm{ZnO} 20 / \mathrm{Co})$.

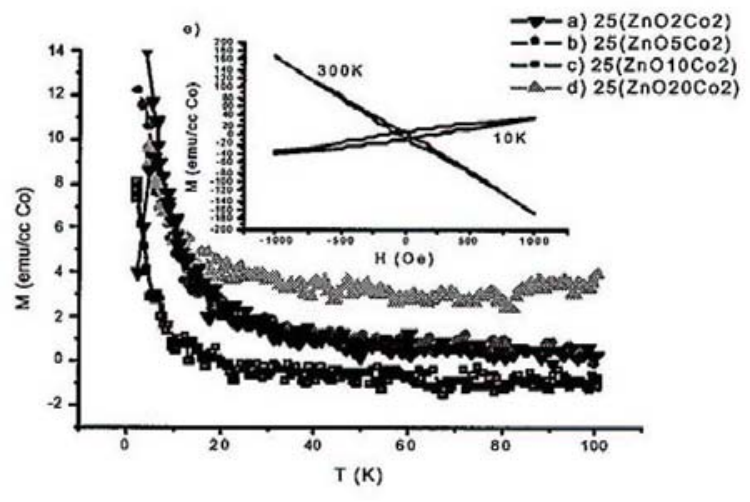

Fig. 2. (a-d) $Z F C$ and $F C$ magnetization at 20 Oe, (e) Hysteresis loops for sample (d). 


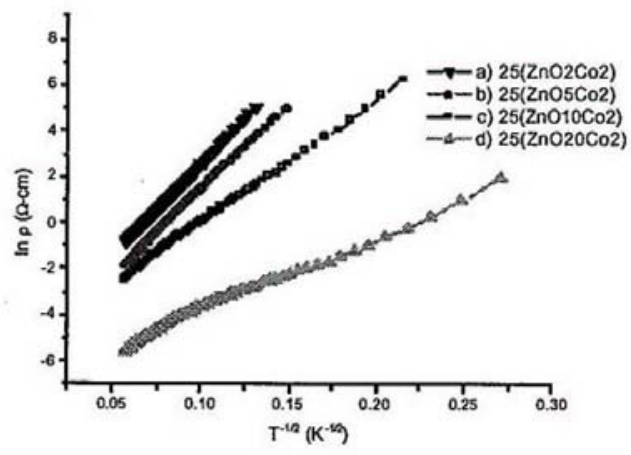

Fig. 3. Temperature dependences of resistivity.

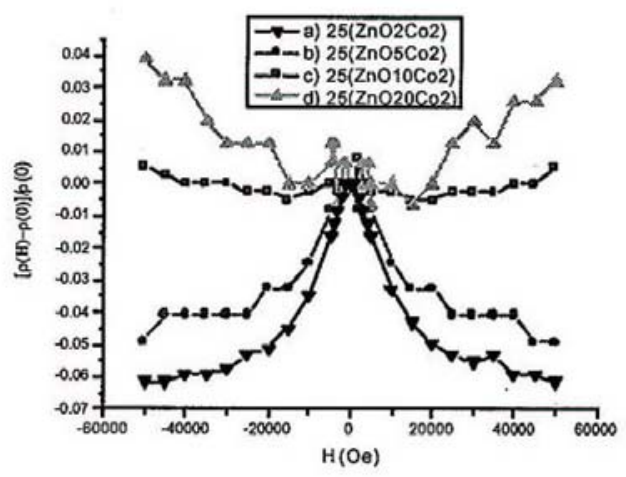

Fig. 4. Magnetoresistance for different compositions at low temperature. 


\section{Interfacing Chip-Based Nanofluidic-Systems to Surface-Desorption Mass Spectrometry}

Awardees: Jason S. Kuo/Gina Fiorini

Mentors: Daniel Chiu - UW; Cynthia Bruckner-Lea - PNNL

\section{Project Summary}

Proteomics provides new understanding of cellular mechanisms that genomic information alone does not explain. However, unlike DNA analysis, the analysis of proteins is a much more complex problem due to the variety of proteins present and low concentration. To meet the high separation capacity and ultrasensitivity requirements, we propose to develop a robust method to interface a chip-based protein separation method to surface-desorption mass spectrometry. Successful development of an interface will accommodate high data throughput required in cell lysate protein separation, be compatible with the vacuum environment for mass spectrometric analysis, and allow minimal sample cross contamination.

One aspect of the interface is the on-chip protein sample transportation and subsequent nanoscale chemical reaction. To accomplish this, we investigated electrowetting as the method of shuttling discrete droplet reaction vessels among different regions of the chip-based device. The attached figures (excerpted from [1]) illustrate the characterization and application of the electrowetting phenomenon by which individual droplets in an immiscible medium can be transported with ease. New aspects of the microfluidic phenomenon (see [2]) and new fabrication procedure (see [3]) were reported and developed by Kuo and others during the course of this project. Ms. Gina Fiorini is a graduate student that works with Jason Kuo. She has worked on materials issues that relate to the interfacing of microfluidics with mass spectrometry. Her work is still in progress and is in preparation for publication.

\section{Publications, Presentations, and Proposals}

1. Langmuir 2003, 19, 250-255

Title: "Electrowetting-Induced Droplet Movement In An Immiscible Medium"

Authors: Jason S. Kuo, Paolo Spicar-Mihalic, Indalesio Rodriguez, Daniel T. Chiu*

2. Appl. Phys. Lett (in press):

Title: "Dynamic Formation of Ring-Shaped Patterns of Colloidal Particles in Microfluidic Systems

Authors: David S. W. Lim, J. Patrick Shelby, Jason S. Kuo, Daniel T. Chiu*

3. Anal. Chem. 2003, 75, 1578-1583

Title: "Selective Electroless and Electrolytic Deposition of Metal for Applications in Microfluidics: Fabrication of a Microthermocouple"

Authors: Peter B. Allen, Indalesio Rodriguez, Christopher L. Kuyper, Robert M. Lorenz, Paolo Spicar-Mihalic, Jason S. Kuo, Daniel T. Chiu* 
Figures
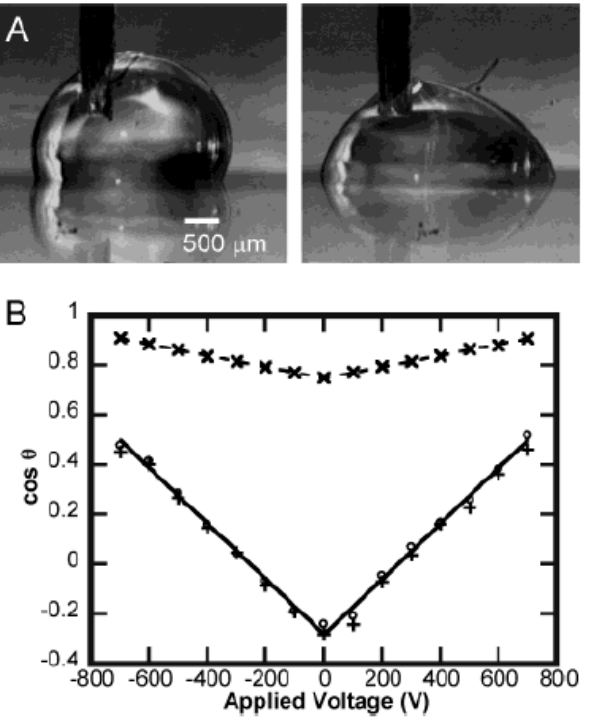

Figure 2. (A) Before (left) and after (right) the application of $-500 \mathrm{~V}$ that causes the $100 \mathrm{mM} \mathrm{KCl}$ droplet to flatten out. (B) Equilibrium contact angle measurements for DI water $(\mathrm{O}), 100$ $\mathrm{mM} \mathrm{KCl}(+)$, and olive oil $(x)$. Virtually no difference was observed in the electrowetting behaviors of DI water and 100 $\mathrm{mM} \mathrm{KCl}$. To perform the measurement, the droplet is placed on top of a disk-shaped electrode with a $38-\mu \mathrm{m}$ thick PDMS layer spun coated on top. A grounding electrode is inserted into the droplet to complete the circuit.
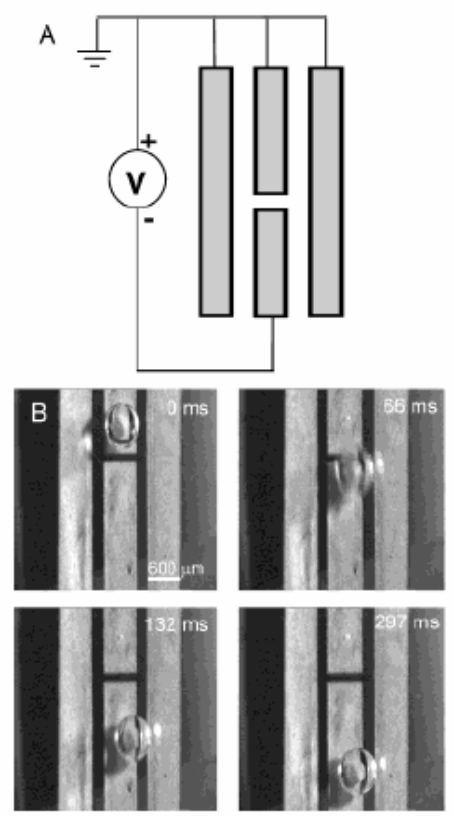

Figure 6. (A) Schematic of the electrode design used to demonstrate the gliding of a $\mathrm{KCl}$ droplet in olive oil. (B) Successive video frames showing the gliding of the $\mathrm{KCl}$ droplet with the application of $-700 \mathrm{~V}$ to the bottom electrode. 


\section{Molecular Engineered Conjugated Polymers for High - Performance Light-Emitting Diodes (LEDs)}

Awardee: Michelle S. Liu - UW

Mentors: Alex K-Y. Jen - UW; Paul Burrows - PNNL

\section{Project Summary}

The objective of this project is to develop novel luminescent copolymers for highly efficient light-emitting diodes (LEDs).

The first approach we adopted is to maximize the confinement of the charge carrier in the luminescent polymers from both molecular design and device engineering. Molecular engineered conjugated polymers containing randomly distributed lower-energy segments are designed to provide electrons and/or holes trapping sites. In addition to directly or sequentially trapping electrons and holes on these lower-energy sites, the excitons formed on higher-energy segments could also be transferred to these lower-energy sites through the Förster energy transfer mechanism. This will increase device efficiency due to lower self-absorption loss. By further introducing a hole/exciton blocking layer in the LED devices to block the hole migration to the electrode, this will also significantly enhance the charge capture efficiency and prevent the luminescence quenching. Based on these concepts, we have developed a series of fluorine-based copolymers with a small amount (less than $10 \mathrm{~mol}-\%$ ) randomly distributed electron-deficient low bandgap moieties to improve the device performance (Figure 1). These low-energy moieties with electron-deficient nature are designed to increase electron-affinity of the resulting polymers and to facilitate charge-recombination through their function as charge trapping sites for both holes and electrons. The emission colors of these polymers are green, yellow, and red, respectively. Future work will be focused on engineering the device structure through the introduction of a hole/exciton blocking layer and optimization of thickness of individual layers to further improve the LED performance. This will be conducted at Dr. Burrow's group in PNNL.

Hole-electron recombination in organic LEDs leads to the formation of both singlet and triplet excitons, the efficiency of LEDs based on fluorescent conjugated polymers is limited because only $25 \%$ of the singlet excitons are emissive. Another approach we employed in this project to improve the device performance is to utilize the phosphorescence emission; the phosphorescent compounds will be incorporated into conjugated polymer matrix to harvest both singlet and triplet excitons. However, phosphor-doped organic LEDs usually exhibit low quantum efficiencies in conjugated polymers comparing to nonconjugated polymers due to the low triplet energy level of these conjugated polymers. The back transfer of the exciton to the polymer host from the phosphor leads to phosphorescence quenching and lower device efficiency. To overcome this problem, blue-emitting materials having short conjugated segments with ether linkage will be synthesized to elevate their triplet energy level while still maintaining the good charge-transporting properties (Figure 2). This type of material will be used as the host to achieve highly efficient phosphorescent emission for white LED applications. 


\section{Publications, Presentations, and Proposals}

1. M. S. Liu, J. Luo, A. K-Y. Jen, "Efficient Green Light-Emitting Diodes from SiloleContaining Copolymers", Chem. Mater. 15, 3496 (2003).

2. J.-H. Kim, M. S. Liu, A. K-Y. Jen, B. Carlson, L. R. Dalton, R. Dodda, C. F. Shu, "Bright Red-Emitting Electrophosphorescent Device Using Osmium Complex as a Triplet Emitter", Appl. Phys. Lett. 83, 776 (2003).

3. C. F. Shu, R. Dodda, F. I. Wu, M. S. Liu, A. K-Y. Jen, "Highly Efficient Blue Light-Emitting Diodes from Polyfluorene Containing Bipolar Pendent Groups", Macromolecules 36, 6698 (2003).

4. F-I. Wu, D. S. Reddy, C. F. Shu, M. S. Liu, A. K-Y. Jen, “A Novel Oxadiazole-Containing Polyfluorene with Efficient Blue Electroluminescence”, Chem. Mater. 15, 269 (2003).

5. P. Herguth, J.-H. Kim, X. Z. Jiang, M. S. Liu, A. K.-Y. Jen, “Absorption and luminescence properties of sequentially random- and defined copolymers based on poly(fluorenebenzothiadiazole)", MRS Proc. 771(Organic and Polymeric Materials and Devices), 357 (2003).

6. M. S. Liu, X. Z. Jiang, P. Herguth, S. Liu, A. K.-Y. Jen, “Development of Efficient ElectronTransporting Polymers for Light-Emitting Diodes", Proc. SPIE 4800, 130 (2003).

7. P. Herguth, X. Z. Jiang, M. S. Liu, A. K.-Y. Jen, "Poly(fluorene-co-benzothiadiazole)s: Effect of Structure, Molecular Weight and Polydispersity on Their Performance in Polymer Light-Emitting Diodes", Proc. SPIE 4800, 138 (2003).

\section{Fundings that has resulted from this research}

We are in the process of preparing a proposal to be submitted to the Air Force Office of Scientific Research (AFOSR) based on the preliminary results and concepts derived from this JIN supported work. It will be submitted in the beginning of next year.

\section{Figures}
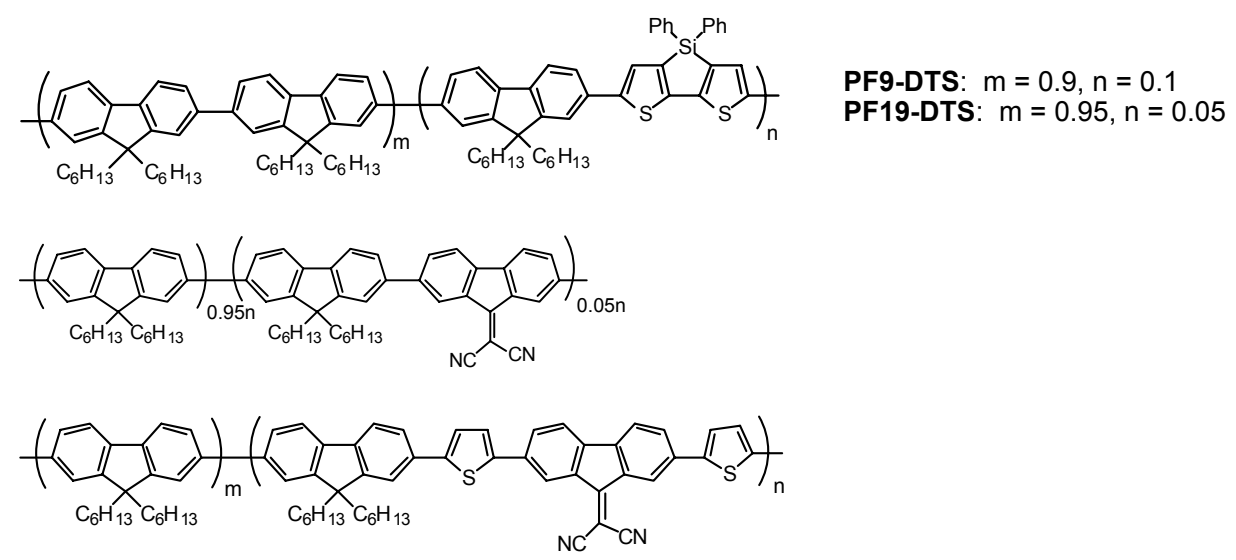

Figure 1. Chemical structure of conjugated polymers with lower energy segements 

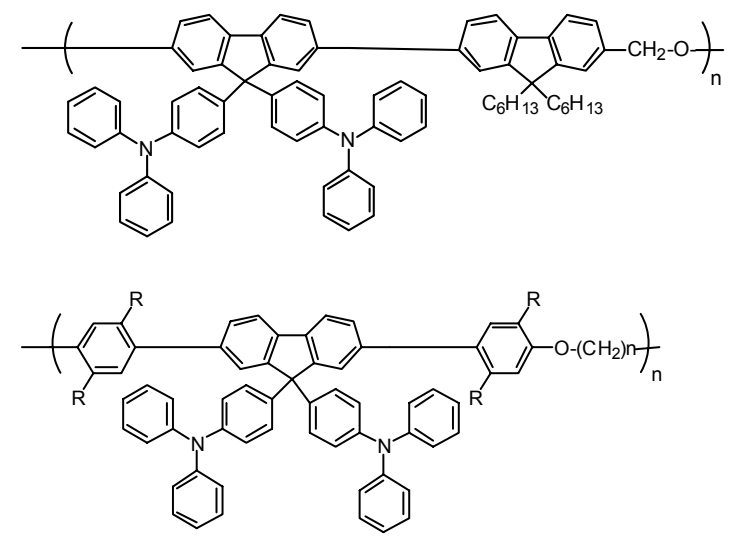

Figure 2. Chemical structure of polymers with breaking conjugation length. 


\section{Redox Reactions of Colloidal Metal Oxides}

Awardee: James M. Mayer

Mentors: James M. Mayer - UW; James A. Franz - PNNL

\section{Project Summary:}

It is proposed to study chemical reactions of colloidal metal oxide particles. An understanding of the chemical reactivity of nanoscale particles is critical to their use and to their behavior in the environment. There are a variety of procedures known to make well-defined colloidal dispersions of metal oxides, both in aqueous and non-aqueous solvents. Our initial studies will focus on colloidal manganese dioxide as a well defined nanostructured oxide. Extensions to iron oxides $\left(\mathrm{FeOOH}, \mathrm{Fe}_{2} \mathrm{O}_{3}\right)$ and photo-activated $\mathrm{TiO}_{2}$ are planned. These colloidal particles will be reacted with organic substrates such as 9, 10-dihydroanthracene, toluenes, phenols, and hydroquinone. Reduction of these particles causes dissolution, which will be monitored optically and by EPR. Because the particles dissolve away completely, the average thermodynamic driving force for the reaction (.G, .H) is essentially that of the bulk material. Knowledge of this thermodynamic driving force enables testing of the recently developed Marcus/Polanyi approach to hydrogen atom transfer/proton coupled electron transfer reactions of molecular metal oxide materials. Successful application of this approach would provide new and important understanding of the reactivity of metal oxide particles.

Mira Kanzelberger was supported by this award for six months. Mira prepared colloidal manganese dioxide following a wide variety of different procedures, some reported and some newly developed, and she studied their reactivity in the oxidation of hydrocarbons. We were unable to get reproducible reactivity, in contrast with our own preliminary studies and surprisingly in contrast with the known reactivity of bulk $\mathrm{MnO}_{2}$. Since this reactivity was the prerequisite for the proposed work, the project was terminated after 6 months and the remaining funds returned to JIN. 


\title{
Electronic Structure of Thin Film Anatase $\mathrm{TiO}_{2}$ : A Candidate Spintronics Material
}

\author{
Diedrich A. Schmidt ${ }^{(1)}$, Scott A. Chambers ${ }^{(2)}$, Marjorie A. Olmstead ${ }^{(1)}$ \\ (1) Department of Physics, University of Washington, Seattle, WA \\ ${ }^{(2)}$ Fundamental Science Division, PNNL, Richland, WA
}

\section{Project Summary}

The discovery and utilization of new semiconducting materials that are ferromagnetic at room temperature is required for the realization of spintronics - a potentially very important development in electronics and magnetics technology. In spintronics, the spins of electrons, holes, ions, and/or atoms are utilized to develop faster, smaller, and less power dissipative ways of processing, transmitting, and storing information. Applications range from on-chip integration of magnetic storage and electronic processing functions over nanometer length scales to quantum computing. In all cases, the essential physics occurs over length scales that are of the order of a few to a few tens of lattice spacings in crystalline solids. Over the next year, we propose to continue our work in the synthesis and properties of candidate oxide semiconductors that may be ferromagnetic at ambient temperature. These include $\mathrm{Mn}_{\mathrm{x}} \mathrm{Zn}_{1-\mathrm{x}} \mathrm{O}(\mathrm{x}<\sim 0.35)$ and $\mathrm{Co}_{\mathrm{x}} \mathrm{Ti}_{1-\mathrm{x}} \mathrm{O}_{2}$ anatase $(\mathrm{x}<\sim 0.08)$.

The anatase and cobalt-doped anatase phase of $\mathrm{TiO}_{2}$ are grown at PNNL using oxygen plasma assisted molecular beam epitaxy (OPA-MBE). The doped and un-doped $\mathrm{TiO}_{2}$ is grown on two different substrates: lanthanum aluminate, $\mathrm{LaAlO}_{3}(001)$ (lattice mismatch $-0.26 \%$ ), and strontium titanate $\mathrm{SrTiO}_{3} / \mathrm{Si}(100)$ (lattice mismatch $-3.1 \%$ with $\mathrm{SrTiO}_{3}$ ). The films are studied ex situ and thus must be cleaned. Surface contaminants were removed by annealing the sample at $530^{\circ} \mathrm{C}$, first in $\sim 5 \times 10^{-5}$ torr $\mathrm{O}_{2}$, then in vacuum, which removes $90 \%$ of the contaminating carbon. No sputtering is required.

A key element in predicting the magnetic and catalytic properties of anatase is knowledge of the electronic band structure. We do this by analyzing the samples with various techniques, such as x-ray photoelectron spectroscopy (XPS), photoelectron spectroscopy (PES), and near-edge xray absorption fine structure (NEXAFS). The XPS and PES can be performed at UW, while the XPS, PES, and NEXAFS are all done at LBNL's Advanced Light source (ALS) in Berkeley, CA. XPS is an element specific technique for composition, PES is useful for valence band mapping, and NEXAFS can distinguish different crystal structure, the local atomic environment, and empty electronic states in the local conduction bands.

From our studies comparing the doped and un-doped $\mathrm{TiO}_{2}$, we have determined that there are no added electronic states when doping $\mathrm{TiO}_{2}$ of $<\sim 3 \%$ Co. This is in stark contrast to the theoretical calculations of Co-doped $\mathrm{TiO}_{2}$. While we have gathered much information from the above techniques, there are still more questions to be answered. In the future, we plan to study these films using Photothermal Deflections Spectroscopy (PDS) to determine any states in the optical gap. We will also study the growth and nucleation of anatase and Co doped anatase on 
LAO and Si substrates with scanning probe microscopy. Both experimental techniques will be carried out at UW.

\section{Publications, Presentations and Proposals}

1. "Electronic Structure of Thin Film Anatase $\mathrm{TiO}_{2}$ : A Candidate Spintronics Material." D. A. Schmidt, J. A. Adams, A. A. Bostwick, S. A. Chambers, M. A. Olmstead. 2002 Nanotech Workshop, UW, Seattle, WA; 2002 PNW-AVS, Vancouver, WA; 2003 CDO Networking Day, UW, Seattle, WA.

2. "The Preparation of Lanthanum Aluminate $\left(\mathrm{LaAlO}_{3}\right)$ Substrates for $\mathrm{MBE}$ Growth of $\mathrm{TiO}_{2}$." D. A. Schmidt, T. Ohta, Q. Yu, S. A. Chambers, M. A. Olmstead. 2003 Nanotech Workshop, UW, Seattle, WA; 2003 PNW-AVS, Troutdale, OR; 2003 CDO Networking Day, UW, Seattle, WA.

\section{Selected Figures}

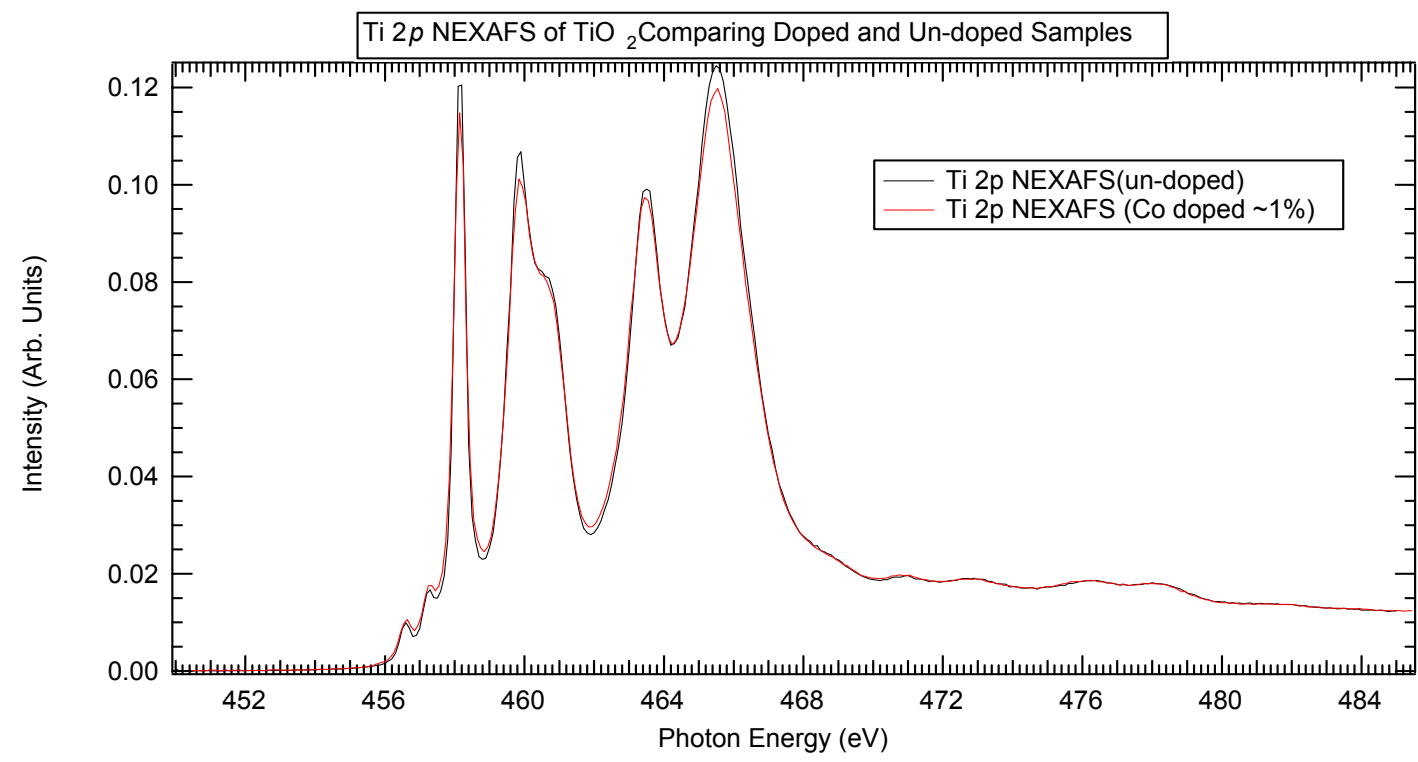

Figure 1. This Graph Shows a Comparison of the Ti L-Edge for Anatase and Co-Doped Anatase(001) Films. The two curves are extremely similar with very minor differences. The differences seen here are attributed to apparatus error and not any electronic changes from Codoping. This graph also indicates no existence of a state in the gap $\left(\mathrm{E}_{\mathrm{g}}=3.2 \mathrm{eV}\right.$ for anatase) induced by Co doping as is predicted by some theory. 

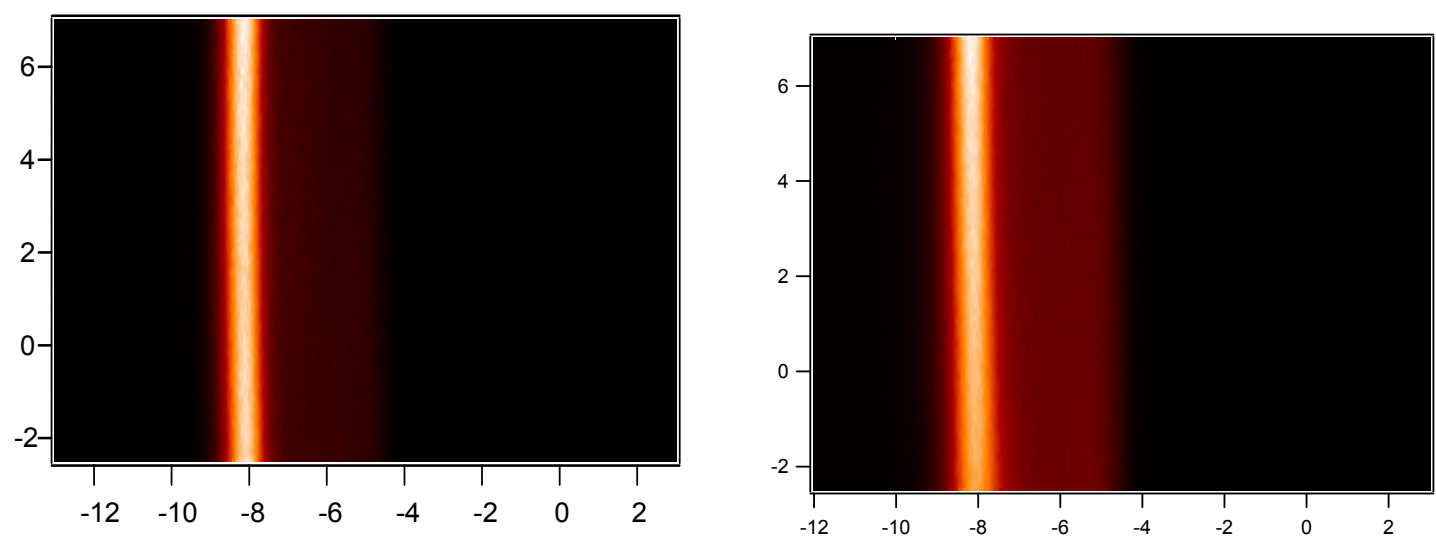

Figure 2a $\& \mathbf{b}$. The image on the left (2a) is the valence band (VB) of $50 \mathrm{~nm}$ $\mathrm{Co}_{0.01} \mathrm{Ti}_{0.99} \mathrm{O}_{2} / \mathrm{LAO}(001)$. The image on the right (2b) is the $\mathrm{VB}$ of $12.5 \mathrm{~nm}$ $\mathrm{Co}_{0.01} \mathrm{Ti}_{0.99} \mathrm{O}_{2} / 12 \mathrm{nmTiO} / 2 \mathrm{nmSTO} / \mathrm{Si}(100)$. The horizontal axis is binding energy, in eV. Of most importance to note here is the lack of a Co-induced state at, or near, the Fermi energy $(0 \mathrm{ev})$. Figures 1 and 2 show that even though the films are macroscopically ferromagnetic, there are no electronic states due to the Co doping. 


\section{Surface Recognition and Incorporation of Additives into Calcium Oxalate Host Crystals}

Awardee: Lara Touryan

Mentors: Viola Vogel - UW; Allison Campbell - PNNL

\section{Project Summary}

Biological systems direct inorganic mineral synthesis and subsequent composite growth via molecular interactions between macromolecules and mineral phases. The systems are striking examples of materials engineering, but describing the structure/function relationships between the organic and inorganic molecules at the molecular level remains difficult. The aim of this research was to learn how specific additives, ranging in size from ions and small molecules to macromolecular proteins, influence the growth morphology and kinetics of biomineral crystals by molecular recognition of surfaces and eventual incorporation into the bulk lattice structure. Understanding additive/host interactions may eventually lead to engineering crystals at the nanoscale using bioinspired approaches. Our focus was to probe how additives interact (i.e., by way of lattice matching, electrostatics, stereochemistry) with inorganic host crystals. Our model is calcium oxalate, the primary mineral found in kidney stones, and we are using atomic force microscopy (AFM) to directly measure how additives with known charge and structure change the morphology and growth rate on different crystal faces. Fluorescence microscopy compliments these results by providing spectral data that are based on changes in the local environment of labeled additives with the orientation of the transition dipole moments of dyes incorporated within the crystal lattice of the energy transfer between dyes on an incorporated double labeled protein. 


\title{
Epitaxial Growth and Characterization of $\mathrm{Co}_{\mathrm{x}} \mathrm{Zn}_{1-\mathrm{x}} \mathrm{O}$ and $\mathrm{Co}_{\mathrm{x}} \mathrm{Ti}_{1-\mathrm{x}} \mathrm{O}_{2-\mathrm{x}}$ for Spintronic Applications
}

\author{
Allan Tuan*, J. W. Rogers, Jr.**, and Scott A. Chambers** \\ "Department of Chemical Engineering, University of Washington \\ **PNNL Environmental Molecular Sciences Laboratory (EMSL)
}

\section{Project Summary}

While conventional electronic devices utilize the charge of an electron to process data, those that are based on spin electronics, commonly referred to as spintronics, would rely on quantum mechanical spin. Many such devices would require electrical injection of a spin-polarized current into semiconductor heterostructures in order to function. Semiconducting materials that are ferromagnetic represent an ideal means of meeting that requirement, provided the material remains ferromagnetic above room temperature and exhibits a high degree of spin polarization. However, thus far, only a handful of these materials has been discovered. The main focus of this research is on understanding the epitaxial growth and properties of two such materials $-\mathrm{Co}_{\mathrm{x}} \mathrm{Zn}_{1-}$ ${ }_{x} \mathrm{O}$ films grown on $\mathrm{Al}_{2} \mathrm{O}_{3}(01 \cdot 2)$ substrates and $\mathrm{Co}_{\mathrm{x}} \mathrm{Ti}_{1-\mathrm{x}} \mathrm{O}_{2}$ thin films grown on $\mathrm{Si}(001)$. Both of these materials exhibit ferromagnetism at and above room temperature.

The epitaxial $\mathrm{Co}_{\mathrm{x}} \mathrm{Zn}_{1-\mathrm{x}} \mathrm{O}$ films were grown by metalorganic chemical vapor deposition using a liquid precursor delivery system. Large amounts of Co $(\mathrm{x} \leq 0.35)$ can be uniformly incorporated into the film without phase segregation. Furthermore, the Co is found to be in the +2 oxidation state. As illustrated in Figure 1, measurements of the temperature-dependent saturation moment and remanence show that low-resistivity, n-type films remain ferromagnetic up to $350 \mathrm{~K}$, the highest temperature measured to date, and that oxygen vacancies contribute the majority of those n-type carriers. Finally, absorption and magnetic circular dichroism (MCD) spectra suggest that the film is in fact a diluted magnetic semiconductor.

The $\mathrm{Co}_{\mathrm{x}} \mathrm{Ti}_{1-\mathrm{x}} \mathrm{O}_{2}$ anatase films were deposited on $\mathrm{Si}(001)$ substrates through the use of a $\mathrm{SrTiO}_{3}$ buffer layer. All of the films were synthesized by molecular beam epitaxy (MBE) and represent the first instance of epitaxially-grown $\mathrm{Co}_{\mathrm{x}} \mathrm{Ti}_{1-\mathrm{x}} \mathrm{O}_{2}$ anatase films on $\mathrm{Si}$ substrates. The results show that the highest quality films are grown at low Ti evaporation rates $(0.027 \AA$ of Ti metal/second) and high temperatures $\left(675^{\circ} \mathrm{C}\right)$. However, at these conditions, the $\mathrm{SrTiO}_{3}$ layer is unable to prevent oxidation of the underlying Si. A cross-sectional TEM micrograph of the heterostructure is shown in Figure 2. All of the cobalt-doped films show the Co segregating to particles that form on the film surface during growth. Given the non-uniform distribution, we have devised a simple modeling procedure that utilizes both AFM and RBS data to accurately determine the amount of Co that is present. Furthermore, using VSM, we have found that the Co-doped $\mathrm{TiO}_{2}$ that are grown on $\mathrm{Si}$ are ferromagnetic at room temperature. Finally, band offset measurements at the $\mathrm{TiO}_{2} / \mathrm{SrTiO}_{3}$ and $\mathrm{SrTiO}_{3} / \mathrm{Si}$ heterojunctions indicate that the overall band structure will be conducive to spin-polarized charge transport from the ferromagnetic $\mathrm{Co}_{\mathrm{x}} \mathrm{Ti}_{1-\mathrm{x}} \mathrm{O}_{2}$ film into Si. 


\section{Presentations}

"MOCVD Growth of $\mathrm{Co}_{\mathrm{x}} \mathrm{Zn}_{1-\mathrm{x}} \mathrm{O}$ on R-sapphire: Structure, Composition, and Magnetic Properties." Allan Tuan, Dave McCready, Dan Gaspar, Mark Engelhard, Theva Thevuthasan, Shuttha Shutthanandan, Tim Droubay, J. W. Rogers, Jr., Scott Chambers. AVS $49^{\text {th }}$ International Symposium in Denver, Colorado, November 2002

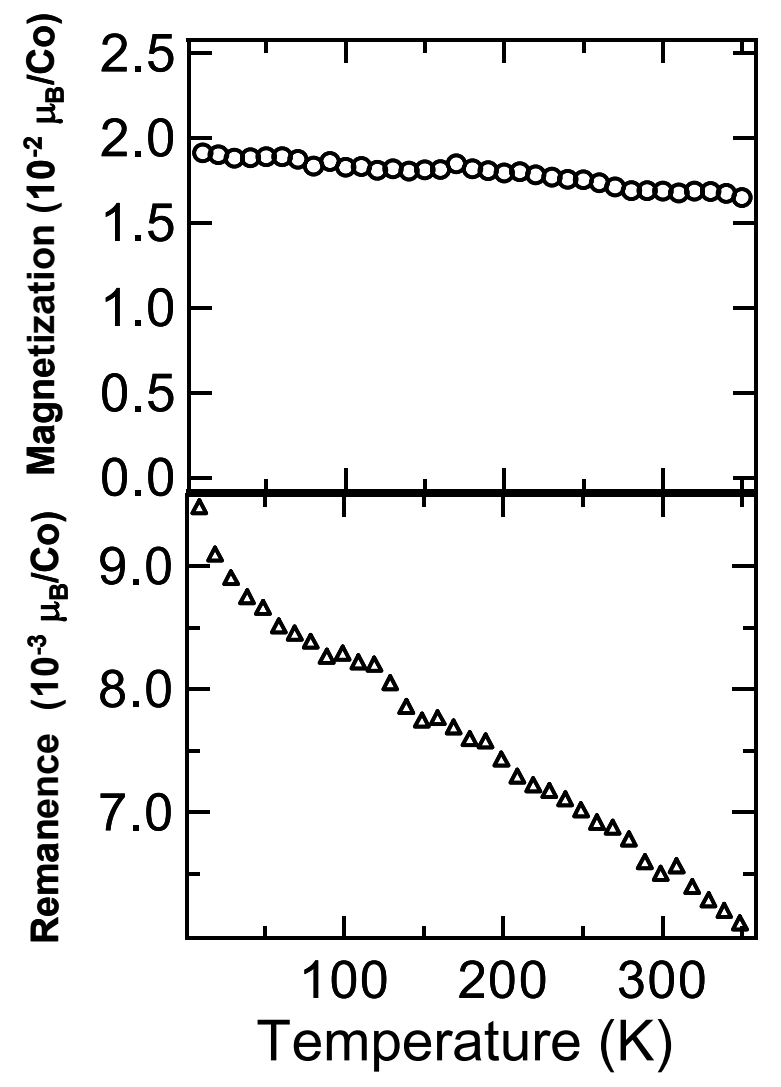

Figure 1. Plots of both the temperature dependence of the saturation moment, measured from $10 \mathrm{~K}$ to $350 \mathrm{~K}$ at a field of $2000 \mathrm{Oe}$, and the remanence, measured at zero field for a $\mathrm{Co}_{\mathrm{x}} \mathrm{Zn}_{1-\mathrm{x}} \mathrm{O}$ film, where $\mathrm{x}=0.09$. 


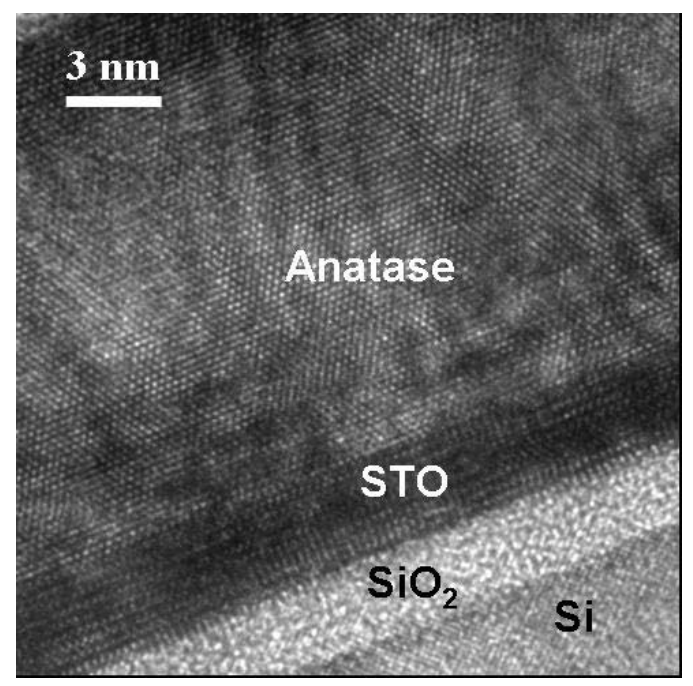

Figure 2. High-Resolution, Cross-Section TEM Micrograph of a $\mathrm{TiO}_{2} / \mathrm{STO} / \mathrm{Si}(001)$ Sample Grown by MBE 


\section{Sol-Gel Electrophoresis for the Formation of Nanosized Nanostructured Materials}

Awardee: Steven Limmer

Mentors: Guozhong Cao - UW; Timothy L. Hubler - PNNL

\section{Project Summary}

We have demonstrated a new technique for the formation of oxide nanorods using sol-gel electrophoresis. $\mathrm{Pb}(\mathrm{Zr}, \mathrm{Ti}) \mathrm{O}_{3}$ nanorods with a diameter of 70 to $150 \mathrm{~nm}$ and a length of $10 \mu \mathrm{m}$, as well as $\mathrm{BaTiO}_{3}, \mathrm{TiO}_{2}, \mathrm{SiO}_{2}$, and hierarchically structured Mesoporous silica rods with diameters of about 125 to $150 \mathrm{~nm}$ were grown in polycarbonate membranes. This technique offers the advantages of growing large areas of uniformly sized nanorods with nearly unidirectional alignments. Further research into the fundamental science underlying sol-gel electrophoresis and physical properties of such nanorods is suggested. We also suggest an examination of other applications of this technique, such as the growth of thick films, mesoporous materials, functionally graded materials, or ordered macroporous materials.

\section{Publications, Presentations and Proposals}

1. "Template-based growth of oxide nanorods by sol electrophoresis," G.Z. Cao and S.J. Limmer, Advanced Materials, scheduled for publication in 2002.

2. "Nanorods of Various Oxides and Hierarchically Structured Mesoprous Silica by Sol-Gel Electrophoresis," S.J. Limmer, T.L. Hubler, and G.Z. Cao, Journal of Sol-Gel Science and Technology, in press (2002).

3. "Electrophoretic deposition of oxide nanorods inside pores of template from sols," S.J. Limmer and G.Z. Cao, Proceedings of the Electrochemical society (2002).

4. "Nanoscale optics and applications", SPIE Proceedings 4809, Ed. G.Z. Cao, (2002).

5. "Oxide Nanorods", G.Z. Cao and S.J. Limmer, in Encyclopedia of Nanomaterials, ed. H.S. Nalwa, The American Scientific Press, scheduled for publication this year.

6. "Sol electrophoretic deposition of oxide nanorods", G.Z. Cao and S.J. Limmer, in Nanowire Materials, ed. Z.L. Wong, Kluwer, (2003).

7. "Template-Based Growth of Various Oxide Nanorods by Sol-Gel Electrophoresis," S.J. Limmer, S. Seraji, M.J. Forbess, Y. Wu, T.P. Chou, C. Nguyen, and G.Z. Cao, Advanced Functional Materials 12, 59-64 (2002).

8. "Formation and Optical Properties of Cylindrical Gold Nanoshells on Silica and Titania," S.J. Limmer, T.P. Chou, and G.Z. Cao, in Nanoscale Optics and Applications, Proceedings of SPIE 4809, ed. G.Z. Cao and W.P. Kirk, 222-230 (2002).

9. "Functionalized, Hierarchically Structured Mesoporous Silica by Sol Electrophoresis and Self Assembly," T.P. Chou, S.J. Limmer, and G.Z. Cao, in Nanoscale Optics and Applications, Proceedings of SPIE 4809, ed. G.Z. Cao and W.P. Kirk, 239-248 (2002). 
10. "Films, Patterned Structures and Nanorods of Various Oxides and Mesoporous Silica by SolGel Electrophoresis," S.J. Limmer, T. Hubler, and G.Z. Cao, Journal of Sol-Gel Science and Technology 26, 577-581 (2003).

11. "Synthesis and Optical Properties of Nanostructured CdWO4 Films by Sol-Gel Processing," K. Lennstrom, S.J. Limmer, and G.Z. Cao, in Nanoscale Optics and Applications, Proceedings of SPIE 4809, ed. G.Z. Cao and W.P. Kirk, 231-238 (2002).

12. "Growth of Oxide Nanorods through Sol-Gel Processing and Electrophoretic Deposition," (invited), Steven J. Limmer and G.Z. Cao, Advanced Materials, in press (2003).

13. "A study on the Growth of $\mathrm{TiO}_{2}$ Nanorods by Sol Electrophoresis," S.J. Limmer, T.P. Chou, and G.Z. Cao, Journal of Materials Science, in press (2003). 


\subsection{Awards Started June 2002}

\section{Superparamagnetic Nanoparticles for Imaging and Therapeutics}

Awarded: Nathan Kohler

Mentors: M. Zhang - UW; Glen E. Fryxell - PNNL

\section{Project Summary:}

Superparamagnetic nanoparticles have many biomedical applications (e.g., cell separation, contrast enhancement in magnetic resonance imaging (MRI), drug delivery, hypothermic therapies at the cellular level, and magnetic-field-assisted radionuclide therapy). The goal of this research is to develop novel liposome/nanoparticles-conjugate/drug systems with combined cancer diagnostic and therapeutic functions. These "smart" nanoparticle conjugates or liposomes are designed to recognize tumorspecific markers and target only individual tumor cells. These particles will enable doctors to detect tumors with MRI at the cellular level in very early stages and measure the therapeutic efficiency of hyperthermia simultaneously.

Superparmagnetic nanoparticle drug delivery systems have been developed by modifying the nanoparticle surface with methotrexate (MTX), a common chemotherapeutic drug used extensively in cancer therapies for leukemia, breast, and several other forms of cancer. MTX was grafted onto the nanoparticle surface via a peptide bond, enabling the drug to be released only under intracellular conditions. In vitro results of MTX modified nanoparticles grown in culture with human breast cancer cells have demonstrated (1) a lowered cellular viability, indicating that the MTX has been cleaved from the nanoparticle and is released into the cellular cytoplasm and (2) the existence of the magnetite nanoparticles in the lysozomal compartments where the MTX would be cleaved from the particle surface.

To improve circulation time in vivo, PEG amine and carboxylate terminal self assembled monolayers capable of targeted drug delivery are being synthesized. Currently, a PEG molecular weight 600 carboxylate silane has been demonstrated via NMR and FTIR and is being tested on the superparamagnetic nanoparticle system.

\section{Publications, Presentations and Proposals:}

1. Zhang Y, Kohler N, Sun Conroy, Zhang M. Self-assembled coatings on individual monodispersed magnetite nanoparticles for efficient intracellular uptake. In preparation.

2. Y. Zhang, N. Kohler, and M. Zhang "High-Efficiency Intracellular Uptake of Superparamagnetic Magnetite Nanoparticles for Biomedical Applications" in Nanoscience and Nanotechnology in Perspective", G. Liu, et al. (eds), pp 282, Frontiers of Science and Technology for the 21st Century, Tshinghua University Press (2002).

3. Kohler N, Zhang Y, Zhang M. Characterization of methotrexate modified superparamagnetic nanoparticles and their uptake into human chronic myologenous leukemia cells. 2003 Nanotech Conference and Tradeshow, San Francisco, CA, February 23-27, 2003. (Submitted September, 2002) 
4. Kohler N, Zhang Y, Zhang M. Synthesis of methotrexate modified superparamagnetic nanoparticles and their uptake into Breast Cancer Cells. MRS Fall Meeting, Boston, MA. December 2-6, 2002.

5. Kohler N, Zhang Y, Busche B, Zhang M. Superparamagnetic Nanoparticles for Imaging. International Symposium on Optical Science and Technology. SPIE Annual Meeting, July 2002.

\section{Selected Figures}

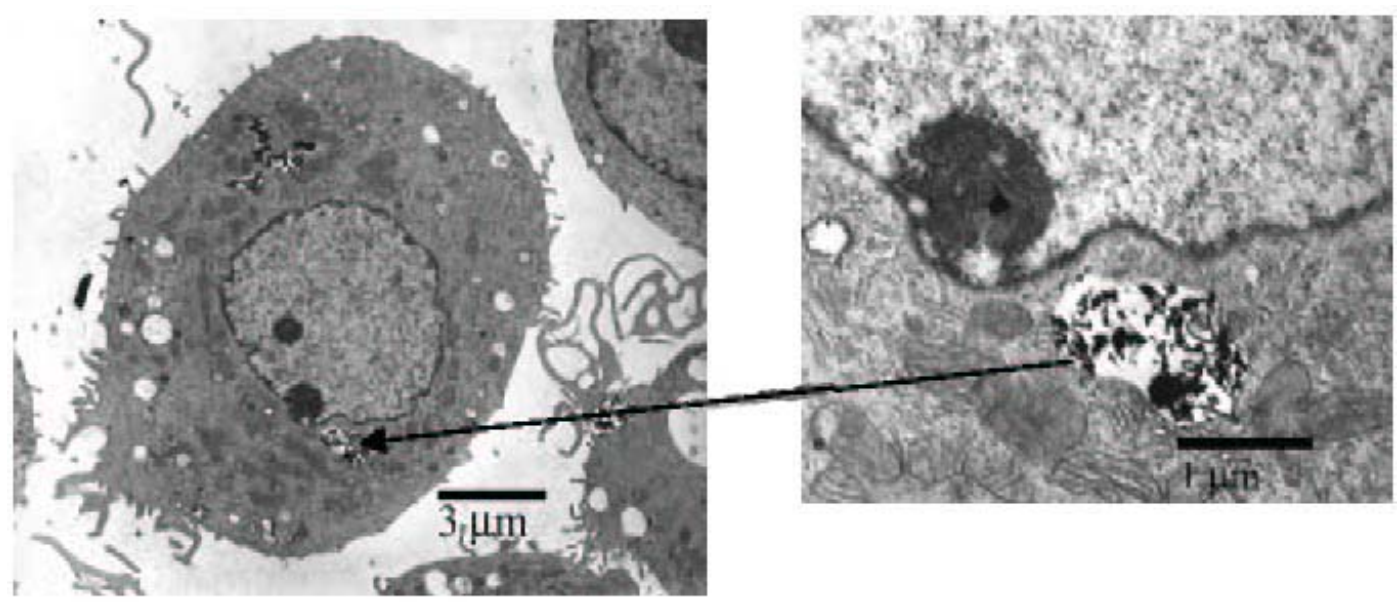

Figure 1. MTX modified nanoparticles have been visualized via TEM in human breast cancer cells. Nanoparticles are in lysozomal compartments where the MTX molecule is cleaved from the particle surface.

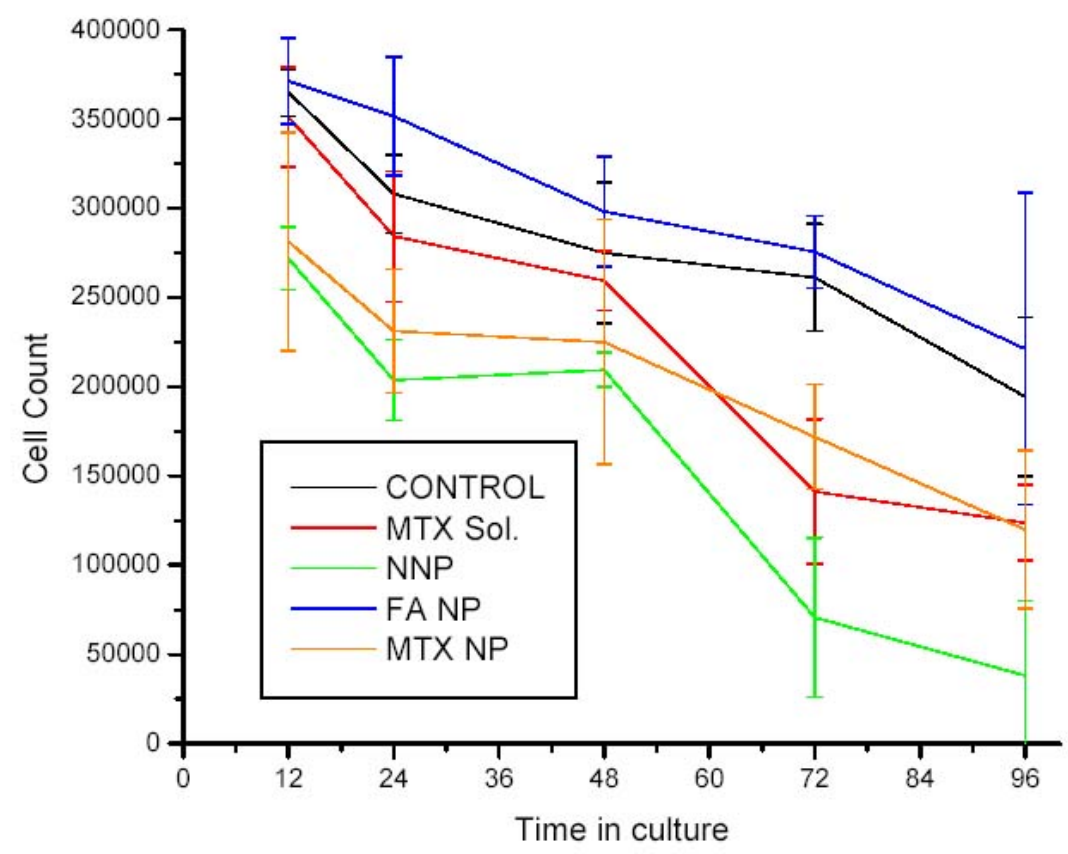

Figure 2. In Vitro Cell Culture Results Have Demonstrated that the MTX Grafted Nanoparticles Show a Similar Reduction in Cellular Viability Compared to Soluble (unmodified) MTX at Blood Plasma Concentrations. 


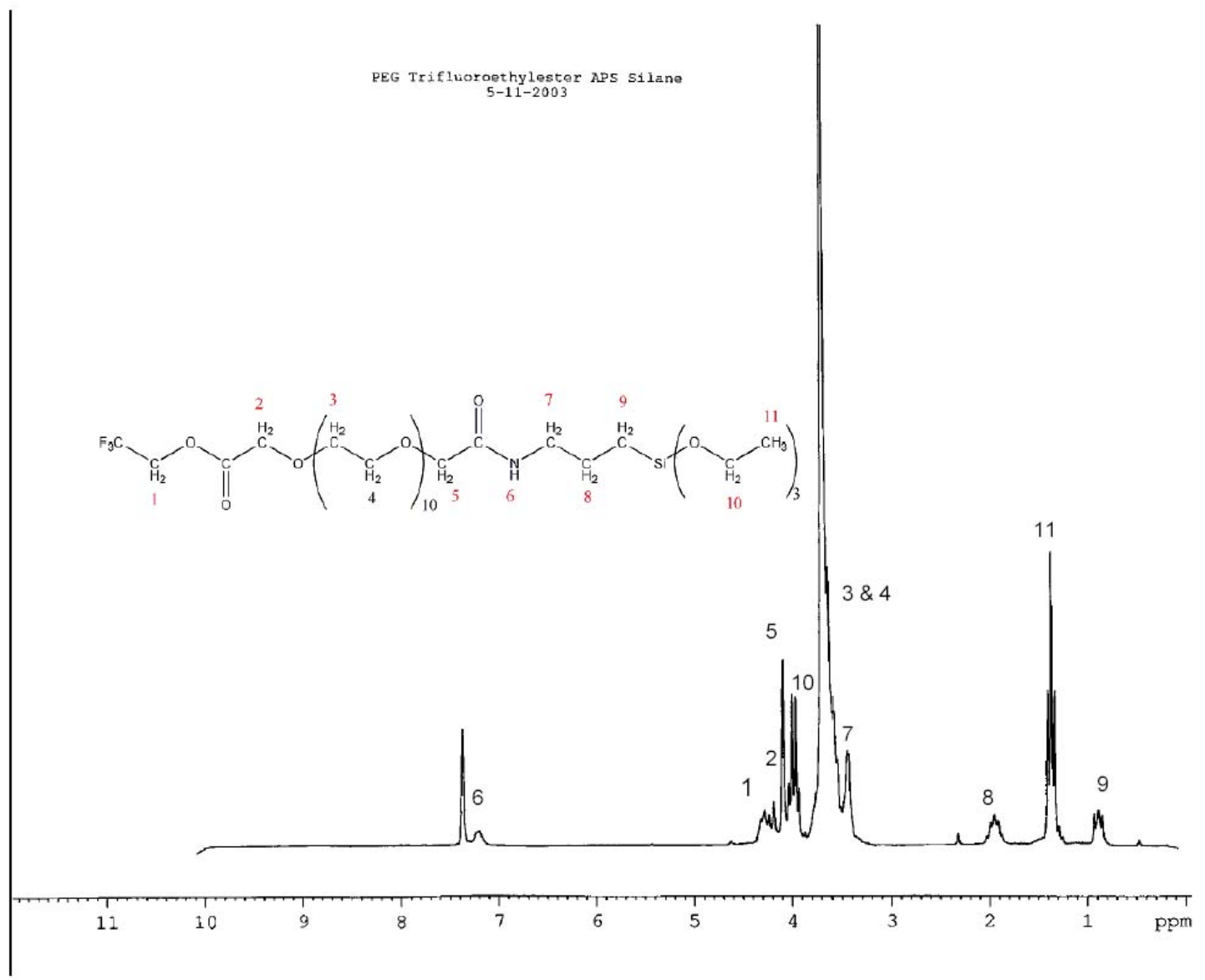

Figure 3. HNMR Analysis of Trifluoroethylester (Carboxylate Terminal) PEG Silane. Peak analysis demonstrates the self assembled monolayer structure that can be immobilized on the nanoparticle surface. 


\section{Direct Simulation Approach to Multi-Phase Biomaterial Transport and Nano-Interactions in Microfluidic Systems}

Awardee: David S.W. Lim

Mentors: Daniel T. Chiu - UW; David Rector - PNNL

\section{Project Summary:}

Multi-phase transport in microchannels is an essential feature in a chip-based microfabricated fluidic device that integrates multiple operational steps to analyze and manipulate biomaterials. Physical insights of the underlying processes are crucial to successful device development, and these processes usually operate in small length scales. The use of micro-beads in a microfluidic system has been central to many emerging biotechnological and bioanalytical applications. In these systems, the transport phenomena usually operates in the length scale in the order of $100 \mathrm{~s} \mathrm{~nm}$ due to the sizes of micro-bead used. In our investigation, we observed a formation of ring patterns when a suspension of micro-bead flows past a microcavity, as shown in Figure 1. The ring-patterns are very reproducible and were observed in different fluid flow rates, bead sizes, and densities of the two phases.

The mechanism of ring formation has been attributed to a balance of forces within the cavity described by eq. (1)

$$
\mathrm{F}_{\text {centrifugal }}+\mathrm{F}_{\text {displacement }}+\mathrm{F}_{\text {lift }} \approx 0
$$

The forces involved are (1) the centrifugal force experienced by the bead due to the fluid recirculating motion, $F_{\text {centrifugal }}=m_{p} v_{p}{ }^{2} / r$, (2) the displacement force acting on the bead by the fluid as it displaces a corresponding fluid volume when traveling through solution,

$F_{\text {displacement }}=\iiint(\partial p / \partial \mathrm{r}) d V=\iiint \rho_{f} v_{\theta}^{2} / r d V$, and (3) the hydrodynamic lift force experienced by the bead as it travels parallel to the boundary of the microcavity, $F_{l i f t}=\rho_{f} a^{2} v^{2} \iint \sigma \boldsymbol{n} d S$. All these forces are related to the fluid motion through the Navier-Stokes equation, and simulated velocity profiles of the fluid in the cavity are shown in Figure 2, in excellent agreement with experimental measurements. Using this model, we can predict the size of the ring within the cavity as shown in Figure 3. The results compare favorably with the measured ring diameters, and the slight over-estimation is probably caused by a flat-wall assumption used in the lift force estimation that under-predicted the force experienced by the particle.

Flow past cavity has been a classical subject in fluid mechanics, but similar aggregation of suspended particles has never been reported, probably due to the absence of significant wallinduced lift forces. The hydrodynamic lift in a microfluidic system is significant $(\sim 60 \mathrm{pN})$ due to the of large velocity gradients, $10^{5} \mathrm{~s}^{-1}$, in the wall region, a result of characteristic high surface-to-volume ratio environment in microfluidic systems. 


\section{Publications:}

1. D.S.W. Lim, P. Shelby, J.S. Kuo, D.T. Chiu (2003) "Dynamic formation of ring-shaped patterns of colloidal particles in microfluidic systems" Appl. Phys. Lett 83, 1145-1147.

2. G.S. Fiorini, G.D.M. Jeffries, D.S.W. Lim, C.L. Kuyper, D.T. Chiu (2003) "Molding techniques for the rapid prototyping of polymeric microfluidic devices" Lab Chip 3, 158-163.

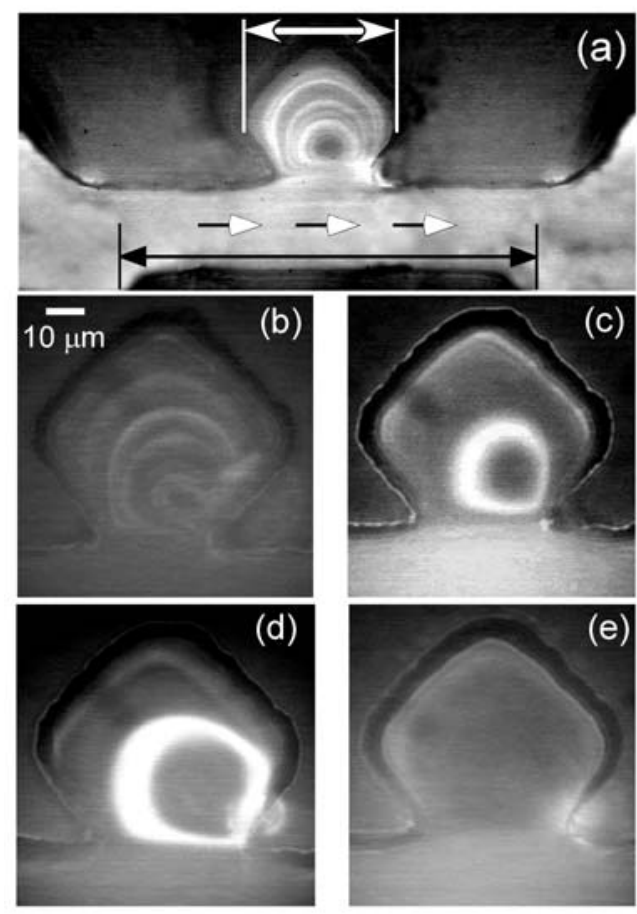

Figure 1. (a) Fluorescence micrograph showing the layout of the microchannel used in our experiments. The fluorescence observed in the channel and cavity is caused by the presence of $1-\mu \mathrm{m}$ fluorescent polystyrene beads flowing through the channel. (b) - (e) show the formation of patterns of re-circulating $1-\mu \mathrm{m}$ polystyrene beads (density $\sim 1.05 \mathrm{~g} / \mathrm{cm}^{3}$ ) in water (volume fraction, $\phi \sim 10^{-5}$ ), as a function of average flow rate in the $30-\mu \mathrm{m}$ wide straight channel, (b):5 m/s, (c): $9 \mathrm{~m} / \mathrm{s},(\mathrm{d}): 17 \mathrm{~m} / \mathrm{s}$, and (e) $45 \mathrm{~m} / \mathrm{s}$. 

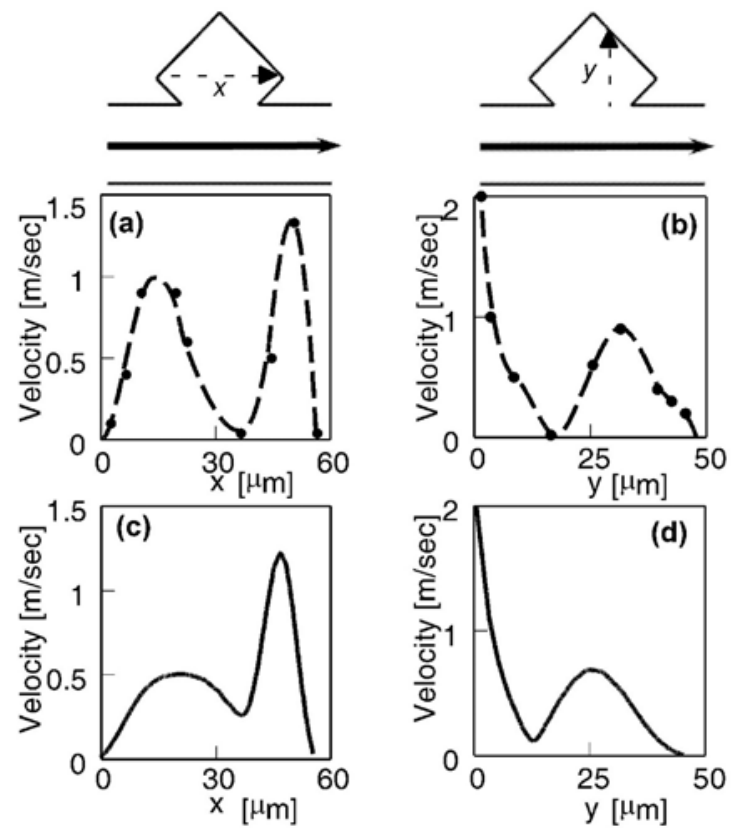

Figure 2. (a) and (b) are experimental measurements of the velocity profiles inside the microcavity in the absence of beads and at an average flow rate of $5 \mathrm{~m} / \mathrm{s}$ in the $30-\mu \mathrm{m}$ wide channel. (c) and (d) are the simulated velocity profiles under identical conditions as that shown in (a) and (b).

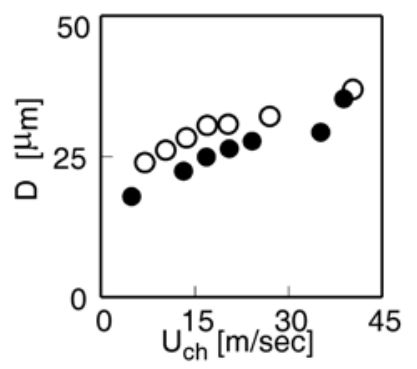

Figure 3. A plot of ring diameter versus the average flow velocity inside the microchannel. (•) are experimental measurements and $(\circ)$ are simulated ring diameters using our force-balance model. 


\section{Nature of Genetically Engineered Protein/Inorganic Interactions: Novel Molecular Linkers for Nanotechnology}

Awardee: Dan Heidel

Mentors: Mehmet Sarikaya - UW; Wendy Shaw - PNNL

\section{Project Summary}

Organisms can be viewed as fully integrated and mature nanotechnological systems. They are composed of molecular scale components that self-assemble into hierarchical, selfreplicating, self-contained systems. Ultimately, nanotechnology must be able to emulate these properties of living organisms if it is to transcend the limitations of traditional materials synthesis. Biological hard tissues are of particular relevance to the focus of most nanotechnological research. The inorganic components of living organisms (e.g.: bone, enamel, shells, spicules, magnetic particles) often exhibit extraordinary properties, which arise from the precise control organisms have over the morphology of the inorganic phase and its interface to an organic matrix. Central to formation of biological hard tissues is surface interactions with macromolecules, through which organisms monitor nucleation, growth, and morphogenesis of inorganic crystallites. These macromolecules may be matrix proteins or polysaccharides residing in hard tissues, or genetically engineered polypeptides. For the robust design and manufacturing of protein/nanoinorganic hybrid structures, we must control protein/inorganic interfaces. We use combinatorial biology (such as phage display and cell-surface display) and select short (4 to 14 aa long) polypeptides that specifically bind to inorganic surfaces, and then use them as molecular erectors for materials nanoassembly, nanobiofabrications, and target selection in nano- and nano-biotechnology.

\section{Accomplishments to Date}

Gold-binding protein, selected via cell surface display protocol, was used as the model engineered polypeptide system and broad-based experiments focusing on

polypeptide/inorganic interactions have been carried out, the topic of this grad student fellowship research. Some of the accomplishments to date include:

- Assembly of gold-binding polypeptide on gold surface as a single layer molecular thin film with organized structure (w/Dr. H. Zareie)

- Preliminary CD and NMR experiments on the structure and binding of single-repeat and three-repeat gold binding protein on Au surface (collaboration with John Evans, NYU)

- Immobilization of nanogold particles on GBP-covered surfaces

- Selection of Pt and Pd-specific polypeptide sequences

- Kinetics and thermodynamics of binding using surface plasmon resonance spectroscopy and quartz crystal microbalance

- Cross specificity experiment of gold-binding proteins using XPR and TOF-SIMs (collaboration with F. Ohuchi and his student N. Suzuki). 
One of our plans was to label one of the gold-binding proteins and carry out solid-sate NMR in collaboration with Dr. Wendy Shaw, using her unique expertise and facilities at PNNL. This part of the work is still underway. In the meantime, we have plans to use other surface science facilities at PNNL such as XPS, TOF-SIMS, IR, and RAMAN to characterize binding of GBP on gold and other noble metals.

\section{Publications, Presentations and Proposals}

1. C. Tamerler, S. Dincer, D. Heidel, H. Zareie, and M. Sarikaya, "Biomimetic functional molecular coatings using engineered proteins," Progress in Organic Coatings, 47, 267-274 (2003).

2. S. Dincer, C. Tameler, D. Heidel, and M. Sarikaya, Phage display selection of Pt-binding Septopeptides," submitted to J. Amer. Chem. Soc. (2004).

3. J. L. Kulp III, D. Heidel, M. Sarikaya, and J. E. Evans, "Characterization of Integral Sequence repeat of gold binding proteins with NMR," submitted to Chemistry of Materials (2003).

4. M. Duman, E. Venkatasubramanian, C. Tamerler, D. Heidel, E. Oren, and M. Sarikaya, “ Kinetics of GBP on gold," prepared for Langmuir (2004).

5. N. Suzuki, C. Tamerler, D. Heidel, M. Sarikaya, and F. Ohuchi, "Specificity of geneticallyengineered gold binding protein on noble metals: A surface-spectroscopic study," in preparation to be submitted to Chem. Mater. (2004).

6. B. W. Reed, D. Heidel, H. Zareie, E. Oren, and M. Sarikaya, "Self-assembled structural model of gold-binding protein on $\mathrm{Au}(111)$, in prep (2004).

Other papers that D. Heidel's work has contributed:

1. M. Sarikaya et al., "Molecular biomimetics: Nanotechnology through biology," NatureMaterials, 2 (9) 577-586 (2003).

2. M. Sarikaya et al., "Materials Assembly and Formation using engineered polypeptides," Annu. Rev. Mater. Res., 34 in print (2004).

\section{Presentations}

There have been about 20 presentations to date on this work in various workshops, focused symposia, and international conferences, that include Materials Research Society Spring and Fall Meetings (2002 F, 2003 Sp, and 2004 Sp), Topical Conference on Nanotechnology, by the American Microbiology Society, New York (July 10-13, 2003), American Chemical Society Conferences, 2003, NATO Summer School, Portugal, Oct. 14-20, 2003, International Conferences of MRS, Yokohama, October, 2003; Biomimetics-III and IV, International Workshop, January 27029, 2003, and 28-30, 2004, Nagoya, Japan, TMS 2004 Spr. Meeting, Charlotte, NC, March 14-18, 2004.

\section{Proposals}

NSF-NIRT (Nanotechnology Interest Research Teams) proposal, "Nature of engineered polypetide binding on inorganics," Oct. 2003 (5 Co-PIs, \$2,000,000 (in review); "Functional molecule-Engineered polypeptides conjugates for molecular electronics," to be submitted to Technological Challenges Inorganic Electronics, Photonics, and Magnetics Program (NSF 04-554), May 11, 2004 (3 Co-PIs); "Engineered polypeptides as molecular erectors," in Bioinspired Concepts Program (BIC) in AFOSR, to be submitted, May 1, 2004. 


\section{Figures}

Figure 1. MALI/Time of flight mass spectra showing binding of gold only to $\mathrm{AuCl}_{3}$, and not $\mathrm{AlCl}_{3}$ or $\mathrm{LaCl}_{3}$, showing specificity to atomic gold.
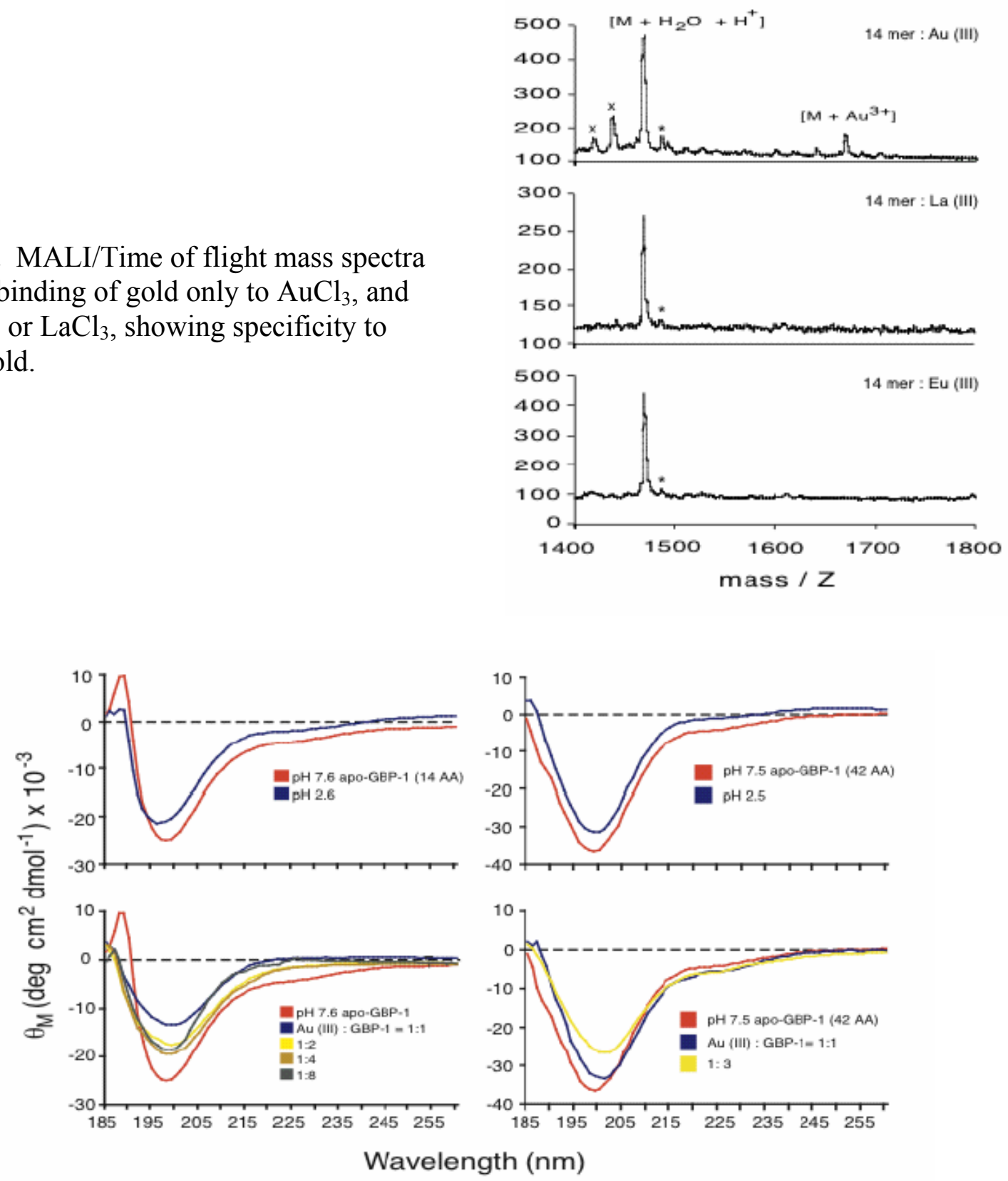

Figure 2. UV-CD spectra from single and 3-repeat GBP showing linear nature of the polypeptides. 
Figure 3. A model of 3-repeat GBP based on molecular dynamics study showing antiparallel $\beta$-sheet structure (adapted from Braun, Sarikaya, and Schulten, Biomater. Sci., 2002) confirming CD results of $b$.

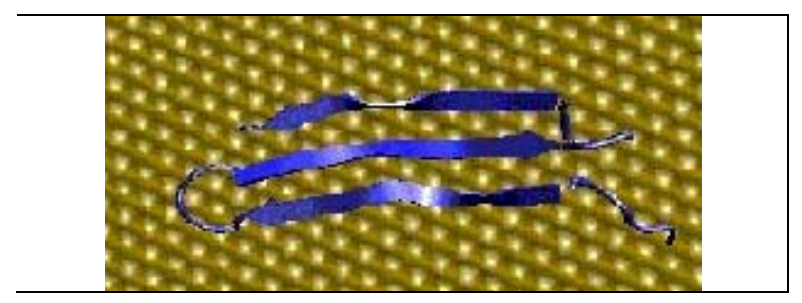




\section{Magnetic Nanocrystals: Synthesis and Study of ZnO and GaN Diluted Magnetic Semiconductors}

Awardee: Nick Norberg - UW, Dept. of Chemistry

Mentors: Daniel Gamelin - UW; James Amonette - PNNL

Progress Report: JIN award 2003/2004

Diluted Magnetic Semiconductors (DMSs) are currently attracting intense interest in the emerging field of spin-based electronics, or "spintronics." The broad objective of this field is to control electron spins, in addition to charges, in order to transmit information and provide new functionality to semiconductor devices. However, obtaining above room temperature ferromagnetic ordering in these DMSs, essential for their use in spintronics technology, has been an experimental challenge, with many materials exhibiting Curie temperatures $\left(T_{c}\right)$ well below room temperature. Several theoretical studies have focused on II-VI and III-V semiconductor DMSs and have proposed that $\mathrm{ZnO}$ may be an ideal candidate for providing high temperature ferromagnetism. This work presents a chemical approach to the synthesis of $\mathrm{Co}^{2+}: \mathrm{ZnO}$ and $\mathrm{Ni}^{2+}: \mathrm{ZnO}$ nanocrystals. With the robustness, optical transparency, and unique magnetic properties of $\mathrm{ZnO} \mathrm{DMSs}$, this synthetic route may offer opportunities towards the development of novel nanoscale devices.

The synthesis of colloidal $\mathrm{TM}^{2+}: \mathrm{ZnO}$ nanocrystals was previously reported ${ }^{1}$ from our lab using ethanol as the primary solvent. We have recently developed a better approach towards the synthesis of high quality $\mathrm{TM}^{2+}: \mathrm{ZnO}$ colloidal nanocrystals ${ }^{2}$, where an ethanolic solution of $\mathrm{N}(\mathrm{Me})_{4} \mathrm{OH}$ is added dropwise to a stirring DMSO solution of $\mathrm{Co}(\mathrm{OAc})_{2}$ or $\mathrm{Ni}\left(\mathrm{ClO}_{4}\right)_{2}$, yielding relatively monodispersed, colloidal nanocrystals. Homogeneous speciation of the dopant ion in the $\mathrm{ZnO}$ nanocrystals was achieved either by growing a $\mathrm{ZnO}$ shell around the $\mathrm{ZnO}$ core (iso-crystalline core/shell method or ICS as previously reported ${ }^{1}$ ), or by treating the nanocrystals in a $180^{\circ} \mathrm{C}$ solution of tri-octylphosphine oxide (TOPO). The TOPO strips off the $\mathrm{TM}^{2+}$ from the $\mathrm{ZnO}$ surface, leaving purely internally doped $\mathrm{Co}^{2+}: \mathrm{ZnO}$ or $\mathrm{Ni}^{2+}: \mathrm{ZnO}$ nanocrystals. Ligandfield electronic absorption spectroscopy confirms the homogeneous speciation of the TOPOtreated particles. A TEM of these particles shows relatively monodispersed nanocrystals with electron diffraction matching that for wurtzite $\mathrm{ZnO}$ (Figure 1).

When $\mathrm{Co}^{2+}: \mathrm{ZnO}$ nanocrystals were prepared from DMSO, followed by the ICS method (ensuring only internal dopants), and allowed to slowly aggregate from colloidal solution, ferromagnetic ordering was observed by a SQUID magnetometer (Figure 2). The coercivity and remanence both indicate that the Curie temperature is well above room temperature. Although high $\mathrm{T}_{\mathrm{c}}$ ferromagnetism has been observed on $\mathrm{Co}^{2+}: \mathrm{ZnO}$ samples prepared through high vacuum deposition routes, observations of Co metal in some samples have raised questions on whether this ferromagnetism is intrinsic to $\mathrm{Co}^{2+}: \mathrm{ZnO}$ or arises from impurity phases. Due to the low temperature and chemically controlled synthesis of this material, these data demonstrate intrinsic ferromagnetism in $\mathrm{Co}^{2+}: \mathrm{ZnO}$.

Further work is in progress on the synthesis and magnetic properties of $\mathrm{ZnO}$ DMSs. 


\section{References}

1. P. V. Radovanovic, N. S. Norberg, K. E. McNally, D. R. Gamelin, J. Am. Chem. Soc., 124, 15192 (2002).

2. Schwartz, Dana A.; Norberg, Nick S.; Nguyen, Quyen P.; Parker, Jason M.; Gamelin, Daniel R. J. Am. Chem. Soc., 125, 13205 (2003).

\section{Figures}
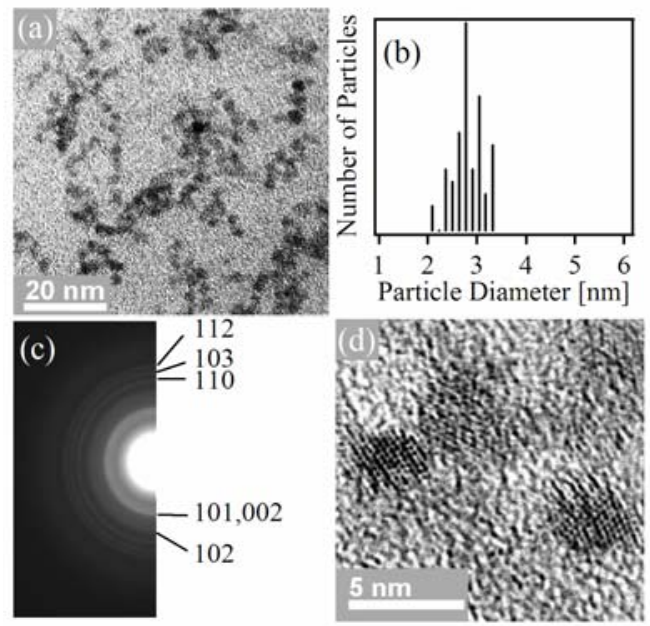

Figure 1. TEM data for $5 \% \mathrm{Co}^{2+}: \mathrm{ZnO}$ nanocrystals prepared in DMSO; (a) Low-resolution TEM image; (b) Histogram computed for $\sim 100$ nanocrystals showing an average particle diameter of $2.9 \pm 0.3 \mathrm{~nm}$; (c) Wide-area electron diffraction image; (d) High-resolution TEM image.
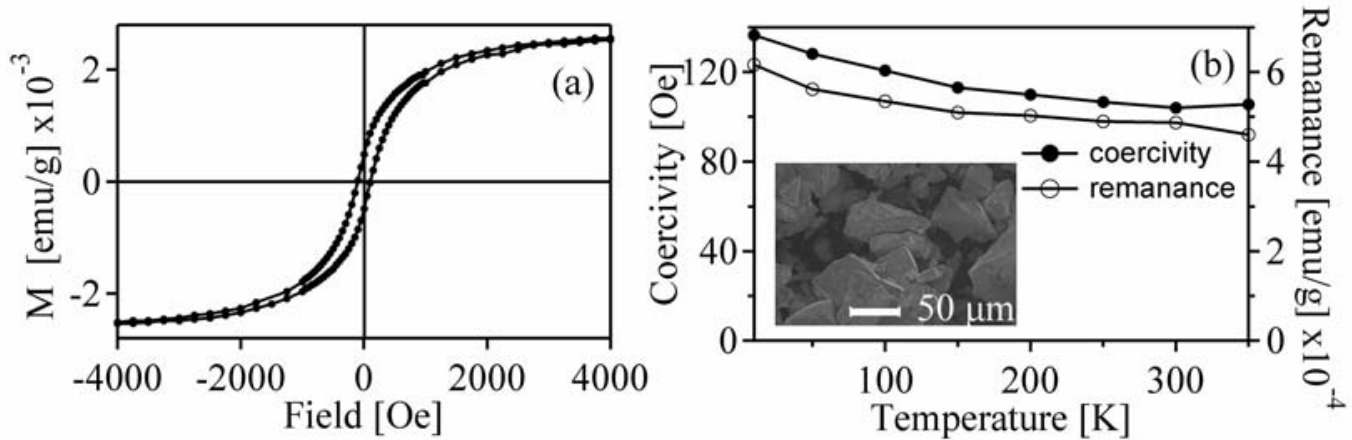

Figure 2. (a) $300 \mathrm{~K}$ magnetic hysteresis loop and (b) hysteresis coercivity and remanance temperature dependence collected on a powder sample of $3.6 \% \mathrm{Co}^{2+}: \mathrm{ZnO}$ DMS-QD aggregates (inset). 


\section{Publications, Presentations and Proposals}

- "Magnetic Quantum Dots: Synthesis, Spectroscopy, and Magnetism of Co2+- and Ni2+Doped ZnO Nanocrystals." Schwartz, Dana A.; Norberg, Nick S.; Nguyen, Quyen P.; Parker, Jason M.; Gamelin, Daniel R. J. Am. Chem. Soc., 125, 13205 (2003).

- "Magneto-optical and Magnetic Studies of Diluted Magnetic Semiconductor Nanocrystals." Norberg, Nick S.; Radovanovic, Pavle V.; Schwartz, Dana A.; Amonette, James E.; Gamelin, Daniel R., Third Annual Nanoscale Science and Technology Workshop, University of Washington, Seattle, Washington, September 2003 (poster presented).

- Norberg, Nick S.; Kittilsvted, Kevin; Gamelin, Daniel R., (manuscript in preparation). 


\title{
Materials Characterization and Magnetic Studies of Epitaxial $\mathrm{Co}_{\mathrm{x}} \mathrm{Ti}_{1-\mathrm{x}} \mathrm{O}_{2-\mathrm{x}}$ Deposited on Si(001) by Molecular Beam Epitaxy
}

\author{
Tiffany Kaspar, ${ }^{+}$J. W. (Bill) Rogers, Jr., ${ }^{+*}$ and Scott Chambers ${ }^{*}$ \\ ${ }^{+}$Department of Chemical Engineering, University of Washington \\ "PNNL Environmental Molecular Sciences Laboratory (EMSL)
}

For spintronic devices such as spin-FETs, efficient injection of spin-polarized electrons into a semiconductor material is necessary. Progress has been made using ferromagnetic metals to tunnel spin-polarized electrons into $\mathrm{AlGaAs} / \mathrm{GaAs}$ quantum well structures. However, for devices compatible with current semiconductor technology, efficient spin injection into $\mathrm{Si}$ is desired. Diluted magnetic semiconductors (DMSs) that can be grown epitaxially on Si are prime candidates. The epitaxial growth will result in a high-quality interface, reducing depolarization caused by scattering at interfacial defects. Further, the conductivity of the DMS can be tuned by doping to match that of $\mathrm{Si}$, greatly increasing the spin injection efficiency. While most known DMS materials have Curie points well below room temperature, anatase $\mathrm{Co}_{\mathrm{x}} \mathrm{Ti}_{1-\mathrm{x}} \mathrm{O}_{2-\mathrm{x}}$ has been shown to have a Curie temperature of at least $700 \mathrm{~K}$ when deposited on $\mathrm{LaAlO}_{3}(001)$. In addition, anatase is well lattice-matched to $\mathrm{Si}$. To prevent interfacial reactions between the film and substrate, resulting in $\mathrm{SiO}_{2}$ and/or silicide formation, a buffer layer of epitaxial $\mathrm{SrTiO}_{3}$ (STO) is first deposited. In this study, a STO buffer layer and $\mathrm{Co}_{\mathrm{x}} \mathrm{Ti}_{1-\mathrm{x}} \mathrm{O}_{2-\mathrm{x}}$ film on $\mathrm{Si}(001)$ are deposited by molecular beam epitaxy (MBE). Deposition parameters will be optimized to obtain magnetic thin films with $\mathrm{Co}$ in the +2 charge state and minimal or no $\mathrm{SiO}_{2}$ formation. The growth mode of pure anatase and $\mathrm{Co}_{\mathrm{x}} \mathrm{Ti}_{1-\mathrm{x}} \mathrm{O}_{2-\mathrm{x}}$ will be investigated to minimize the formation of Co-rich anatase particles on the film surface. Thorough materials characterization of the $\mathrm{Si}$ interface, the STO buffer layer, and the $\mathrm{Co}_{\mathrm{x}} \mathrm{Ti}_{1-\mathrm{x}} \mathrm{O}_{2-\mathrm{x}}$ film will be accomplished by several complementary analytical techniques, such as reflection high energy electron diffraction (RHEED), x-ray photoelectron spectroscopy (XPS), atomic force microscopy (AFM), x-ray diffraction (XRD), Rutherford backscattering (RBS), and high resolution transmission electron spectroscopy (HRTEM). To determine the presence of metallic Co atoms in the film, K-shell x-ray absorption near-edge fine structure (XANES) will be used. In addition, the electronic and magnetic properties of the final structures will be determined by several techniques, including four-point probe measurements for film conductivity and vibrating sample magnetometry (VSM) for magnetic properties.

\section{Introduction}

Current microelectronic devices, such as metal-oxide-semiconductor field effect transistors (MOSFETs), utilize the charge of electrons for their operation. As devices shrink and speed increases, it is desirable to introduce another degree of freedom into device operation by utilizing the quantum spin state of the electrons in spintronics devices. Electron spin is already employed in high-density magnetic computer hard drives, where the current flow through a bit is controlled by magnetoresistance between two magnetic layers that can be independently aligned. For future devices such as spin-FETs, electron injection of spin-polarized electrons from a material into a semiconductor is necessary. Since electron spin alignment is accomplished by the application of a magnetic field, a ferromagnetic material is needed to generate the spin-polarized 
electrons. Initial attempts to use thin films of ferromagnetic metals such as iron for spinpolarized injection into semiconductors found that the large conductivity mismatch between the ferromagnetic metal and semiconductor resulted in very low injection efficiency. It has recently been shown that using a tunnel barrier between the ferromagnetic metal and $\mathrm{AlGaAs} / \mathrm{GaAs}$ quantum well structure can improve the efficiency. ${ }^{1}$ A more desirable approach, however, is to use a ferromagnetic material whose conductivity more closely matches the semiconductor. This has led to a significant effort to develop diluted magnetic semiconductors (DMSs) that are ferromagnetic at room temperature. The main advantage of DMSs is the ability to tune their conductivity by doping to match the host semiconductor. Research into thin films of Mn-doped II-VI, III-V, and Group IV materials has resulted in some DMS materials that are ferromagnetic at very low temperatures, but no material has yet been found to have a Curie temperature near room temperature.

The most robust DMS to date is semiconducting anatase $\mathrm{TiO}_{2}$ doped with a few percent Co. It was discovered by Matsumoto et al. using combinatorial laser molecular beam epitaxy (CL-MBE) to dope anatase and rutile $\mathrm{TiO}_{2}$ with all $3 d$ transition metals. ${ }^{2}$ Doping anatase with Co produced the only film to exhibit ferromagnetic behavior at room temperature. Further work by pulsed laser deposition (PLD) has produced $\mathrm{Co}_{\mathrm{x}} \mathrm{Ti}_{1-\mathrm{x}} \mathrm{O}_{2-\mathrm{x}}$ with ferromagnetic properties, although these can generally be traced to the formation of metallic Co nanoclusters in the film. When deposited epitaxially on $\mathrm{LaAlO}_{3}$ (LAO) using oxygen-plasma-assisted MBE (OPA-MBE), however, $\mathrm{Co}_{\mathrm{x}} \mathrm{Ti}_{1-\mathrm{x}} \mathrm{O}_{2-\mathrm{x}}$ exhibits ferromagnetic behavior with a Curie point well above room temperature with no evidence of metallic Co.,

For integration into current microelectronics technology, it is highly desirable to integrate spintronics materials onto silicon. $\mathrm{Co}_{\mathrm{x}} \mathrm{Ti}_{1-\mathrm{x}} \mathrm{O}_{2-\mathrm{x}}$ is a prime candidate for $\mathrm{Si}$ integration due to the low lattice mismatch between anatase $\mathrm{TiO}_{2}$ and $\mathrm{Si}$. Epitaxial deposition will result in a highquality interface that will reduce depolarization of spin-polarized electrons caused by scattering at interfacial defects.

\section{Proposed Research}

Co-doped anatase $\mathrm{TiO}_{2}\left(\mathrm{Co}_{\mathrm{x}} \mathrm{Ti}_{1-\mathrm{x}} \mathrm{O}_{2-\mathrm{x}}, \mathrm{x}<5 \%\right)$ will be epitaxially deposited by $\mathrm{MBE}$ onto $\mathrm{Si}(100)$. Three major issues will be addressed in the thin film deposition: oxidation of the $\mathrm{Si}$ substrate, formation of Co-rich particles on the film surface, and the oxidation state of Co in the film. In addition, the electronic and magnetic properties of the films will be explored.

One significant hurdle to be overcome in the deposition of oxides on silicon is the ease with which silicon itself oxidizes. The formation of an amorphous $\mathrm{SiO}_{2}$ layer at the interface will disrupt the oxide epitaxy, as well as interfere with subsequent device operation. To prevent $\mathrm{Si}$ oxidation in the oxygen-rich conditions necessary for oxide deposition, several approaches ${ }^{5,6}$ have been developed based on an $\mathrm{SrO}$ and/or $\mathrm{SrTiO}_{3}$ (STO) buffer layer. In this work, it has been found previously that deposition of $1 / 4$ monolayer (ML) of Sr metal on the clean Si surface, followed by $9 \mathrm{ML}$ of STO, is effective at minimizing the formation of $\mathrm{SiO}_{2}{ }^{7}$ STO has a larger mismatch to anatase $\mathrm{TiO}_{2}$ than does $\mathrm{Si}$; however, a thin layer of STO should remain strained relative to the $\mathrm{Si}$ substrate, reducing the mismatch with $\mathrm{TiO}_{2}$. More work is necessary to fully understand the nature of this Sr/STO layer and the mechanisms of its oxygen barrier qualities, leading to improvements that will prevent Si oxidation completely. 
In previous work, it has been shown that deposition of both pure anatase $\mathrm{TiO}_{2}$ and $\mathrm{Co}: \mathrm{TiO}_{2}$ on $\mathrm{STO}, \mathrm{LAO}$, and $\mathrm{STO} / \mathrm{Si}(100)$ substrates results in particle formation on the film surface. While the particles on pure $\mathrm{TiO}_{2}$ are fairly small, the addition of Co appears to enhance particle formation, with particle height on the order of the film thickness. Further, scanning Auger electron spectroscopy (AES) has shown that essentially all the Co migrates to the particles, resulting in Co concentrations well above the bulk solid solubility limit of $\sim 7 \%$. HRTEM results of $\mathrm{Co}: \mathrm{TiO}_{2}$ on LAO substrates indicate that the particles still possess anatase crystallinity with no evidence of second phases. Additionally, x-ray absorption measurements show no evidence of metallic Co. Magnetic force microscopy (MFM) scans of these films indicate that the magnetic activity is centered in the Co-rich particles, as expected. The growth mode of $\mathrm{TiO}_{2}$ and $\mathrm{Co}: \mathrm{TiO}_{2}$ will be studied to understand the origins of particle formation. This should lead to techniques to eliminate particles, resulting in $\mathrm{Co}: \mathrm{TiO}_{2}$ films in which the Co is distributed throughout the film.

Preliminary work in this area has begun. $100 \AA$ of pure anatase $\mathrm{TiO}_{2}$ was deposited by $\mathrm{MBE}$ using oxygen plasma on various thicknesses of STO buffer layer deposited on $\mathrm{Si}(001)$ (see Figure 3). Tapping mode atomic force microscopy (AFM) shows the surface coverage of particles increases as the STO buffer layer increases from $10 \mathrm{ML}$ to $50 \mathrm{ML}$. This may be due to either strain relaxation of the STO buffer layer with increasing thickness, which would increase the lattice mismatch between STO and anatase, or degradation of the STO buffer layer surface as thicker STO films are deposited. When $100 \AA \AA$ of anatase is deposited on a single crystal STO(001) substrate, which should have maximum lattice mismatch, a low coverage of particles results. This points to the surface quality of STO as a determining factor in particle formation. Further study on the lattice parameters of the STO and anatase layers by XRD and HRTEM is currently underway to determine the effect of strain and lattice mismatch.

The third issue to be addressed is the exact charge state of Co in the film. When Co substitutes for $\mathrm{Ti}^{4+}$ in anatase, it takes the formal charge state of +2 , creating a nearby oxygen vacancy to maintain charge neutrality. In films deposited by other techniques, notably PLD, metallic $\mathrm{Co}$ is present in the film in the form of metallic nanoclusters. It is these nanoclusters that are responsible for the observed ferromagnetic behavior. For a true DMS material, all the Co must be substitutionally doped into the lattice. Due to the small amount of Co present, traditional techniques such as XPS cannot be used to determine its chemical state. Instead, a combination of careful crystallinity determination (by XRD and HRTEM) and x-ray absorption is necessary. K-shell x-ray absorption near-edge fine structure (XANES) at the Advanced Photon Source at Argonne National Laboratory will be used to accurately determine the charge state of Co in the film.

In summary, $\mathrm{Co}_{\mathrm{x}} \mathrm{Ti}_{1-\mathrm{x}} \mathrm{O}_{2-\mathrm{x}}$ films $(\mathrm{x}<5 \%)$ will be epitaxially deposited by molecular beam epitaxy on $\mathrm{Si}(100)$. A buffer layer structure of $\mathrm{Sr} / \mathrm{STO}$ will be used to prevent oxidation of the Si substrate while still maintaining the epitaxial relationship to the substrate. The growth mode of $\mathrm{Co}_{\mathrm{x}} \mathrm{Ti}_{1-\mathrm{x}} \mathrm{O}_{2-\mathrm{x}}$ will be studied in detail to understand and prevent the formation of Co-rich anatase particles on the film surface. The charge state and local environment of the Co ions will be explored. In addition, the electronic and magnetic properties of the films will be characterized. 


\section{References}

1. A.T. Hanbicki, B.T. Jonker, G. Itskos et al., Appl. Phys. Lett. 80 (7), 1240 (2002).

2. Y. Matsumoto, M. Murakami, T. Hasegawa et al., App. Surf. Sci. 189, 344 (2002).

3. S.A. Chambers, C.M. Wang, S. Thevuthasan et al., Thin Solid Films 418, 197 (2002).

4. S.A. Chambers, T. Droubay, C.M. Wang et al., Appl. Phys. Lett. 82 (8), 1257 (2003).

5. R.A. McKee, F.J. Walker, and M.F. Chisholm, Phys. Rev. Lett. 81 (14), 3014 (1998).

6. J. Lettieri, J.H. Haeni, and D.G. Schlom, J. Vac. Sci. Technol. A 20 (4), 1332 (2002).

7. A. Tuan, S.A. Chambers, T. Droubay et al., unpublished. 


\section{Preliminary Results}

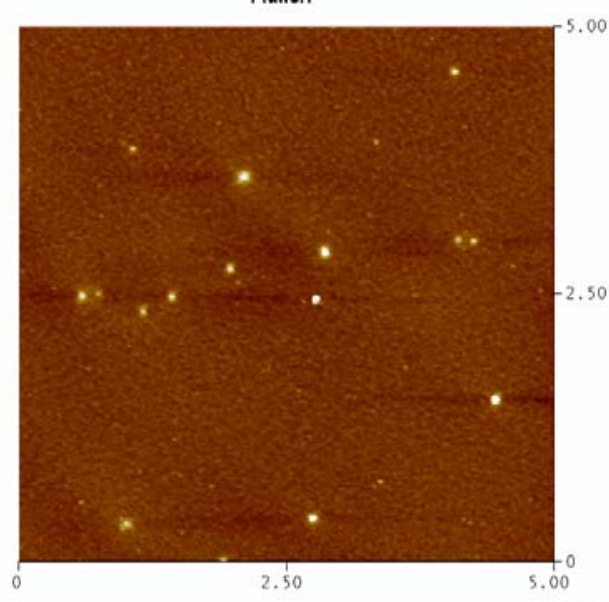

(a)

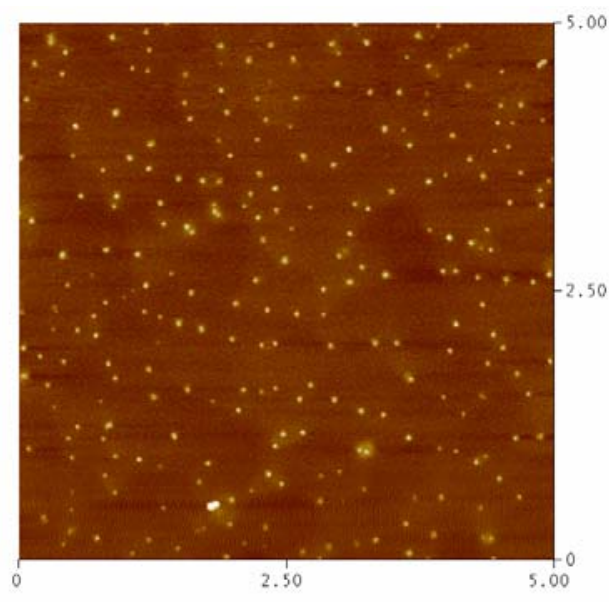

(c)

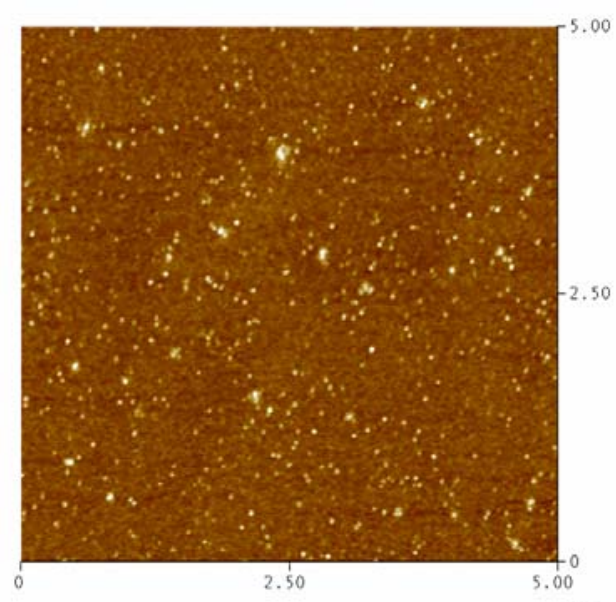

(b)

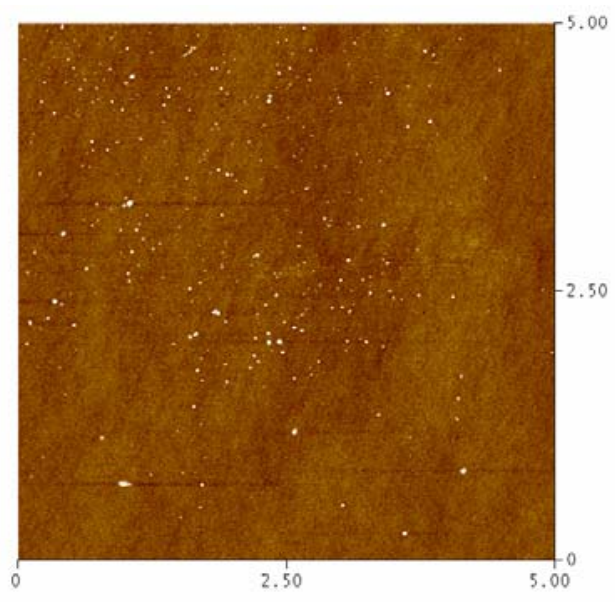

(d)

Figure 3. Tapping mode atomic force microscopy (AFM) images of $100 \AA$ anatase $\mathrm{TiO}_{2}$ deposited on various thickness of STO buffer layer on $\mathrm{Si}(100)$. (a) 10 ML STO buffer layer; height scale $15 \mathrm{~nm}$. (b) 20 ML STO buffer layer; height scale $30 \mathrm{~nm}$. (c) 50 ML STO buffer layer; height scale $25 \mathrm{~nm}$. (d) STO(001) substrate; height scale $10 \mathrm{~nm}$. As the STO buffer layer thickness increases, the surface coverage of particles on the anatase film increases. This may be due to strain relaxation in the STO buffer layer, increasing the lattice mismatch between STO and anatase. However, when anatase is deposited on a single crystal STO(001) substrate, few particles result. This indicates that the increase in particles may arise from the degradation of the STO surface as the buffer layer thickness is increased. Further studies of the lattice parameters of the anatase film and STO buffer layer are necessary to resolve this issue. 


\section{Publications, Presentations, and Proposals}

1. "Investigation of the Interfacial Region of $(\mathrm{Ba}, \mathrm{Sr}) \mathrm{TiO}_{3}$ Thin Films Deposited on $\mathrm{Pt}$ Substrates by MOCVD.” Tiffany Kaspar, Laxmikant Saraf, Chris Aardahl, Scott Lea, Shuttha Shutthanandan, Dave McCready, J.W. (Bill) Rogers, Jr., Tom Dory. AVS $49^{\text {th }}$ International Symposium in Denver, Colorado, November 2002.

2. "Materials Characterization and Magnetic Studies of Epitaxial $\mathrm{Co}_{\mathrm{x}} \mathrm{Ti}_{1-\mathrm{x}} \mathrm{O}_{2-\mathrm{x}}$ Deposited on Si(001) by Molecular Beam Epitaxy." Tiffany Kaspar, Tim Droubay, Allan Tuan, Chongmin Wang, Scott Chambers, J.W. (Bill) Rogers, Jr. AVS 50 ${ }^{\text {th }}$ International Symposium in Baltimore, Maryland, November 2003. Received the Leo M. Falicov Student Award from the Magnetic Interfaces and Nanostructures Division.

3. "Band Offsets for the Epitaxial $\mathrm{TiO}_{2} / \mathrm{SrTiO}_{3} / \mathrm{Si}(001)$ System." A.C. Tuan, T.C. Kaspar, T. Droubay, J.W. Rogers, Jr., S.A. Chambers, Applied Physics Letters 83 (19) November 2003.

4. "Investigation of $\mathrm{Cr}$ as an Alternative Adhesion Layer in Pt/Si Electrodes for Ferroelectric Perovskites." Tiffany Kaspar, Chris Aardahl, Dave McCready, Scott Lea, Brad Johnson, Dean Matson, Tom Dory, J.W. (Bill) Rogers, Jr. Submitted to Thin Solid Films December 2003.

\section{Funding that has resulted from this research}

Aside from my stipend support from JIN, the primary funding source for the spintronics project headed by Scott Chambers at PNNL is the DARPA SpinS Initiative. The funding from SpinS was guaranteed for fiscal year 2004, with an option for funding for two more years. However, the SpinS initiative is ending at the end if fiscal year 2004, so no funds will be available after that. As a result of Scott's presentation at the SpinS review in October, which included work performed by JIN students (myself and students in Prof. Dan Gamelin's group at UW), his was one of only 4 groups out of 43 to receive next year's funding this year, resulting in a doubling of this year's funds. 


\section{Smart Magnetic Nanoparticle Imaging Probes}

Awardee: Yong Zhang

Mentors: M. Zhang - UW; Kevin Minard - PNNL

\section{Project Summary}

In this proposal, we prepare magnetic nanoparticles-polyethylene glycol) (PEG) conjugates coupled with fluorescent tags to enable subcellular targeting. The resultant nanoparticle conjugates are uniquely suited for cellular analysis using the combined confocal and magnetic resonance microscopy (CM-MRM) at PNNL. The magnetic reagents provide enhanced contrast for MRM analysis, while the fluorescent tags provide subcellular targeting and rapid detection via simultaneous confocal microscopy.

\section{Publications, Presentations and Proposals}

1. Y. Zhang, N. Kohler, and M. Zhang "High-Efficiency Intracellular Uptake of Superparamagnetic Magnetite Nanoparticles for Biomedical Applications" in Nanoscience and Nanotechnology in Perspective," G. Liu, et al. (eds), pp 282, Frontiers of Science and Technology for the 21st Century, Tshinghua University Press (2002).

2. Kohler N, Zhang Y, Zhang M. Characterization of methotrexate modified superparamagnetic nanoparticles and their uptake into human chronic myologenous leukemia cells. 2003 Nanotech Conference and Tradeshow, San Francisco, CA, February 23-27, 2003. (Submitted September, 2002)

3. Kohler N, Zhang Y, Zhang M. Synthesis of methotrexate modified superparamagnetic nanoparticles and their uptake into Breast Cancer Cells. MRS Fall Meeting, Boston, MA. December 2-6, 2002.

4. Kohler N, Zhang Y, Busche B, Zhang M. Superparamagnetic Nanoparticles for Imaging. International Symposium on Optical Science and Technology. SPIE Annual Meeting, July 2002. 


\section{Photochemistry of Colloidal Dilute Magnetic Semiconductor Quantum Dots}

Kevin R. Kittilstved, ${ }^{\S}$ Alan G. Joly, ${ }^{\ddagger}$ and Daniel R. Gamelin ${ }^{\S}$

${ }^{\S}$ University of Washington, Department of Chemistry

PNNL Environmental Molecular Sciences Laboratory

\section{Project Summary}

Wide-bandgap semiconductors $\left(E_{\mathrm{g}}>3.0 \mathrm{eV}\right)$ have been known for years to photocatalytically promote otherwise thermodynamically unfavorable reactions. The major drawback to these materials is that they only create photogenerated conduction band electrons $\left(\mathrm{e}_{\mathrm{CB}}\right)$ and valence band holes $\left(\mathrm{h}_{\mathrm{VB}}\right)$ with potentials sufficient enough to promote, for instance, the photo-splitting of water with ultraviolet photons. Doping these materials with transition metal ions has been shown to improve the photocatalytic activity toward hydrogen evolution in the case of $\mathrm{Ni}^{2+}$ doped $\mathrm{ZnS}$ bulk powders, ${ }^{1}$ supposedly from the production of the same high potential transients to promote the photochemical reaction with visible photons. Figure 1 shows the Jablonski diagram for $\mathrm{Ni}^{2+}$ doped into a wide-bandgap semiconductor (i.e., $\mathrm{ZnO}$ or $\mathrm{ZnS}$ ), which displays a broad ligand-to-metal charge transfer transition in the visible region. Excitation into this charge transfer transition produces a delocalized carrier that can catalyze a reaction at or near the surface of the nanocrystals. Recently, nanocrystalline $\mathrm{Ni}^{2+}: \mathrm{ZnO}$ and $\mathrm{Co}^{2+}: \mathrm{ZnO}$ have been prepared in the Gamelin lab. ${ }^{2}$ The reduced dimensionality drastically increases the surface-tovolume ratio of the material, which could also play an important part in enhancing the photocatalytic efficiency.

During the past year, the synthesis of $\mathrm{Ni}^{2+}: \mathrm{ZnO}$ and $\mathrm{Co}^{2+}: \mathrm{ZnO}$ nanocrystals has successfully been scaled-up to produce gram-scale quantities for photocatalytic experiments. Currently, the photochemical reactions that we are attempting include the photochemical water-splitting reaction and the degradation of various phenolic compounds. Future experiments at PNNL include variable wavelength excitation transient absorption spectroscopy and time-resolved emission of other transition metal doped $\mathrm{ZnO}$ nanocrystals.

\section{Publications}

1. Schwartz, D.A.; Kittilstved, K.R.; Gamelin, D.R. “Above-Room-Temperature Ferromagnetic $\mathrm{Ni}^{2+}: \mathrm{ZnO}$ Thin Films Prepared from Colloidal Diluted Magnetic Semiconductor Quantum Dots" Appl. Phys. Lett. 2003, submitted for publication.

2. Kittilstved, K.R., Schwartz, D.A., Gamelin, D.R. "Synthesis and Characterization of $\mathrm{Ni}^{2+}$ Doped II-VI Nanocrystals" manuscript in preparation.

\section{Presentations}

\footnotetext{
${ }^{1}$ Kudo, A. and Sekizawa, M. Chem. Commun. 2000, 1371-1372.

${ }^{2}$ Schwartz, et al. J. Amer. Chem. Soc. 2003, 125, 13205-13218.
} 
Kittilstved, K.R.; Schwartz, D.A.; Joly, A.G.; Gamelin, D.R. Classical and Dynamic Spectroscopy of $\mathrm{Ni}^{2+}$ in Nanoscale II-VI Semiconductor. Nanoscale Science and Technology Workshop 2003, September 22-23 (Poster).

\section{Research Grants}

Anticipated submittal in February 2004.

Kittilstved, JIN Annual Report 2003

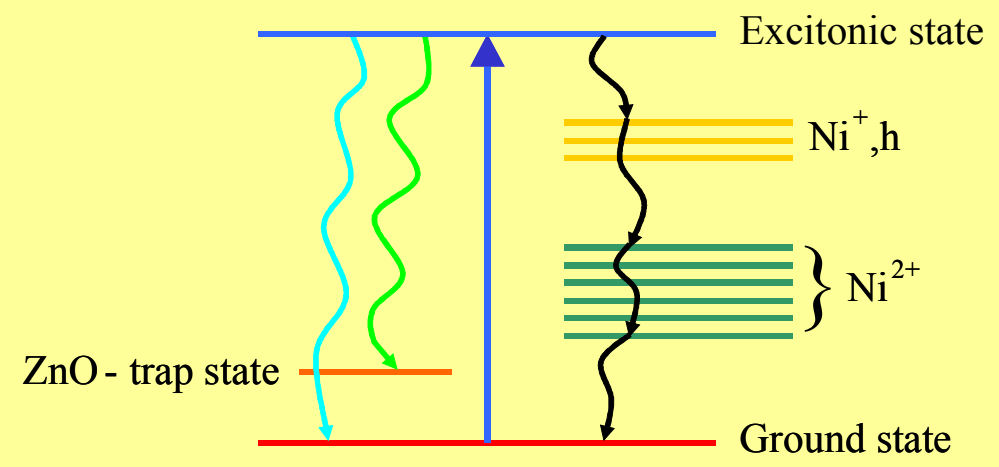

Figure 1. Jablonski diagram of the possible pathways for relaxation of an exciton excited from the ground state of the $\mathrm{Ni}^{2+}$-doped wide-gap semiconductor to the excitonic state at room temperature. Non-radiative pathways are shown as black curved lines, while the radiative pathways are shown as colored straight lines, where the length of the lines is roughly proportional to the energy of the emitted photons.

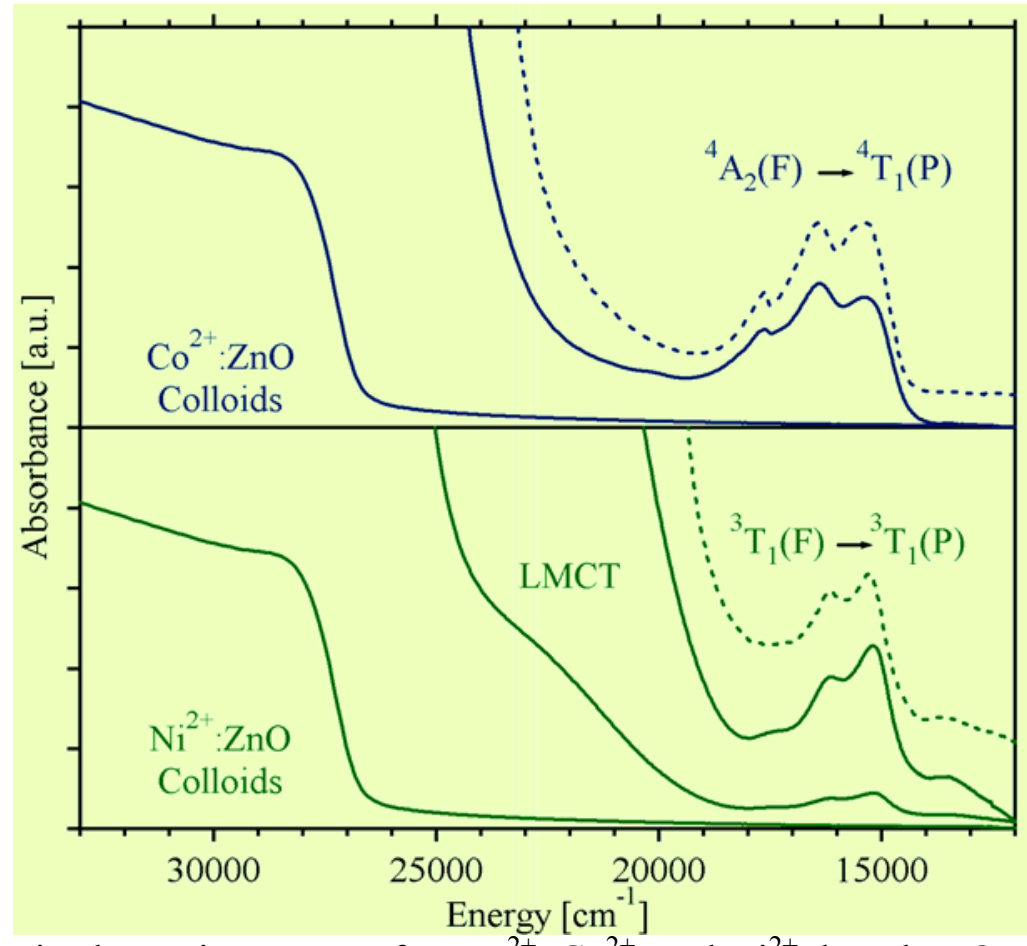

Figure 2. Electronic absorption spectra for $\mathrm{Mn}^{2+}, \mathrm{Co}^{2+}$, and $\mathrm{Ni}^{2+}$ doped $\mathrm{ZnO}$ colloids. The broad valence band (ligand) to metal charge transfer transition is observed $\mathrm{Ni}^{2+}: \mathrm{ZnO}$. The charge transfer transition is occluded by the bandgap transition in $\mathrm{Co}^{2+}: \mathrm{ZnO}$, but the onset has been observed in the magnetic circular dichroism spectrum. The spin-allowed ligand field 
transitions in $\mathrm{Co}^{2+}$ and $\mathrm{Ni}^{2+}: \mathrm{ZnO}$ are readily assigned as substitutional dopants in a pseudotetrahedral environment inside the $\mathrm{ZnO}$ lattice. 


\section{Pd Nanoclusters Supported on MgO(100): Effects of Cluster Size on Chemisorption Properties}

Awardee: Steven Tait - UW

Mentors: Charles Campbell - UW; Zdenek Dohnálek and Bruce Kay - PNNL

\section{Project Summary}

Nanometer-size Pd particles supported on oxides are active catalysts for a variety of important reactions involving small alkanes. For example, the low-temperature combustion of methane allows for cleaner energy production, as it minimizes $\mathrm{NO}_{\mathrm{x}}$ pollution.

The intent of this project is to study particle size effects on the adsorption and dissociation of methane, ethane, and propane on model catalysts consisting of size-controlled Pd nanoclusters supported on $\mathrm{MgO}(100)$. The reactions are studied by molecular beams and temperature programmed desorption at low temperatures, a regime little explored for such well-defined model catalysts. $\mathrm{MgO}(100)$ thin films are grown on a $\mathrm{Mo}(100)$ substrate. Pd is vapor deposited at low temperatures and annealed to control the size of the Pd nanoparticles. The organic molecules are deposited with a cold molecular beam to prevent direct dissociation upon impact, or at higher energies to open up direct dissociation.

We have first conducted experiments to measure the interaction of the small alkane molecules with the $\mathrm{MgO}$. Their initial sticking coefficients are plotted in Figure 1. We see that the initial sticking increases with molecule size up to octane, at which point the sticking coefficient is unity. The adsorption energy is derived from a measurement of the flux of desorbing molecules as the temperature of the sample is increased at a controlled rate. Figure 2 shows temperature programmed desorption spectra for these molecules from a 1.0 ML initial coverage. There is a clear trend of increasing desorption temperature with increasing alkane chain length. This represents an increase in desorption energy, which is due in part to the number of binding sites per molecule as the size of the molecule increases.

We have also measured the dissociation of methane on $\mathrm{MgO}$-supported Pd nanoparticles for several Pd coverages and beam energies. Some fraction of the hydrocarbon molecules dissociates as they reach the surface, leaving behind surface $\mathrm{C}$. The residual $\mathrm{C}$ is titrated from the surface with a molecular $\mathrm{O}_{2}$ beam to calculate the dissociation rate. Preliminary analysis of the data indicate that dissociation of methane is more active on smaller Pd particles. We will look at the dissociation rates for the larger hydrocarbon molecules at various beam energies and for several Pd particle sizes. By studying the larger hydrocarbon molecules, we hope to gain more information about the ability of the Pd particles to break the $\mathrm{C}-\mathrm{H}$ bonds in these molecules, which is a critical step in the dissociative adsorption of the molecules and in the combustion of methane.

Complementary non-contact atomic force microscopy (NC-AFM) measurements, which will be conducted at the UW, will yield information about the morphology and number density of the $\mathrm{Pd}$ nanoclusters as a function of deposition temperature and coverage, under the same conditions as the TPD experiments conducted at PNNL. Together, these measurements will allow a greater 
understanding of the catalytic activity of this important combustion catalyst and particle size effects in hydrocarbon catalysis in general.

\section{Publications, Presentations and Proposals}

1. "Adsorption energies of small alkane molecules on $\mathrm{MgO}$ (100) by temperature programmed desorption.” S. L. Tait, Jr., Z. Dohnálek, B. D. Kay, C. T. Campbell, AVS $50^{\text {th }}$ International Symposium, Baltimore, Maryland, November 2003.

2. "Adsorption energies of small alkane molecules on $\mathrm{MgO}(100)$ by molecular beams and temperature programmed desorption.” S. L. Tait, Jr., Z. Dohnálek, B. D. Kay, C. T. Campbell (in preparation).

3. "Dissociative adsorption of $\mathrm{CH}_{4}$ on $\mathrm{MgO}$-supported Pd particles.” S. L. Tait, Jr., Z. Dohnálek, B. D. Kay, C. T. Campbell (in preparation).

\section{Figures}

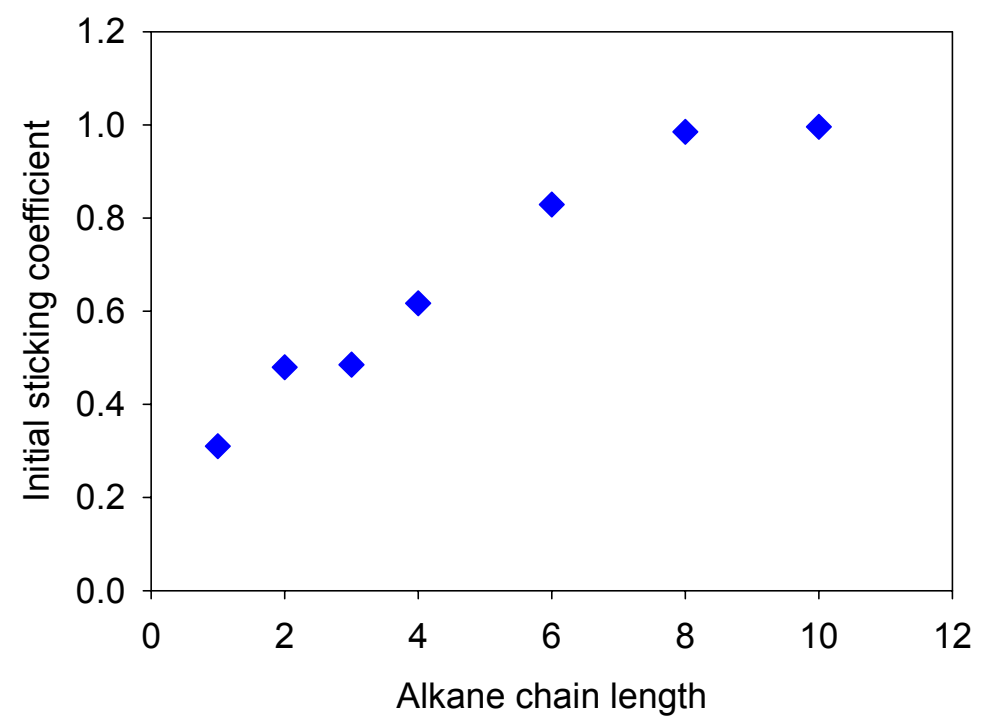

Figure 1. Initial sticking coefficient on $\mathrm{MgO}(100)$ versus alkane chain length for small alkane molecules ( 1 methane, 2 ethane, 3 propane, 4 butane, 6 hexane, 8 octane, 10 decane). 


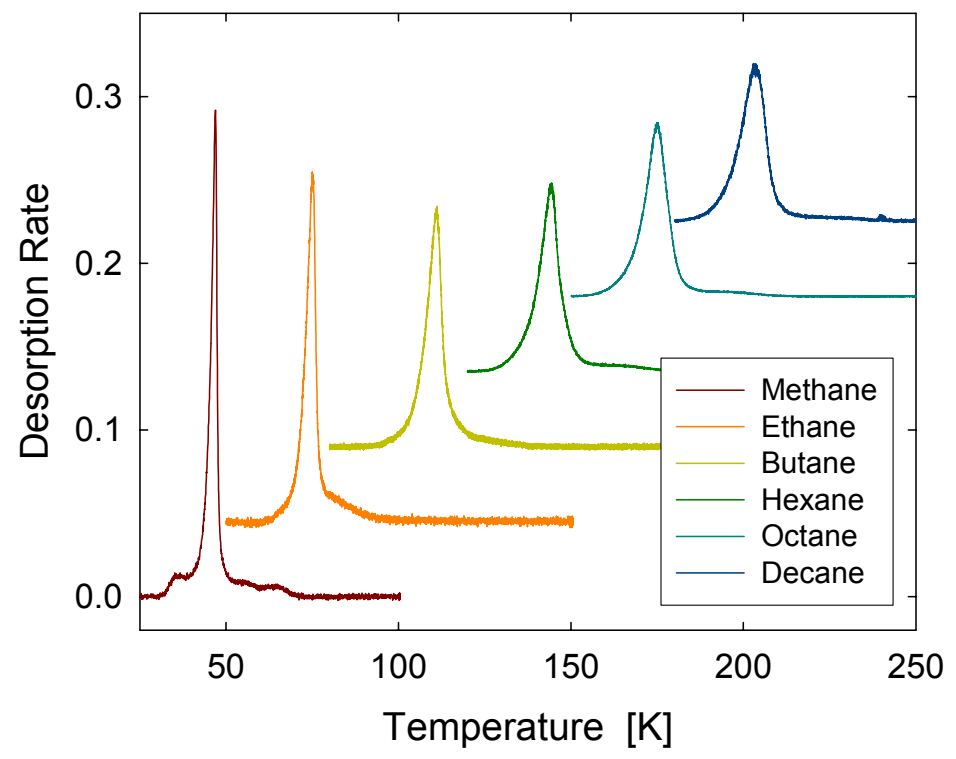

Figure 2. Temperature Programmed Desorption of Small Alkane Molecules from MgO. Initial coverage of each molecule was about 1.0 ML. 


\title{
2.3 Awards Started May 2003
}

\section{Bioaerosol Detection via Nanoparticle Surface Enhanced Raman Spectroscopy}

\author{
Awardee: Mary Laucks - postdoc, UW, Department of Chemical Engineering \\ Mentors: E. James Davis - UW, Cindy Bruckner-Lea (for Mark Kingsley)- PNNL, Richard \\ Zheng-PNNL
}

\section{Project Summary}

Conventional methods of sampling and analyzing bioaerosols do not presently provide rapid identification of potential bio-threats. Time-of-flight mass spectrometers have made possible the rapid detection of inorganic and some organic molecules, but these systems ablate the particles, and the identification of the fragments would be especially difficult for bioaerosol particles. To detect small quantities of biomaterial against a high background of other commonly occurring atmospheric particles, any potential bio-detection system would require both high sensitivity (small quantities of material present) and the ability to separate the signal of interest from the background (much biomaterial is similar). Rapid identification requires that sampling and analysis occur in the same instrument.

The idea of this project is to study the potential of surface enhanced resonance Raman spectroscopy (SERRS) or surface enhanced Raman spectroscopy (SERS) as a method for detecting bioaerosol. We will use the recent advances in nanosurface techniques to produce a surface onto which we can deposit sample bioaerosol and chemically analyze it using SERRS or SERS.

We have made significant progress on the first phase of our research plan, which was to identify a surface preparation that would provide significant enhancement when a known material was adsorbed on it. As a baseline study, we used silver colloid suspensions (50 to 75 $\mathrm{nm}$ ) to demonstrate enhancements of pyridine on the order of $10^{9}$. We were able to detect the $\sim 1050 \mathrm{~cm}^{-1}$ peak in a $10^{-9} \mathrm{M}$ pyridine solution and compare it to the same peak from a nonenhanced (no silver colloid present) $1 \mathrm{M}$ solution of pyridine. For these experiments, we used optical glass Raman cuvettes and the $514.5 \mathrm{~nm}$ line of an Ar ion laser. From this baseline study, we found that our setup was able to detect nanomolar levels of pyridine, demonstrating that we will be able to detect these levels of other materials if we achieve similar enhancements on prepared surfaces.

We have also prepared silver film surfaces by etching them in nitric acid solution and have demonstrated large enhancements of the same pyridine peak on these surfaces. The prepared Ag surface was soaked in a $10^{-4} \mathrm{M}$ solution of pyridine and then washed and air-dried. This enhancement was not measurable because we could not detect the pyridine peak on a non-etched Ag surface, even though we deposited pure pyridine $(\sim 13 \mathrm{M})$ on it. However, we can say that the enhancement was larger than $7 \times 10^{5}$. Figure 1 shows the comparison between pyridine adsorbed on a smooth, non-etched Ag surface and on a prepared (modified) surface. 
In addition to pyridine, we have deposited 100-nm latex nanospheres on the nitric acidetched Ag surface and were able to see some enhancement. Particles smaller than 1 micrometer are very difficult to detect (and have not been detected to our knowledge) with Raman scattering, but Figure 2 provides evidence that nanometer particles may be detectable.

Another aspect of our research to date has been the study of the Raman scattering from common bacteria so as to determine if their spectra are different enough to be "fingerprints" for each type of bacteria. Dr. Cindy Bruckner Lea's group at PNNL has provided us with samples of gram negative (E. Coli), gram positive (Staphylococcus epidermidis), and spore (Bacillus globigii) bacteria as agreed upon in our proposal. We used 785-nm laser radiation to study these samples, but as yet have not been able to see any spectra. We are modifying our optics to allow the collection of more scattered light from the samples in hopes of increasing our signal-to-noise ratio. So far we have only deposited these bacteria on non-prepared surfaces, but we plan to test the enhanced surfaces soon.

We are planning to do a study of the surface characteristics of the etched Ag films using SEM so as to be able to identify which surface preparation is optimal for enhancement. Our collaborator, Dr. Richard Zheng at PNNL, will provide some time on their SEM for this purpose.

We hope to be able to show enhancements of biomaterial on Ag surfaces soon.

\section{Proposals}

1. A team grant entitled, "Bioaerosol Detection via Nanoparticle Surface Enhanced Raman" was submitted by E. James Davis, Francois Baneyx, and Daniel T. Schwartz to NSF $(\$ 749,711)$ for 36 months funding (denied).

2. A single investigator grant is in preparation to NSF by E. James Davis for 36 months of funding (not yet submitted).

\section{Presentations}

Center for Nanotechnology, NSF site visit, presented by Atanu Sengupta (graduate student) titled, "Chemical Analysis of Nanogram Quantities of Matter by Raman Enhancement using Nanoscale Surfaces." 


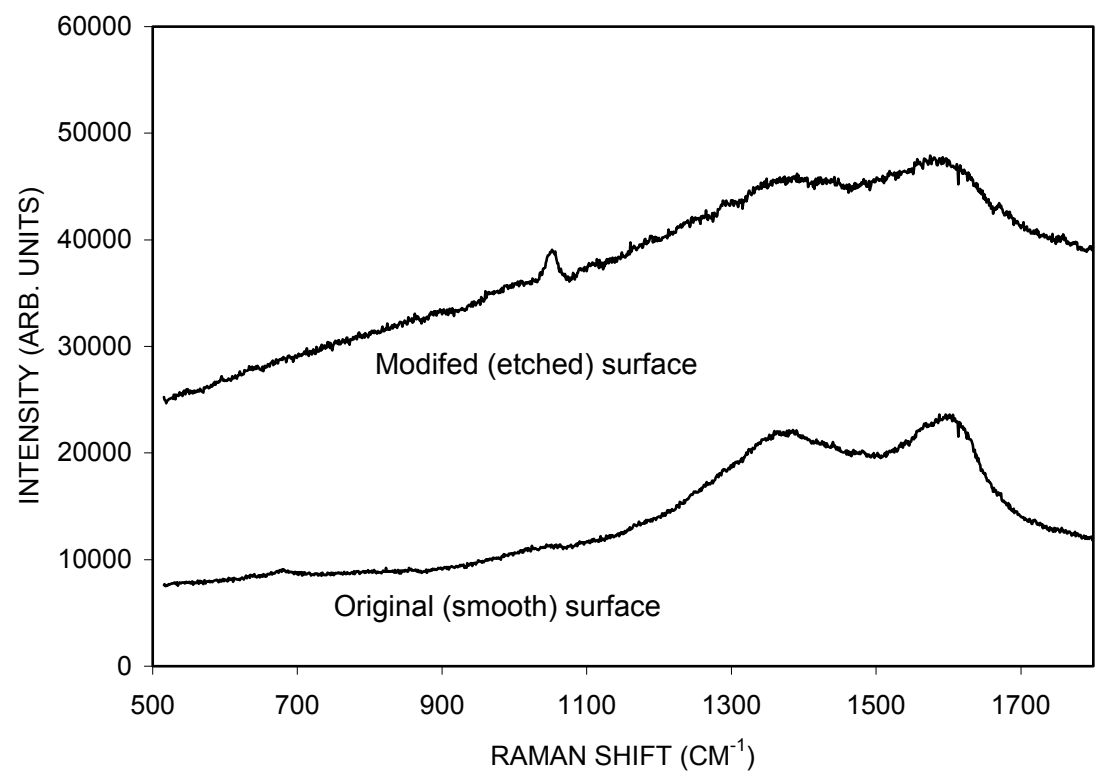

Figure 1. Raman spectra of pyridine on two surfaces. On the modified surface, we adsorbed $10^{-4} \mathrm{M}$ pyridine, and on the original surface, we adsorbed pure pyridine $(\sim 13 \mathrm{M})$. An enhancement of about $10^{5}$ can be seen.

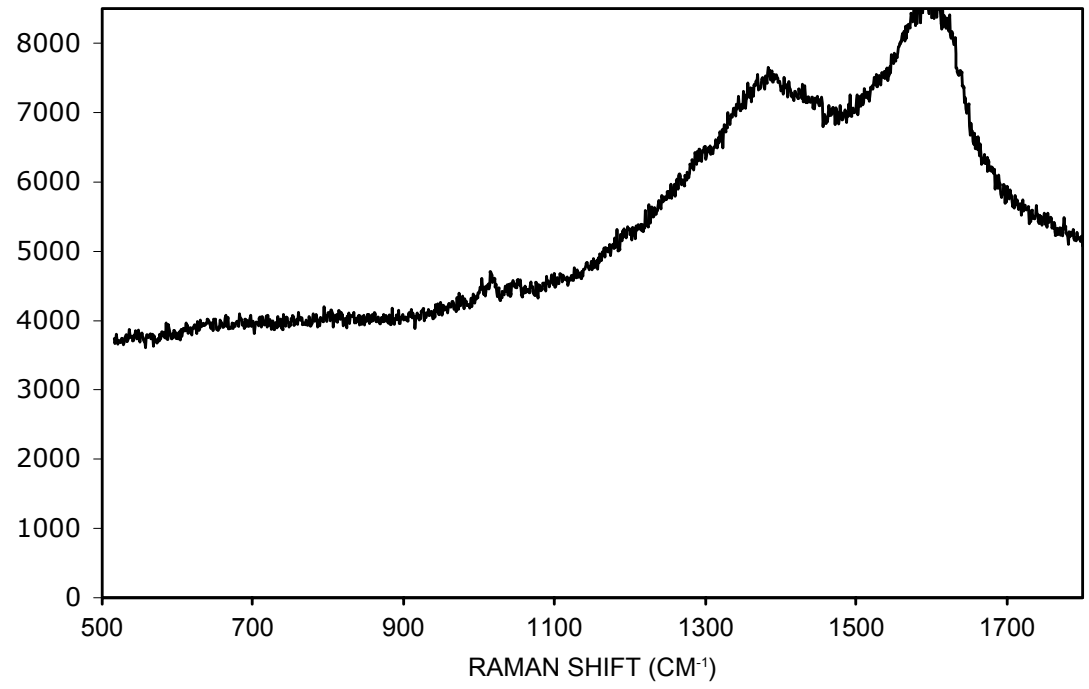

Figure 2. Preliminary data for 100-nm latex spheres deposited on a prepared Ag surface shows a small peak near $1000 \mathrm{~cm}^{-1}$. 


\subsection{Impacts of the JIN}

\subsection{Summary of Impacts}

Although it is much too soon to evaluate long range impacts of the JIN on the University of Washington or Pacific Northwest National Laboratory (PNNL), there are several near term qualitative and quantitative indications of increasing impacts that can be reported now. Quantitative information about JIN related presentations and publications have been collected, and these are included in this report. We are aware of at least one patent discloser that has resulted. The numbers are impressive and verify the vibrant nature of the research at the two institutions as well as the potential impact of the joint efforts. In addition to research output, the JIN is also having an impact on other critical areas of the operation of both institutions, including the recruitment of students and staff, the ability to speed research progress, and development of new concepts and enhancing the range of markets for proposing research.

Because both UW and PNNL researchers will seek research funding in any exciting area, it is almost impossible to keep accurate track of how ideas resulting from JIN activities or awards lead to new research proposals. It is, however, clear that they occur in a variety of forms and different ways. To some degree, there are different natural markets for a university and national laboratory. New program development related to the JIN might be classified in three different ways: joint (both institutions in one proposal), parallel (several single institution projects in a common area), and single institution (the idea developed in common is of great value to one party). Some aspects of spintronics research development provides a useful example of something with a large impact with a complex path of development.

A large amount of excitement in JIN-related research activity has focused on oxide based room temperature diluted magnetic semiconductor material. This material has the potential of playing a significant role in future generations of spintronic devices as it maintains the magnetic properties to over $300^{\circ} \mathrm{C}$ and could allow integration of memory and active electronic components. Work in this area has been significantly advanced at PNNL by Dr. Scott Chambers, and he has interacted with a number of outstanding collaborators at the university. As a result, several new programs have developed in this area at both institutions. Although the first generation of these new research programs involved participation from the two institutions, the funding paths often did not cross institutional borders. For example, NSF funding was obtained at the university with Dr. Chambers as an unfunded collaborator. Similarly, new DOE and some DARPA programs at PNNL included some funding for JIN students, but little or no funding for UW faculty. Thus, there was a significant overlapping and parallel effort developing programs in this spintronics area at both institutions, but little joint funding. The boundaries were caused by the size of funding available and traditional barriers in some agencies to subcontracts or funding of a different type of institution. Both UW and PNNL have been working on methods, including joint appointments, as one effort to minimize the impacts of such barriers. Between the two institutions, there is more than $\$ 4 \mathrm{M}$ in research funds, over several years, associated with the oxide based spintronics materials, and it is growing steadily. 
Many of the newer projects of the JIN are associated with the two JIN focus areas (identified in early 2003) and the major impacts may not yet appear. However, UW JIN participants report at least 16 proposals directly or indirectly linked to JIN activities. Of these proposals, 10 were to the NSF (1 education, 3 instrumental, 6 programmatic), 3 to defense agencies, 2 to DOE, and one to the American Chemical Society (a postdoctoral proposal). In addition to these proposals, a connection to PNNL through the JIN was included in the UW input to the multi-institutional National Nanoscience Infrastructure Network (NNIN) led by Cornell and Stanford. This successful proposal will lead to approximately $\$ 1 \mathrm{M}$ per year of research funding at the UW for at least the next 5 years.

Many PNNL staff members who are serving or have served as JIN award mentors indicate that JIN activities are having a wide variety of positive impacts on their work. As one researcher said, the JIN helps in at least three ways:

1. Promoting stronger institutional ties that assist in the formation of interactions that previously did not exist (often with departments and disciplines outside the sphere of normal contact) and that these new interactions and capabilities are useful in marketing new research.

2. They speed research progress when skills or capabilities at one location or in one group can be shared or learned without the need to redevelop them.

3. Providing a source of new talent into the lab (or placement opportunities from the university view).

Other PNNL staff members observed that JIN activities facilitate the testing of new concepts, provide opportunities for sharing of skills, and create ways for concepts developed in one laboratory to be applied in others. In most cases, the PNNL research teams are using or planning to use the team formation, idea testing, or new concepts in proposals for additional work. PNNL staff members mentioned specific current or future proposals to be submitted to the DOE, NIH, DHS, Navy, and private industry. The familiarity of different members of newly formed teams to have access to different funding sources seemed to be a welcome feature of many collaborations.

Another area of novel institutional collaboration is the NSF-funded development of UW and PNNL courses in Nanoscience and Nanotechnology. The NSF funds the course development through the UW, but the project currently pays for the direct time that PNNL staff members spend in teaching. These courses function to benefit PNNL and the UW in a variety of different ways. Because the courses have involved a variety of students, postdocs, and faculty members from a wide variety of institutions, the courses serve as an introduction to PNNL, EMSL, and UW research interests and capabilities. The courses are apparently quite effective at introducing new graduate students to Nanoscience and allowing more experienced researchers to gain a quite broad exposure to science, technology, and research tools. It is also important to note that this effort has involved participation and support of a wide variety of institutions. In addition to UW and PNNL involvement with organization and instructions, Washington State University has helped with course coordination, and lecturers have come from Washington State University, the University of Idaho, and the University of Alaska. The PNNL education office has helped make 
contacts with regional and national undergraduate schools and assisted the formation of a steering committee.

The educational experience of graduate students at UW has been strongly impacted in a very favorable way by the JIN. A very large number of our students have taken part in the courses mentioned above, spent time touring PNNL to get an overview of the research there, or spent time training on instrumentation there or actually performing all or part of their research experiments (or computations) at PNNL. This has broadened the experience tremendously for our students interested in nanotechnology.

In part, the initial JIN agreement indicated many different areas where increased interaction was expected to lead to enhanced research output, as well as increased research and educational opportunities. In each of the anticipated areas, significant success and productivity has been observed. Some benefits are similar in both institutions, while in other cases, the benefits of the JIN differ because of the different functions of a university and national laboratory. However, there are clear benefits to both institutions. The future of the JIN and long-range success must build on the current progress and establish financial approaches for long term stability and continued refreshing of ideas.

\subsection{Papers Related to JIN Awards}

The information included in this section has been provided by the research team members as publications linked to JIN Awards and is provided as an indication of JIN activity. The accuracy of each citation has not been fully verified.

\subsubsection{Published in 2002}

1. "Functionalized, Hierarchically-Structured Mesoporous Silica by Sol Electrophoresis and Self-Assembly," T.P. Chou, S.J. Limmer, and G.Z. Cao in Nanoscale Optics and Applications, Proceedings of SPIE 4809, eds. G.Z. Cao and W.P. Kirk, 239-248 (2002).

2. "High-Efficiency Intracellular Uptake of Superparamagnetic Magnetite Nanoparticles for Biomedical Applications in Nanoscience and Nanotechnology in Perspective," Y. Zhang, N. Kohler, and M. Zhang G. Liu, et al. (eds), pp 282, Frontiers of Science and Technology for the 21st Century, Tshinghua University Press (2002).

3. "Growth of Oxide Nanorods using Sol-Gel Electrophoretic Deposition," Limmer, Steven J.; Cao, Guozhong, Electrophoretic Deposition: Fundamentals and Applications Electrochemical Society Proceedings v. 2002-21), 271-278 (2002).

4. "Formation and optical properties of cylindrical gold nanoshells on silica and titania nanorods," Limmer, Steven J.; Chou, Tammy P.; Cao, Guozhong. Proceedings of SPIE The International Society for Optical Engineering, v 4809, p 222-230 (2002). 
5. "Colloidal Transition-Metal-Doped ZnO Quantum Dots." Radovanovic, Pavle V.; Norberg, Nick S.; McNally, Kathryn E.; Gamelin, Daniel R. Journal of the American Chemical Society 124, 15192, (2002).

6. "Electrophoretic deposition of oxide nanorods inside pores of template from sols," S.J. Limmer and G.Z. Cao, Proceedings of the Electrochemical Society (2002).

7. “Nanoscale optics and applications," G.Z. Cao, SPIE Proceedings 4809, Ed. (2002).

8. "Processing and Properties of $\mathrm{Sr}_{2} \mathrm{Nb}_{2-\mathrm{x}} \mathrm{V}_{\mathrm{x}} \mathrm{O}_{7}$ Ferroelectrics," S. Seraji, S.J. Limmer, M.J. Forbess, Y. Wu, T.P. Chou, C. Nguyen, and G.Z. Cao, Materials Science and Engineering B88, 73-38 (2002).

9. "Template-Based Growth of Various Oxide Nanorods by Sol-Gel Electrophoresis," S.J. Limmer, S. Seraji, M.J. Forbess, Y. Wu, T.P. Chou, C. Nguyen, and G.Z. Cao, Advanced Functional Materials 12, 59-64 (2002).

10. "Influence of Tungsten Doping on Dielectric Properties of Strontium Bismuth Niobate Ferroelectric Ceramics," Y. Wu and G.Z. Cao, Journal of Materials Science Letters 21, 251253 (2002).

11. "Organic-Inorganic Sol-Gel Coating for Corrosion Protection of Stainless Steel," T.P. Chou, C. Chandrasekaran, S. Limmer, C. Nguyen, and G.Z. Cao, Journal of Materials Science Letters 21, 947-949 (2002).

12. "Synthesis and Optical Properties of Nanostructured CdWO4 Films by Sol-Gel Processing," K. Lennstrom, S.J. Limmer, and G.Z. Cao, in Nanoscale Optics and Applications, Proceedings of SPIE 4809, ed. G.Z. Cao and W.P. Kirk, 231-238 (2002).

13. "Nanoscale Optics and Applications," Guozhong Cao and Wiley P. Kirk. Proceeding of SPIE, Vol. 4809, The International Society for Optical Engineering, Bellingham, WA (2002).

\subsubsection{Published in $\mathbf{2 0 0 3}$}

1. "Ordered, Dye-Functionalized Titania Nanorods and Their Applications as Sensors," T.P. Chou, C.M. Chung, and G.Z. Cao, in Nanomaterials and Their Optical Applications, SPIE Proceedings 5224, eds. 53-61, (2003).

2. "Monolayer Protected Gold Nanoparticles as a Stationary Phase for Open Tubular Gas Chromatography," G.M. Gross, D.A. Nelson, J.W. Grate, R.E. Synovec, Analytical Chemistry, 75, 4558-4564 (2003).

3. "Transition from granular to dilute magnetic semiconducting multilayers in iron beam deposited ZnO/Co," A. Pakhomov, B. Roberts and K.M. Krishnan, Applied Physics Letters 83, 21 (2003). 
4. "Electrowetting-Induced Droplet Movement in an Immiscible Medium," Jason S. Kuo, Paolo Spicar-Mihalic, Indalesio Rodriguez, Daniel T. Chiu, Langmuir, 19, 250-255 (2003).

5. "Dynamic formation of ring-shaped patterns of colloidal particles in microfluidic systems," D.S.W. Lim, P. Shelby, J.S. Kuo, D.T. Chiu, Applied Physics Letters 83, 1145-1147, (2003).

6. "Selective Electroless and Electrolytic Deposition of Metal for Applications in Microfluidics: Fabrication of a Microthermocouple," Peter B. Allen, Indalesio Rodriguez, Christopher L. Kuyper, Robert M. Lorenz, Paolo Spicar-Mihalic, Jason S. Kuo, Daniel T. Chiu, Analytical Chemistry, 75, 1578-1583 (2003).

7. "Molding techniques for the rapid prototyping of polymeric microfluidic devices," G.S. Fiorini, G.D.M. Jeffries, D.S.W. Lim, C.L. Kuyper, D.T. Chiu, Lab Chip 3, 158-163, (2003).

8. "Template-based growth of oxide nanorods by sol electrophoresis," Limmer, Steven J.; Cao, Guozhong. Advanced Materials, 15(5), 427-431, (2003).

9. "Nanorods of Various Oxides and Hierarchically Structured Mesoprous Silica by Sol-Gel Electrophoresis," Limmer, Steven J.; Hubler, Timothy L.; Cao, Guozhong. Journal of SolGel Science and Technology, 26(1/2/3), 577-581, (2003).

10. "Sol electrophoretic deposition of oxide nanorods," G.Z. Cao and S.J. Limmer, in Nanowire Materials, ed. Z.L. Wong, Kluwer, Nanowires and Nanobelts: Materials, Properties and Devices v2, 93-110 (2003).

11. "Efficient Green Light-Emitting Diodes from Silole-Containing Copolymers," M. S. Liu, J. Luo, A. K-Y. Jen, Chemical Materials 15, 3496 (2003).

12. "Bright Red-Emitting Electrophosphorescent Device Using Osmium Complex as a Triplet Emitter," J.-H. Kim, M. S. Liu, A. K-Y. Jen, B. Carlson, L. R. Dalton, R. Dodda, C. F. Shu, Applied Physics Lettets 83, 776 (2003).

13. "Highly Efficient Blue Light-Emitting Diodes from Polyfluorene Containing Bipolar Pendent Groups,” C. F. Shu, R. Dodda, F. I. Wu, M. S. Liu, A. K-Y. Jen, Macromolecules 36, 6698 (2003).

14. A Novel Oxadiazole-Containing Polyfluorene with Efficient Blue Electroluminescence," F-I. Wu, D. S. Reddy, C. F. Shu, M. S. Liu, A. K-Y. Jen, Chemical Materials 15, 269 (2003).

15. "Absorption and luminescence properties of sequentially random- and defined copolymers based on poly(fluorene-benzothiadiazole)," P. Herguth, J.-H. Kim, X. Z. Jiang, M. S. Liu, A. K.-Y. Jen, MRS Procedings 771 (Organic and Polymeric Materials and Devices), 357 (2003).

16. "Development of Efficient Electron-Transporting Polymers for Light-Emitting Diodes," M. S. Liu, X. Z. Jiang, P. Herguth, S. Liu, A. K.-Y. Jen, Procedings of SPIE 4800, 130 (2003). 
17. "Poly(fluorene-co-benzothiadiazole)s: Effect of Structure, Molecular Weight and Polydispersity on Their Performance in Polymer Light-Emitting Diodes," P. Herguth, X. Z. Jiang, M. S. Liu, A. K.-Y. Jen, Procedings of SPIE 4800, 138 (2003).

18. "Magnetic Quantum Dots: Synthesis, Spectroscopy, and Magnetism of $\mathrm{Co}^{2+}$ - and $\mathrm{Ni}^{2+}$-Doped ZnO Nanocrystals." Schwartz, Dana A.; Norberg, Nick S.; Nguyen, Quyen P.; Parker, Jason M.; Gamelin, Daniel R. Journal of the American Chemical Society, 125, 13205 (2003).

19. "Band offsets for the epitaxial $\mathrm{TiO} 2 / \mathrm{SrTiO} 3 / \mathrm{Si}(001)$ system." AC Tuan, TC Kaspar, T Droubay, JW Rogers, Jr, SA Chambers. Applied Physics Lettets Vol. 83 p. 3734 (2003).

20. "Sol-Gel Processing of Hybrid Organic-Inorganic Films for Corrosion Protection," T.P. Chou, C. Chandrasekaran, and G.Z. Cao, Journal of Sol-Gel Science and Technology 26, 321-327 (2003).

21. "Films, Patterned Structures and Nanorods of Various Oxides and Mesoporous Silica by SolGel Electrophoresis," S.J. Limmer, T. Hubler, and G.Z. Cao, Journal of Sol-Gel Science and Technology 26, 577-581 (2003).

22. "Adhesion of Sol-Gel-Derived Organic-Inorganic Hybrid Coatings on Polyester" (invited), T.P. Chou and G.Z. Cao, Journal of Sol-Gel Science and Technology 27, 31-41 (2003).

23. "The Role of O(1D) in the Oxidation of Si(100)," T.C. Kaspar, A.C. Tuan, R.G. Tonkyn, W.P. Hess, J.W. Rogers, Jr., Y. Ono, Journal of Vacuum Science and Technology BMicroelectronics and Nanometer Structures 21 (2), 895-899 (2003).

24. "Sol-gel Electrophoretic Deposition for the Growth of Oxide Nanorods," S.J. Limmer, G. Cao, Advanced Materials, v 15, n 5, p 427-431 (March 4, 2003).

\subsubsection{Published in 2004}

1. "Monolayer-Protected Gold Nanoparticles as an Efficient Stationary Phase for Open Tubular Gas Chromatography using a Square Capillary: A Model for Chip-Based Gas

Chromatography in Square Cornered Microfabricated Channels," G.M. Gross, J.W. Grate, R.E. Synovec, Journal of Chromatography A, 1029, 185-192 (2004).

2. "A study on the growth of TiO2 using sol electrophoresis," S.J. Limmer, T. P. Chou, G. Z. Cao, Journal of Materials Science 399, 895-901 (2004).

\subsubsection{In Press}

1. "Growth of Oxide Nanorods through Sol-Gel Processing and Electrophoretic Deposition," (invited), Steven J. Limmer and G.Z. Cao, Advanced Materials.

2. "A Novel Oxadiazole-Containing Polyfluorene with Efficient Blue Electroluminescence," 
3. Fang-Iy Wu, D. Sahadeva Reddy, Ching-Fong Shu, Michelle S. Liu, Alex K-Y. Journal of Chemical Materials.

4. "Synthesis and Optical Properties of Nanostructured CdWO ${ }_{4}$ Films by Sol-Gel Processing," K. Lennstrom, S.J. Limmer, and G.Z. Cao, Solid Thin Films.

5. "Metal Nanoparticles Protected with Monolayers: Applications for Chemical Vapor Sensing and Gas Chromatography," J.W. Grate, D.A. Nelson, R. Skaggs, R.E. Synovec, G.M. Gross, invited chapter for the Encyclopedia of Nanoscience and Nanotechnology.

6. "Sol Electrophoretic Deposition of Oxide Nanorods," G.Z. Cao and S.J. Limmer, in Nanowire Materials, ed. Z.L. Wong, Kluwer.

7. "Oxide Nanorods," G.Z. Cao and S.J. Limmer, in Encyclopedia of Nanomaterials, ed. H.S. Nalwa, The American Scientific Press.

\subsubsection{Submitted (as of January 2004)}

1. "Above-Room-Temperature Ferromagnetic $\mathrm{Ni}^{2+}: \mathrm{ZnO}$ Thin Films Prepared from Colloidal Diluted Magnetic Semiconductor Quantum Dots" D.A. Schwartz, K.R. Kittilstved, D.R. Gamelin, Applied Physics Letters.

2. "Comment on the Interface Phase and the Schottky Barrier for a Crystalline Dielectric on Silicon," S.A. Chambers, T.C. Droubay, T.C. Kaspar, M.S. Gutowski, American Journal of Science.

3. "Room Temperature Ferromagnetism in Ion-Implanted Co-doped TiO2(110 Rutile," V. Sutthanandan, S. Thevuthasan, S.M. Heald, T.C. Dourbay, M.H. Engelhard, T.C. Kaspar, D.E. McCready, L.V. Saraf, Applied Physics Letters.

4. "Studies of Two-and-Three Dimensional ZnO:Co Structures Through Different Synthetic Routes," A. Pakhomov, B.K. Roberts, A.C. Tuan, V. Shutthanandan, D.E. McCready, S. Thevuthasan, S.A. Chambers, K.M. Krishnan, Applied Physics Letters.

5. "Epitaxial Growth and Properties of Cobalt-doped $\mathrm{ZnO}$ on $\mathrm{I}_{2} \mathrm{O}_{3}$ Single Crystal Substrates," A.C. Tuan, J.D. Bryan, A. Pakhomov, V. Shutthanandan, S. Thevuthasan, D.E. McCready, D.J. Gaspar, M.H. Engelhard, J.W. Rogers, Jr., K.M. Krishnan, G.R. Gamelin, S.A. Chambers, Physical Review B, Condensed Matter.

6. "Magnetization Process in Exchange Biased MnPd/Fe Bilayers," P. Blomqvist, K.M. Krishnan, E. Girt, Applied Physics Letters.

7. "Noncovalent Functionalization of Carbon Nanotubes with Molecular Anchors using Supercritical Fluids," L.S. Fifield, L.R. Dalton, R.S. Addleman, M. H. Engelhard, G.E. Fryxell, C.L. Aardahl, Journal of Physics Chemistry B. 
8. "Accurate Valence Band Maximum Determination for SrTiO3(001)," S.A. Chambers, T. Droubay, T.C. Kaspar, M. Gutowski. Surface Science Letters.

9. "High-Speed Gas Chromatography using a Synchronized Dual-Valve Injector", G.M. Gross, B.J. Prazen, J.W. Grate, R.E. Synovec, Analytical Chemistry.

10. "The Development of Novel Gas Chromatographic Stationary Phases Using Monolayer Protected Gold Nanoparticles for Application in High-Speed and Multi-Dimensional Gas Chromatographic Separations," G.M. Gross, J.W. Grate, R.E. Synovec, Journal of Chromatography A, invited manuscript.

11. "Experimental Determination of Valence Band Maxima for SrTiO3, TiO2, and $\mathrm{SrO}$ and the Associated Valence Band Offsets with Si(001)," S.A. Chambers, T. Droubay, T.C. Kaspar, M. Gutowski. Journal of Vacuum Science and Technology.

12. "Investigation of $\mathrm{Cr}$ as an Alternative Adhesion Layer in Pt/Si Electrodes for Ferroelectric Perovskites,” T.C. Kaspar, C.L. Aardahl, D.E. McCready, A.S. Lea, B.R. Johnson, D.W. Matson, T.S. Dory, J.W. Rogers, Jr., Thin Solid Films.

13. "Dynamic Formation of Patterns of Colloidal Particles in Microfluidic Systems," D. S. W. Lim, J. P. Shelby, J.S. Kuo, D.T. Chiu, Physics Review Letters.

\subsubsection{In Preparation (as of January 2004)}

1. "Synthesis and Characterization of $\mathrm{Ni}^{2+}$-Doped II-VI Nanocrystals," D.A. Schwartz, K.R. Kittilstved, D.R. Gamelin.

2. "Chemical Synthesis of Colloidal $\mathrm{Mn}^{2+}: \mathrm{ZnO}$ Quantum Dots and Nanostructured High- $\mathrm{T}_{\mathrm{c}}$ Ferromagnetic Thin Films,” N.S. Norberg, K.R. Kittilstved, D.A. Schwartz, D.R. Gamelin.

3. "Self-assembled Coatings on Individual Monodisperse Magnetite Nanoparticles for Efficient Intracellular Uptake,” Y. Zhang, N. Kohler, S. Conroy, M. Zhang.

4. "Adsorption Energies of Small Alkane Molecules on $\mathrm{MgO}$ (100) by Molecular Beams and Temperature Programmed Desorption,” S. L. Tait, Jr., Z. Dohnálek, C. T. Campbell, B. D. Kay.

5. "Temperature Programmed Desorption of Small Alkane Molecules from $\operatorname{Pt}(111)$ and CPt(111),’ S. L. Tait, Jr., Z. Dohnálek, C. T. Campbell, B. D. Kay, in preparation.

6. "Dissociative Adsorption of $\mathrm{CH}_{4}$ on $\mathrm{MgO}$-supported Pd Particles," S. L. Tait, Jr., Z. Dohnálek, C. T. Campbell, B. D. Kay, in preparation. 


\subsection{JIN Related Presentations}

1. "Functionalized, Hierarchically-Structured Mesoporous Silica by Sol Electrophoresis and Self-Assembly." Tammy P. Chou, Steven J. Limmer, and Guozhong Cao. SPIE 47th Annual Meeting: Optical Science and Technology in Seattle, Washington, July 2002.

2. "Nanorods of Various Oxides and Hierarchically-Structured Mesoporous Silica by Sol Electrophoresis." Tammy P. Chou, Steven J. Limmer, and Guozhong Cao. Gordon Research Conference: Solid State Studies in Ceramics in Meriden, New Hampshire, August 2002.

3. "Functionalized, Hierarchically-Structured Mesoporous Silica by Sol Electrophoresis and Self-Assembly." Tammy P. Chou, Steven J. Limmer, and Guozhong Cao. ACerS Regional Meeting in Seattle, Washington, October 2002.

4. "Ordered, Dye-Functionalized Titania Nanostructures for Photoelectrochemical Applications," Tammy P. Chou, Chan-Moon Chung, and Guozhong Cao. SPIE 48th Annual Meeting: Optical Science and Technology in San Diego, California, August 2003.

5. "Nanostructured materials for efficient carbon dioxide separation " Leonard S. Fifield, Glen E. Fryxell, Thomas S. Zemanian, R. Shane Addleman, Feng Zheng, Larry R. Dalton, and Christopher L. Aardahl. 225th ACS National Meeting, New Orleans, LA, March 23, 2003.

6. "Open Tubular Gas Chromatography using Monolayer Protected Gold Nanoparticles as the Stationary Phase." G. M. Gross, D. A. Nelson, J. W. Grate, R. E. Synovec, 26th International Symposium on Capillary Chromatography and Electrophoresis in May 2003, Las Vegas NV, invited poster presentation.

7. "Fundamental Studies of Monolayer-Protected Nanoparticles by Gas Chromatography." G.M. Gross, D.A. Nelson, J.W. Grate, R.E. Synovec, Nanoscience Workshop for the PNNL/UW Joint Institute of Nanoscience, Seattle, WA, September 2002 and 2003, two poster presentations.

8. "Electronic Structure of Thin Film Anstase $\mathrm{TiO}_{2}$ : A Candidate Spintronics Material", Schimdt, D., Adams, J., Bostwick, A., Chambers, S., and Olmstead, M., PNWAVS , Vancouver, September 2002.

9. "MOCVD of ZnO-based Dilute Magnetic Semiconductors." Allan Tuan, Suntharampillai Thevuthasan, Dave McCready, Daniel Gaspar, J. W. Rogers, Jr., Scott A. Chambers, AVS in SF 2001.

10. "Epitaxial Growth and Properties of Co-Doped $\mathrm{TiO}_{2}$ Anatase on $\mathrm{Si}(001)$." Chambers SA, TC Droubay, AC Tuan, and RF Farrow. 2002. Presented by Scott A. Chambers at Materials Research Society Meeting, Boston, MA on December 3, 2002.

11. "Co-doped TiO2 Anatase - A New Candidate DMS for Spintronics." Chambers SA, TC Droubay, AC Tuan, C Wang, SM Heald, T Thevuthasan, RF Farrow, J Thiele, RF Marks, M 
Toney, and A Chattopadhyay. 2002. Presented by Scott A. Chambers at DARPA Spintronics Workshop 2002, Delray Beach, FL on October 1, 2002.

12. " $\mathrm{Co}_{\mathrm{x}} \mathrm{Ti}_{1-\mathrm{x}} \mathrm{O}_{2}$ Anatase Heteroepitaxy on $\mathrm{Si}(001)$." Droubay $\mathrm{TC}, \mathrm{AC}$ Tuan, and SA Chambers. 2002. Presented by Timothy Droubay at 49th International American Vacuum Society Symposium, Denver, CO on November 5, 2002.

13. "MOCVD Growth of $\mathrm{Co}_{\mathrm{x}} \mathrm{Zn}_{1-\mathrm{x}} \mathrm{O}$ on R-plane Sapphire: Structure, Composition, and Magnetic Properties." Tuan AC, TC Droubay, JW Rogers, and SA Chambers. 2002. Presented by Allan Tuan at 49th International American Vacuum Society Symposium, Denver, CO on November 6, 2002.

14. "Materials Characterization and Magnetic Studies of Epitaxial $\mathrm{Co}_{\mathrm{x}} \mathrm{Ti}_{1-\mathrm{x}} \mathrm{O}_{2-\mathrm{x}}$ Deposited on Si(001) by Molecular Beam Epitaxy." TC Kaspar, T Droubay, AC Tuan, CM Wang, SA Chambers, JW Rogers, Jr. 2003. Presented by Tiffany Kaspar at the 50th International American Vacuum Society Symposium, Baltimore MD, Nov. 6, 2003. Awarded Leo M. Falicov Student Award from the Magnetic Interfaces and Nanostructures Division.

15. "Ferromagnetic Co-doped Anatase $\mathrm{TiO}_{2}$ : Are All Growth Methods Created Equal?" T Droubay, SM Heald, TC Kaspar, CM Wang, SA Chambers. 2003. Presented by Tim Droubay at the $50^{\text {th }}$ International American Vacuum Society Symposium, Baltimore, MD, Nov. 6, 2003.

16. "Characterization of methotrexate modified superparamagnetic nanoparticles and their uptake into human chronic myologenous leukemia cells." Kohler N, Zhang Y, Zhang M. 2003 Nanotech Conference and Tradeshow, San Francisco, CA, February 23-27, 2003. (Submitted September 2002)

17. "Synthesis of methotrexate modified superparamagnetic nanoparticles and their uptake into Breast Cancer Cells." Kohler N, Zhang Y, Zhang M. MRS Fall Meeting, Boston, MA, December 2-6, 2002.

18. "Superparamagnetic Nanoparticles for Imaging." Kohler N, Zhang Y, Busche B, Zhang M. International Symposium on Optical Science and Technology. SPIE Annual Meeting, July 2002.

19. "Electrophoretic deposition of oxide nanorods inside pores of template from sols," 1st International conference on electrophoretic deposition, Banff, Canada, Aug. 18-22, 2002.

20. "Template-based growth of oxide nanorods by sol electrophoresis," $42^{\text {nd }}$ International conference on advanced ceramics, Osaka, Japan, Jan. 21-23, 2002.

21. "Development of Efficient Electron-Transporting Polymers for Light-Emitting Diodes," Michelle S. Liu, Xuezhong Jiang, Petra Herguth, Sen Liu, Alex K.-Y. Jen, Presented on SPIE meeting, 07/08-07/12, Seattle, 2002. 
22. "Classical and Dynamic Spectroscopy of $\mathrm{Ni}^{2+}$ in Nanoscale II-VI Semiconductors." Kittilstved, K.R.; Schwartz, D.A.; Joly, A.G.; Gamelin, D.R. Nanoscale Science and Technology Workshop 2003, September 22-23 (Poster).

23. "Characterization of methotrexate modified superparamagnetic nanoparticles and their uptake into human chronic myologenous leukemia cells." Kohler N, Zhang Y, Zhang M. 2003 Nanotech Conference and Tradeshow, San Francisco, CA, February 23-27, 2003. (Submitted September, 2002)

24. "Synthesis of methotrexate modified superparamagnetic nanoparticles and their uptake into Breast Cancer Cells." Kohler N, Zhang Y, Zhang M. MRS Fall Meeting, Boston, MA. December 2-6, 2002.

25. "Superparamagnetic Nanoparticles for Imaging. International Symposium on Optical Science and Technology." Kohler N, Zhang Y, Busche B, Zhang M. SPIE Annual Meeting, July 2002.

26. “Chemical Analysis of Nanogram Quantities of Matter by Raman Enhancement using Nanoscale Surfaces." 2003 NSF IGERT site visit to UW Center for Nanotechnology, UW, Seattle, WA, presented by Atanu Sengupta (graduate student).

27. "Magneto-optical and Magnetic Studies of Diluted Magnetic Semiconductor Nanocrystals." Norberg, Nick S.; Radovanovic, Pavle V.; Schwartz, Dana A.; Amonette, James E.; Gamelin, Daniel R., Third Annual Nanoscale Science and Technology Workshop, University of Washington, Seattle, Washington, September 2003 (poster presented).

28. "Electronic Structure of Thin Film Anatase $\mathrm{TiO}_{2}$ : A Candidate Spintronics Material." D. A. Schmidt, J. A. Adams, A. A. Bostwick, S. A. Chambers, M. A. Olmstead. 2002 Nanotech Workshop, UW, Seattle, WA; 2002 PNW-AVS, Vancouver, WA, 2003, CDO Networking Day, UW, Seattle, WA.

29. "The Preparation of Lanthanum Aluminate (LaAlO3) Substrates for MBE Growth of $\mathrm{TiO}_{2}$." D. A. Schmidt, T. Ohta, Q. Yu, S. A. Chambers, M. A. Olmstead. 2003 Nanotech Workshop, UW, Seattle, WA; 2003 PNW-AVS, Troutdale, OR; 2003 CDO Networking Day, UW, Seattle, WA; 2003 NSF IGERT site visit to UW Center for Nanotechnology, UW, Seattle, WA.

30. "Pd particle size effects on methane dissociation on MgO-supported Pd Nanoparticles." S.L. Tait, Jr., Z. Dohnálek, B. D. Kay, C. T. Campbell, American Physical Society Meeting, Montreal, Canada, March 25, 2004.

31. "Adsorption energies of small alkane molecules on $\mathrm{MgO}$ (100) by temperature programmed desorption." S.L. Tait, Jr., Z. Dohnálek, B.D. Kay, C.T. Campbell, AVS $50^{\text {th }}$ International Symposium, Baltimore, Maryland, November 4, 2003.

32. "Pd Nanoparticles on $\mathrm{MgO}(100)$ : Model Catalysts to Probe Particle Size Effects in Alkane Activation." Outstanding Student Presentation Award, S.L. Tait, Jr., Z. Dohnálek, B.D. 
Kay, C.T. Campbell, Nanoscale Science and Technology Workshop, Seattle, Washington, September 23, 2003.

33. First Prize, Graduate Student Poster Presentation Competition, Symposium of the Pacific Northwest AVS Chapter, Troutdale, Oregon, September 18, 2003.

34. "MOCVD Growth of $\mathrm{Co}_{\mathrm{x}} \mathrm{Zn}_{1-\mathrm{x}} \mathrm{O}$ on R-sapphire: Structure, Composition, and Magnetic Properties." Allan Tuan, Dave McCready, Dan Gaspar, Mark Engelhard, Theva Thevuthasan, Shuttha Shutthanandan, Tim Droubay, J. W. Rogers, Jr., Scott Chambers. AVS $49^{\text {th }}$ International Symposium in Denver, Colorado, November 2002.

35. "Characterization of methotrexate modified superparamagnetic nanoparticles and their uptake into human chronic myologenous leukemia cells." Kohler N, Zhang Y, Zhang M. 2003 Nanotech Conference and Tradeshow, San Francisco, CA, February 23-27, 2003. (Submitted September, 2002)

36. "Synthesis of methotrexate modified superparamagnetic nanoparticles and their uptake into Breast Cancer Cells." Kohler N, Zhang Y, Zhang M. MRS Fall Meeting, Boston, MA. December 2-6, 2002.

37. "Superparamagnetic Nanoparticles for Imaging." Kohler N, Zhang Y, Busche B, Zhang M. International Symposium on Optical Science and Technology. SPIE Annual Meeting, July 2002. 


\section{Appendix A}

\section{List of JIN Awards by Award Dates}




\section{Appendix A: List of JIN Awards by Award Dates}

\begin{tabular}{|l|l|l|l|}
\hline \multicolumn{1}{|c|}{ January-2002 } & \multicolumn{1}{|c|}{ Student or PD } & \multicolumn{1}{|c|}{ UW Mentor } & PNNL Mentor \\
\hline $\begin{array}{l}\text { Magneto-Optical Spectroscopy of Nanocrystalline } \\
\text { Ferromagnetic Oxide Semiconductors }\end{array}$ & John Bryan & Daniel Gamelin & Scott Chambers \\
\hline $\begin{array}{l}\text { Growth Characterization of Dye-Functionalized Titania } \\
\text { Nanostructures for Photoelectrochemical Applications }\end{array}$ & Tammy Chou & Guozhong Cao & Glen Fryxell \\
\hline $\begin{array}{l}\text { Fourier Transform Infrared Spectroscopy Studies (FTIR) and } \\
\text { Temperature Programmed Desorption (TPD) of Amorphous } \\
\text { Solid Water (ASW) }\end{array}$ & Jason Donev & Sam Fain & Bruce Kay \\
\hline $\begin{array}{l}\text { Development and Application of Interatomic Potentials for } \\
\text { Heterogeneous Nanostructures }\end{array}$ & Yoon, Joo Chul & Scott Dunham & Anter El-Azab \\
\hline $\begin{array}{l}\text { Advanced Actuator Materials Based on Carbon Nanotube } \\
\text { Composites }\end{array}$ & Leonard Fifield & Larry Dalton & Chris Aardahl \\
\hline $\begin{array}{l}\text { Fundamental Studies of Monolayer-Protected Nanoparticles } \\
\text { by Gas Chromatography - }\end{array}$ & Gwen Gross & Robert Synovec & Jay Grate \\
\hline $\begin{array}{l}\text { Dilute Magnetic Semiconducting Oxide Thin Films and } \\
\text { Nanostructures }\end{array}$ & $\begin{array}{l}\text { Alex Pakhomov/Brad } \\
\text { Roberts }\end{array}$ & Kannan Krishnan & Scott Chambers \\
\hline $\begin{array}{l}\text { Interfacing chip-based nanofluidic-systems to surface- } \\
\text { desorption mass spectrometry }\end{array}$ & Jason Kuo/Gina Fiorini & Daniel Chiu & Cindy Bruckner-Lea \\
\hline $\begin{array}{l}\text { Nanostructure Conjugated Polymers and Hybrid Photovoltaic } \\
\text { Cells }\end{array}$ & Michelle Liu & Alex Jen & Paul Burrows \\
\hline Redox Reactions of Colloidal Metal Oxides & Mira Kanzelberger & James Mayer & Don Camaioni \\
\hline $\begin{array}{l}\text { Epitaxial Growth and Properties of Nanoscale Oxides for } \\
\text { Spintronics }\end{array}$ & Diedrich Schmidt & Marjorie Olmstead & Scott Chambers \\
\hline $\begin{array}{l}\text { Surface Recognition and Incorporation of Additives into } \\
\text { Calcium Oxalate Host Crystals }\end{array}$ & Lara Touryan & Viola Vogel & Allison Campbell \\
\hline $\begin{array}{l}\text { Metalorganic Chemical Vapor Deposition of Mn } \\
\text { Spintronic Material }\end{array}$ & Allan Tuan as a & J. W. Rogers & Scott Chambers \\
\hline $\begin{array}{l}\text { Sol-gel electrophoresis for the formation of nanosized } \\
\text { nanostructured materials }\end{array}$ & Steven Limmer & G. Cao & Tim Hubbler \\
\hline
\end{tabular}




\begin{tabular}{|l|l|l|l|}
\hline \multicolumn{1}{|c|}{ June-2002 } & \multicolumn{1}{|c|}{ Student or PD } & \multicolumn{1}{|c|}{ UW Mentor } & \multicolumn{1}{c|}{ PNNL Mentor } \\
\hline Superparamagnetic Nanoparticles for Imaging and Therapeutics & Nathan Kohler & Miqin Zhang & Glen Fryxell \\
\hline $\begin{array}{l}\text { Direct Simulation Approach to Multi-Phase Biomaterial Transport } \\
\text { and Nano-Interactions in Microfluidic Systems }\end{array}$ & David Lim & Daniel Chiu & Dave Rector \\
\hline $\begin{array}{l}\text { Nature of Genetically Engineered Protein/Inorganic Interactions: } \\
\text { Novel Molecular Linkers for Nanotechnology }\end{array}$ & Dan Heidel & M. Sarakaya & Wendy Shaw \\
\hline $\begin{array}{l}\text { Transition Metal Doped ZnO Semiconductor Nanoparticles: } \\
\text { Synthesis and Characterization of Electronic Structure }\end{array}$ & Nick Norberg & Dan Gamelin & Jim Amonette \\
\hline $\begin{array}{l}\text { Deposition and Characterization of (Ba,Sr)TiO } \text { for High- } \\
\text { Permittivity Applications }\end{array}$ & Tiffany Kaspar & J. W. Rogers & Scott Chambers \\
\hline Smart Magnetic Nanoparticle Imaging Probes & Yong Zhang & Miqin Zhang & Kevin Minard \\
\hline $\begin{array}{l}\text { Photochemistry of a Diluted Magnetic Semiconductor Quantum Dot: } \\
\text { A Possible Photocatalyst for Water-Splitting }\end{array}$ & Kevin Kittilstved & Dan Gamelin & Alan Joly \\
\hline $\begin{array}{l}\text { Epitaxial Growth of Co-doped TiO } 2 \text { Anatase for Electrical Spin } \\
\text { Injection into Silicon }\end{array}$ & Allan Tuan & J. W. Rogers & $\begin{array}{l}\text { Scott } \\
\text { Chambers }\end{array}$ \\
\hline $\begin{array}{l}\text { Pd nanoclusters supported on } \mathrm{MgO}(100): \text { effects of cluster size on } \\
\text { chemisorption properties }\end{array}$ & Steve Tait & Charles Campbell & Bruce Kay \\
\hline
\end{tabular}

\begin{tabular}{|c|c|c|c|}
\hline January-2003 & Student or PD & UW Mentor & PNNL Mentor \\
\hline $\begin{array}{l}\text { Renewal-Magneto-Optical Spectroscopy of Nanocrystalline } \\
\text { Ferromagnetic Oxide Semiconductors }\end{array}$ & John Bryan/Dana Swartz & Dan Gamelin & Scott Chambers \\
\hline $\begin{array}{l}\text { Renewal-Synthesis and Characterization of Ordered Dye- } \\
\text { Functionalized Oxide Nanostructures for Photoelectrochemical } \\
\text { Applications }\end{array}$ & Tammy Chou & Guozhong Cao & Glen Fryxell \\
\hline $\begin{array}{l}\text { Renewal-Nondestructive Carbon Nanotube Modification for } \\
\text { Tailored Functionality }\end{array}$ & Leonard Fifield & Larry Dalton & Chris Aardahl \\
\hline $\begin{array}{l}\text { Renewal-Fundamental Studies of Monolayer-Protected } \\
\text { Nanoparticles by Gas Chromatography }\end{array}$ & Gwen Gross & Robert Synovec & Jay Grate \\
\hline Renewal-Redox Reactions of Colloidal Metal Oxides & Mira Kanzelberger & James Mayer & Don Camaioni \\
\hline $\begin{array}{l}\text { Renewal-Electronic Structure of Thin Film Anatase } \mathrm{TiO}_{2}: \mathrm{A} \\
\text { Candidate Spintronics Material }\end{array}$ & Deitrich Schmidt & Marjorie Olmstead & Scott Chambers \\
\hline $\begin{array}{l}\text { Bioaerosol Detection via Nanoparticle Surface Enhanced Raman } \\
\text { Spectroscopy }\end{array}$ & Mary Laucks & E. James Davis & $\begin{array}{l}\text { Feng Zheng } \\
\text { Mark Kingsley }\end{array}$ \\
\hline $\begin{array}{l}\text { Fundamental Studies of Nano-structured Oxides for Energy } \\
\text { Applications }\end{array}$ & Dmitry Kukurznyak & $\begin{array}{l}\text { Fumio Ohuchi } \\
\text { Rajendra Bordia }\end{array}$ & Peter Martin \\
\hline
\end{tabular}




\begin{tabular}{|c|c|c|c|}
\hline June 2003 & Student or PD & UW Mentor & PNNL Mentor \\
\hline $\begin{array}{l}\text { Renewal-Superparamagnetic Nanoparticles for Imaging and } \\
\text { Therapeutics }\end{array}$ & Nathan Kohler & Miqin Zhang & Gel Fryxell \\
\hline $\begin{array}{l}\text { Renewal-Magnetic Nanocrystals: Synthesis and Study ZnO and } \\
\text { GaN Diluted Magnetic Semiconductors }\end{array}$ & Nick Norberg & Dan Gamelin & Jim Amonette \\
\hline $\begin{array}{l}\text { Renewal-Deposition and Characterization of }(\mathrm{Ba}, \mathrm{Sr}) \mathrm{TiO}_{3} \text { for High- } \\
\text { Permittivity Applications }\end{array}$ & Tiffany Kaspar & J. W> Rogers & Scott Chambers \\
\hline $\begin{array}{l}\text { Renewal- Photochemistry of Colloidal Dilute Magnetic } \\
\text { Semiconductor Quantum Dots }\end{array}$ & Kevin Kittilstved & Dan Gamelin & Alan Joly \\
\hline $\begin{array}{l}\text { Renewal-Pd nanoclusters supported on } \mathrm{MgO}(100) \text { : effects of } \\
\text { cluster size on chemisorption properties }\end{array}$ & Steve Tait & Charles Campbell & Bruce Kay \\
\hline $\begin{array}{l}\text { Renewal-Nanostructure Conjugated Polymers and Hybrid } \\
\text { Photovoltaic Cells }\end{array}$ & Michelle Liu & Alex Jen & Paul Burrows \\
\hline
\end{tabular}

\begin{tabular}{|c|c|c|c|}
\hline September 2003 & Student or PD & UW Mentor & PNNL Mentor \\
\hline $\begin{array}{l}\text { Using Advanced Mas Spectrometric Techniques to Analze Signalin } \\
\text { Dynamics in Human Peripheral Blood Monocytes in Response to } \\
\text { Nanoscale Topography }\end{array}$ & Allison Golden & Pat Stayton & Wendy Shaw \\
\hline $\begin{array}{l}\text { Growth and optimization of } \mathrm{TM}_{\mathrm{x}}, \mathrm{Ti}_{1-\mathrm{x}}, \mathrm{O}_{2}(\mathrm{TM}=\mathrm{Co}, \mathrm{Mn}, \mathrm{Cr}) \text { films } \\
\text { for silicon based spintronic devices }\end{array}$ & Kelli Griffin & Kannan Krishnan & Scott Chambers \\
\hline Characterization of DNA Microarray Surfaces & Chi-Ying Lee & Dave Castner & A. Scott Lea \\
\hline $\begin{array}{l}\text { Development of Cellular Absorptive Tracers (CATs) for } \\
\text { Quantitative Characterization of the Complaxity of Nanoscale } \\
\text { Biological Systems }\end{array}$ & Deirdre Meldrum & Deirdre Meldrum & Pradad Saripalli \\
\hline Development of Nanostructured Scintillator Materials & Mary Shang & Guozhong Cao & Mary Bliss \\
\hline Predicting catalysis at oxide nano-particles & Kirik Tsemekhman & Hannes Jonsson & Eric Bylaska \\
\hline
\end{tabular}




\section{Appendix B}

\section{JIN Related Award Winners}

Pacific Northwest Chapter AVS Best Graduate Student Poster Sept. 2003

Best Student Presentation Awards, Sept. 2003

Leo Falicov Award, November 2003

E.W. Mueller Award 2004 


\section{Appendix B: JIN Related Award Winners}

\section{Pacific Northwest Chapter AVS Best Graduate Student Poster}

First Prize in the Graduate Student Poster Presentation Competition at the Symposium of the Pacific Northwest AVS Chapter, Troutdale, Oregon, September 18, 2003 - presented to Steve Tait for "Pd Nanoparticles on MgO(100): Model Catalysts to Probe Particle Size Effects in Alkane Activation,” S. L. Tait, Jr., Z. Dohnálek, B. D. Kay, and C. T. Campbell.

\section{Best Student Presentation Awards at $3^{\text {rd }}$ Nanotech Symposium}

Two student Outstanding Presentation Awards, one for an outstanding oral presentation and one for an outstanding poster presentation, were selected from the student participants at the 2003 JIN workshop.

The two award winners were:

Steven L. Tait for the presentation "Pd Nanoparticles on $\mathrm{MgO}(100)$ : Model Catalysts to Probe Particle Size Effects in Alkane Activation."

Robert K. Doot for the Poster "Biomolecular Motors in Hybrid NEMS and MEMS Devices."

These awards consisted of a \$500 cash-prize award and \$500 in travel support for attendance at a scientific meeting.

\section{The Leo M. Falicov Student Award}

Student Tiffany Kaspar was awarded the Leo M. Falicov award by the Magnetic Interfaces and Nanostructures Division of the American Vacuum Society for the presentation "Materials Characterization and Magnetic Studies of Epitaxial $\mathrm{Co}_{\mathrm{x}} \mathrm{Ti}_{1-\mathrm{x}} \mathrm{O}_{2-\mathrm{x}}$ Deposited on $\mathrm{Si}(001)$ by Molecular Beam Epitaxy." TC Kaspar, T Droubay, AC Tuan, CM Wang, SA Chambers, JW Rogers, Jr., 2003. Tiffany made the presentation at the 50th International American Vacuum Society Symposium, Baltimore MD, Nov. 6, 2003.

\section{E. W. Mueller Award, University of Wisconsin}

Scott Chambers, of the Interfacial Chemistry and Engineering (IC\&E) group at PNNL, a Mentor to several JIN students and leader in the spintronics area, has been awarded the 2004

E.W. Mueller Award to recognize outstanding achievements made to the field of surface science. 


\section{Appendix C}

\section{Programs from four Nanotech Workshops:}

Aug. 2001, Feb. 2002, Sept. 2002, Sept. 2003 


\section{Appendix C: Programs from four Nanotech Workshops: Aug. 2001, Feb. 2002, Sept. 2002, Sept. 2003}

JIN Workshop History (Attendance)

First Annual Seattle Nanoscale Science and Technology Workshop (138)

August 16 and 17, 2001, Seattle WA

Business Forum Previous to Second Annual Seattle Nanoscale Science and Technology

Workshop: Nanotech Meets Business Information Exchange (120)

September 18, 2002, Seattle WA

Second Annual Seattle Nanoscale Science and Technology Workshop (155)

September 19-20, 2002, Seattle WA

Third Annual Seattle Nanoscale Science and Technology Workshop (154)

September 22-23, 2003, Seattle WA

Richland Nanoscale Science and Technology Workshop: Relating Nanoscience to Problems: Exploiting Opportunities in Nanoscience and Nanotechnology (90)

February 21, 2002, Richland WA

Workshop agendas follow. 


\title{
First Annual Seattle Nanotechnology Workshop, Aug. 2001
}

\author{
Sponsored by Center for Nanotechnology/UIF and NSF \\ UW/PNNL Joint Institute for Nanoscience and Nanotechnology \\ Co-sponsored by Pacific Northwest National Laboratory/DOE \\ Henry Art Gallery \\ August 16 and 17, 2001 \\ University of Washington, Seattle, WA 98195
}

\section{Nanoscale Science and Technology Workshop 2001 Thursday August 16, 2001 \\ Morning Session}

10:00-12:00 Steering Committee Meeting (Henry Art Gallery conference room)

Afternoon Session

1:00 -1:05 Viola Vogel, UW/BioE

Welcome

1:05-1:20 Bill Rogers, PNNL

Directions of the PNNL Nanoscience and Nanotechnology Initiative

1:20-1:50 Norm Dovichi, UW/Chem

The Chemistry of a Single Enzyme Molecule

1:50-2:20 Peter Lu, PNNL

Single-Molecule Protein Dynamics

2:20-2:35 Daniel Chiu, UW/Chem

Optical Trapping and Microfluidics Approach to Single-Molecule and Single-Cell Manipulations

2:35-2:50 Viola Vogel, UW/BioE

Switching the Functional State of Proteins by Mechanical Force

2:50-3:10 Deidre Meldrum, UW/EE

Integrated Biologically-Active Microsystems

3:10-3:40 Open Forum/Break

Session B: $\quad$ Functional Nanostuctures I (Rogers, Chair)

3:40-4:10 Larry Dalton, UW/Chem

Nanostructured Materials for Novel Photonic and Optoelectronic Applications

4:10-4:25 Alex Jen, UW/MSE

Nanoscale Tailoring of Organic Photonic and Optoelectronic Materials

4:25-4:40 Glen Flyxell, PNNL

Using Self-Assembly to Make Nanostructured Hybrid Materials for environmental Applications

4:40-4:55 Michael Schick, UW/Phys

Self-Assembly of Polymers and Biological Lipids

4:55-5:10 Karl Böhringer, UW/EE

Controlled Part-to-Substrate Micro-Assembly via Electrochemical Surface Modulation

5:10-5:25 Guozong Cao, UW/MSE

Growth of Nanostructured Materials by Sol-Gel Electrophoresis 
Friday August 17, 2001

Morning Session: Functional Nanostructures II (Vogel and Baer, Chairs)

8:30-9:20 George M. Whitesides, Harvard University

Unconventional Methods of Fabricating Nano- and Microstructures

9:20-9:35 Don Baer, PNNL

Oxide Nanostructures: High Surface Area, Quantum Dots, and Spin Structures

9:35-9:55 Charles Campbell, UW/Chem

Catalysis on Metal Nanoparticles: Interplay between Structure, Energetics, and

Catalytic Activity

9:55-10:10 Paul Burrow, PNNL

OLED and Oxide Thin Film Research Oxide

10:10-10:25 Byron Gates, UW/Chem

Self-Assembly Approach to 3-D Order Nanostructures

10:25-11:00 Open Forum/Break

11:00-11:15 Eric Ackerman, PNNL

Immobilization of Enzymes in Nanoporous Materials at High Efficiency While

Retaining Activity

11:15-11:30 Younan Xia, UW/Chem

Well-Controlled Nanowires of Semiconductors and Metals through Soft Solution Processing

11:30-11:45 Li-Qiong Wang, PNNL

Molecular Assembly in Ordered Nanoporosities

11:45-12:00 S. K. Sundaram, PNNL

Synthesis of Semiconductor Nanocrystals Inside a Micelle

\section{Poster Session and NUF open house at Fluke Hall (12:00-2:00 p.m.)}

2:00-2:30 Pat Stayton, UW /BioE

Biomaterials That Talk and Listen in Nano-Space

2:30-3:00 Pedro Verdugo, UW/BioE

Dynamics of Marine Biopolymer Assembly: Nano- and Microgels Formation and its Impact on Global Carbon Cyclying

3:30-3:45 Anter El-Azab, PNNL

Computational Modeling of Nano Structures: Challenges and Opportunities

3:45-4:00 Henry Hess, UW/BioE

Molecular Shuttles Based on Motor Proteins

4:00-4:15 Anna Gutowska, PNNL

Stimuli-Responsive Nanogels for Medical Applications

4:15-4:30 Albert Folch, UW/BioE

Designing the Microfluidic Environment of Cells

4:30-4:45 Jim Davis, UW/Office of Research

Adjoin 
Lara Touryan/Vogel/BioE

Poster Session

Friday August 17, 2001

(12:00-2:00 p.m.)

Surface Recognition and Incorporation of Additives into Calcium Oxalate Host

Crystals

John Clemmens/Vogel/BioE

Engineering Surfaces to Direct Microtubule Motion for Motor Protein Based Shuttles Calvin Hu/BioE/Stayton and Hoffman

Control of Cell Adhesion to RGD-Streptavidin using Temperature Sensitive Polymer

Cynthia Buenviaje/Overney/ChemE

Phase Transitions of Confined Polymer Films using Atomic Force Microscopy

Lingyan Li/Jiang/ChemE

Nanoscale Surface Engineering for Protein Adsorption

Nallakkan S. Arvindan/Stuve/ChemE

Nanoparticles for Clean and Efficient Electric Power

Leo Fifield/Dalton/Chem

Investigation of the Mechanism of Molecular Actuators Based on Carbon Nanotubes

Jennifer Shumaker-Parry/Campbell/Chem

Micro-array Based Studies of Protein-DNA Interactions Using Surface Plasmon

Resonance Microscopy

Pavle Radovanovic/Gamelin/Chem

Electronic Absorption Studies of Transition Metal Centers in Diluted Magnetic

Semiconductor Quantum Dots

Brian T. Mayers/Xia/Chem

A Solution Phase Approach to Large Scale Synthesis of Uniform Nanowires of

Semiconductors

Byron Gates/Xia/Chem

Fabrication of Micro- and Nanostructures with Monodispersed Colloidal Spheres as

the Active Components

Yadong Yin/Xia/Chem

Fabrication of Silicon Nanostructures with Well-Defined Dimensions and Shapes

Steve Limmer/Cao/MSE

Nanosize Effects on the Dielectric Properties of Oxide Materials

Michelle Liu/Jen/MSE

Rod-Coil-Rod Triblock Copolymers for Efficient Photovaltaic Cells

Petra Herguth/Jen/MSE

Electroluminescence of Structurally Defined Copolymer-Block Formation and Phase

Separation

Dan Heidel/Sarikaya/MSE

Nano-Assembly through Engineered Inorganic Recognition Peptides

Jason Donev/Fain/Physics

Morphological Changes in Vapor Deposited Ice on a Au(111)

Milan Diebel/Dunham/EE

Diffusion at the Nanoscale: Quantum Mechanics Meets Fick's Law

Sponsored by the University of Washington and the National Science Foundation IGERT Program Co-sponsored by DOE's Pacific Northwest National Laboratory

Business Forum Previous to Second Annual Seattle 


\section{Nanotechnology Workshop, Sept. 2002}

\section{Technology Forum: Nanotech Meets Business, September 18, 2002}

Boeing Auditorium

Seafirst Executive Education Center

University of Washington, Seattle, WA 98195

\section{Tentative Program}

1:00-1:30 Viola Vogel, BioE/UW

Nanotechnology - an Overview

1:30-2:30 Avogadro Partners, Seattle

The Emerging Age of Nanobusiness

Panel Discussion (20-minute presentation and 10-minute Q\&A)

\section{2:50-3:20 Amazing Materials}

Walt Mahoney (moderator), Larry Dalton, Chem/UW, Paul Burrows, PNNL, Younan Xia, Chem/UW

3:35-4:05 NanoTechnology and Healthcare

Viola Vogel, BioE/UW (moderator), Pat Stayton, BioE/UW, Norm Dovichi, Chem/UW, Paul Yager, BioE/UW

4:15-4:45 NanoTechnology for the Environment

Charlie Campbell, Chem/UW (moderator), Don Baer, PNNL, Eric Stuve, ChemE/UW, Jud Virdin, PNNL

7:00-9:00 Steering Committee Meeting for PNNL/UW Joint Institute in Nanotechnology (Seafirst Executive Education Center Seminar Room) 


\title{
Second Annual Seattle Nanotechnology Workshop, Sept. 2002
}

\author{
Nanoscale Science and Technology Workshop \\ Physics Astronomy A102, University of Washington, Seattle
}

Thursday, September 19, 2002

8:30-8:35 Welcome (Viola Vogel)

Session A: Photonics and NanoMaterials (Burrow, Chair)

8:35-9:15 Liu, J., Sandia National Laboratories

Self-Assembly and Growth of Extended and Oriented Nanostructures

9:15-9:35 Jen, AK-Y, MSE/UW

Nanoscale Tailored Structures for Photonics and Molecular Electronics

9:35-9:55 Dohnálek, Z., Smith, R.S. and Kay, B. D., PNNL

Chemical Activity of Nanoporous Materials

10:10-10:30 Overney, R. M., ChemE/UW

Confinement Effects on Transport Properties in the Interfacial Region

10:30-10:50 Chambers, S. A., Droubay, D., Tuan, A. C., Wang, C.M., Heald, S.M.,

PNNL

Co-doped $\mathrm{TiO}_{2}$ Anatase - A New Material for Spintronics

10:50-11:10 Jiang, S. Y., ChemE/UW

Molecular Engineering of Surfaces for Sensing and Detection

11:10-11:30 Gamelin, D. Chem/UW

Colloidal Transition-Metal-Doped ZnO Quantum Dots

11:30-11:40 Mayers, B. T. and Xia, Y., Chem/UW

Shaped Controlled Synthesis at the Nanoscale

11:40-11:50 Radovanovic, P. and Gamelin, D., Chem/UW

Optical and Magneto-Optical Spectroscopy of Diluted Magnetic Semiconductor Quantum Dots

11:50-12:00 Donev, J. M. K., Long, B. R., Bollinger, R., Yu, Q., and S. C. Fain, Jr.

Physics/UW

Effects of Molecular Transport at the Nanoscale on the Morphology of Vapor-Deposited Amorphous Solid Water (ASW) at $T<150 \mathrm{~K}$

12:00-12:10 Schmidt, M., Djalali, R., and Stephan, T. University of Mainz, Germany Nanostructured Cylindrical Brush Polymers: From Molecular Templates to Responsive Macromolecules

Session B: Nanocatalysis (Campbell, chair)

2:00-2:45 Libuda, J. Fritz-Haber-Institute, Berlin

Nanostructured Model Catalysts: Methods - Mechanisms - Kinetics

2:45-3:05 Campbell, C. Chem/UW

Catalysis by Nanoparticles: State of the Art and Promises for the Future 
3:05-3:25 Baer, D. PNNL

Application to the Reaction of Nanoparticulate Iron and Iron-Bimetallic Compounds with Chlorinated Hydrocarbons and Oxyanions

3:25-3:35 Tait, S. L. Jr., Ngo, L. T., Yu, Q., Fain, S. C. Jr., and Campbell C.T. UW

Nano-Scale Sintering Effects on Model Catalysts for Green Chemistry

\section{Session C: NEMS/MEMS}

3:50-4:30 Heller, M. University of California San Diego

Challenges and Opportunity for Nanofabrication Process Based on Microelectronic

Array Devices

4:30-4:50 Cobden, D. H. Physics, UW

Single-Wall Carbon Nanotube Conducting Probe Tips

4:50-5:10 Hess, H. BioE/UW

Motor Protein Integrated into Nanodevices

5:10-5:20 Zhang, H. F., Wang, C. M., and Wang, L. S., PNNL

Screw Dislocation Driving Formation of Helical Nanowires

5:20-5:30 Tourovskaia, A. and Folch, A. BioE/UW

Micro-Engineered Self-Assembly of Muscle Myotubes

5:45-10:00 Dinner Cruise price included in the registration

\section{Friday, September 20}

\section{Session D: Single Cell Analysis}

8:30-9:10 Dovichi, N. Chem/UW

The Single Cell Proteome Project

9:10-9:30 Chiu, D. Chem/UW

Initiating the Conformational Transitions of Single DNAs with Optical Trapping

9:30-9:50 Folch, A. Chem/UW

Nanoengineered Cell Culture Devices

\section{Session E: Biological Nanosystems}

\section{0:05-10:45 Guo, P. Purdue University}

Construction of Controllable 30nm Viral DNA-Packaging Motor Driven by a RNA Hexamer

10:45-11:05 Vogel, V. BioE/UW

Switching Function by Stretching Molecules

11:05-11:25 Stayton, P. BioE/UW

Smart Materials that Talk and Listen in Nanospace

11:25-11:45 Saripalli, P. and Trease, H. PNNL

Development of Cellular Absorptive Tracers for the Characterization of Nanoscale Biological Systems

11:45-12:25 Groves, J., University of California, Berkeley

Molecular Pattern Formation and Cell Signaling at Inter-membrane Junctions 


\section{Posters}

Ratna, B. R., Blum, A. S., Soto, C. M., Chatterji, A., Lin, T., and Johnson, J. E., Naval Research Laboratory

Cow Pea Mosaic Virus as a Scaffold for Nanoelectronics

Hampton, C. Y. and Emory, S. R., Chemistry, Western Washington University Ultra-Sensitive Quantum Dot Based Bioassays

Wenda, T. and Emory, S. R., Chemistry, Western Washington University Single-Molecule Enzymology Using Surface-Enhanced Raman Spectroscopy

Pugsley, H. R., McMahon, J. M., Wilkinson, F. S., and Emory, S. R., Chemistry, Western Washington University

Metal Nanoparticle Assemblies for Surface-Enhanced Raman Spectroscopy

McLellan, J.M. and Patrick, D.L., Chemistry, Western Washington University Controlled Growth of Organic Semiconductors Using Liquid Crystal Solvents

Stenkamp, V. S., Bond, L. J., TeGrotenhuis, W. E., Grate, J. W. and Flake, M. D. PNNL Standing Ultrasonic Wave Separator

Ngo, L. T., Grant, A. W., Xu, L, and Campbell, C. T., Chemistry, UW Adsorption and Dehydrogenation of Cyclohexane and Benzene on ZnO(0001)-O Supported Pt Nanoparticles

Clemmens, J., Hess, H., Howard, J. and Vogel, V. Bioengineering, UW Engineering Surfaces for Directed Motion of Motor Proteins: Building a Molecular Shuttle System

Lu, Y. and Xia, Y., Chemistry, UW Photonic Crystals Fabricated from Gold-Silica Core-Shell Nanoparticles

Zheng, J. and Jiang, S., Chemical Engineering, UW Molecular Dynamics Simulation of a Protein Adsorption at a Solid Interface

Zheng, J. and Jiang, S., Chemical Engineering, UW Transport Diffusion and Separation of Liquid Mixtures in Carbon Nanotubes: A Molecular Dynamics Simulation Study

Rustad, J. PNNL Molecular Simulation of Water and Hydroxide Exchange on $\mathrm{Al}_{13} \mathrm{O}_{4}(\mathrm{OH})_{24}\left(\mathrm{H}_{2} \mathrm{O}\right)_{127+}$

Gross, G. M., Synovec, R. E., and Grate, J. W., Chemistry, UW and PNNL Fundamental Studies of Monolayer-Protected Nanoparticles by Gas Chromatography

Gutowski, M., Dupuis, M., Bylaska, E., and Rustad, J., PNNL Self-Consistent Charge Density-Functional Based Tight-Binding Method for Predictive Simulations of Nanoscale Materials

Herguth, P., Jiang, X., Liu, M. S., and Jen, K-Y, MSE/UW Energy Transfer in of Random and Structurally Defined Poly(fluorenebenzothiadiazole)s

Zhang, Y., Kohler, N., and Zhang, M., MSE/UW Surface Modification of Superparamagnetic Magnetite Nanoparticles and Their Intracellular Uptake

Veiseh, M., and Zhang, M. MSE/UW Guided Natural Cell Growth on Sensor Surfaces Through a Chemically Selective Protein Patterning Technique 
Ohta, T., Klust, A., Adams, J. A., Yu, Q., Olmstead, M. A., and Ohuchi, F. S. MSE/UW First Atomic-Resolution Ultrahigh Vacuum Scanning Tunneling Microscopy Study of GaSe/Si(111) Ultrathin Films,

Anter A. El-Azab, PNNL Coarse-Grained Atomistic Simulation of Nanoscale Oxides

Gamelin, D. Chemistry, UW Magnetic Properties of Quantum Dots

Liu, X. and Pollack, G. H., Bioengineering, UW Stepwise Sliding of Single Actin and Myosin Filaments

Fifield, L. and Dalton, L., Chemistry, UW Investigation of the Capacitance Minimum of Unannealed Single-Walled Carbon Nanotube Papers in Aqueous Sodium Chloride

Gaither, K. and Goheen, S., PNNL Designing the Interface between Nanodevices and Biological Systems

Adams, J., Bostwick, A., Ohta, T., Ohuchi, F., Rotenberg, E., Klust, A., and Olmstead, M., Physics, UW, and PNNL Electronic and Structural Properties of AlSe Ultrathin Films on Si(111)

Bostwick, A., Adams, J., Klust, A., Rotenberg, E., and Olmstead, M., Physics, UW and PNNL Low Dimension Metallic States in Heavily Irradiated CaF2 Thin Films on Silicon

Klust, A., Bostwick, A., Ohta, T., Yu, Q., Fumio, O., and Olmstead, M., Physics, UW and PNNL Tip-Sample Interactions during Scanning Probe Microscopy on CaF2/Si(111)

Schimdt, D., Adams, J., Bostwick, A., Chambers, S., and Olmstead, M., Physics, UW and PNNL Electronic Structure of Thin Film Anstase TiO2: A Candidate Spintronics Material

Lay, E., Ohta, T., Klust, A., Yu, Q., Adams, J., Bostwick, A., Ohuchi, F., and Olmstead, M., Physics and MSE/UW Impurity-Stabilized Silicon Island Formation on Si(111) $7 x 7$

Gatuna, I., Nakamura, F., and Ohuchi, F., MSE/UW Study of Kinetics and Energies of DNA Hybridization/Dehybridization Using Surface Plasmon Resonance Spectroscopy (SPR) and Atomic Force Microscopy (AFM)

Yan, M.; Bartlett, M.; Harnish, B, Chem/Portland State University Ultrathin Polymer Films and Arrays by Photochemical Immobilization

Keenan, T., Li, N., Kosar, F., Neils, C., Spilker, M., and Folch, A., BioE/UW

Combinatorial Nanofluidic Delivery of Axon Guidance Factors to Embryonic Neurons

\section{Third Annual Seattle Nanotechnology Workshop, Sept. 2003}

\section{Monday Morning, September 22, 2003}

Kane Hall 110

8:30 - 8:45 Welcome (Charles T. Campbell and Don Baer)

\section{Session A: Photonics and Nanomaterials (Scott Chambers, Chair)} 8:45 - 9:30 Jonker, B., Naval Research Laboratory

Semiconductor Spintronics: Promise, Issues, and Prospects

9:30 - 9:50 Gamelin, D., Chem/UW

Magnetic Quantum Dots: Synthesis, Spectroscopy, and Magnetism Nanocrystalline Diluted 
Magnetic Semiconductors

9:50 - 10:00 Zhang, H., Wang, C. and Wang, L. S., WSU/PNNL

Synthesis and Characterization of Helical Nanowires

10:00 - 10:10 Fifield, L. and Dalton, L., Chem/UW

Development of Active Nanomaterials Based on Carbon Nanotubes

10:25 - 10:45 Moeck, P., Portland State University

Structural Transitions in Epitaxial and Endotaxial Self-Assembled Semiconductor Quantum Dots: A Brief Overview

10:45 - 11:05 Xia, Y., Chem/UW

Design and Synthesis of Nanostructured Materials

11:05 - 11:25 Lin, Y., PNNL

Supercritical Fluid Synthesis and Characterization of Catalytic Metal Nanoparticles on Multi-Walled Carbon Nanotubes

11:25 - 11:45 Cobden, D., Physics/UW

Surface Potential Imaging of Single-Walled Carbon Nanotube Devices

11:45 - 11:55 Kopelman, R. and Frank, N., Chem/UW

New Advances in Molecular Bistability: Incorporation of Organic Photochromes into Magnetic Materials

11:55 - 12:15 Koenenkamp, R., Portland State University

Solar Cells and Transistors Grown in and on Nanometer-Sized Templates

\section{Monday Afternoon, September 22}

Kane Hall 110

\section{Session B: Single Cell Detection (Viola Vogel, Chair)}

1:30 - 2:15 Moerner, W. E., Stanford University

A Single Molecule as a Nanoscale Probe

2:15 - 2:35 Chiu, D., Chem/UW

Nanoscale Bioanalysis

2:35 - 2:55 Sanchez, E., Portland State University

Pushing the Limits of Near-Field Microscopy

2:55 - 3:15 Rosa, A. L., McCollum, J. and Chandra, R., Portland State University

Fabrication of Near-Field Multiprobe for Rapid Screening of Single Molecules

3:15 - 3:35 Hu, D. and Lu, P., PNNL

Correlated Topographic and Spectroscopic Imaging Beyond Diffraction Limit by Metallic

Tip-Enhanced Near-Field Fluorescence Lifetime Microscopy

3:35 - 3:55 Lidstrom, M. and Meldrum, D., EE/UW

Life-on-a-Chip: Single Cell Detection for Biological Applications

\section{Session C: NEMS/MEMS (Viola Vogel, Chair)}

4:10 - 4:55 Lee, L., UC Berkeley

Nanogap Biomolecular Junction \& BioPOEMS

4:55 - 5:05 Wang, Y. and Bohringer, K., EE/UW

Protein and Cell Patterning with Programmable Surface Chemistry Chips

5:05 - 5:15 Kosar, T. F. and Folch, A., BioE/UW

Arrays of Microfluidically-Addressable Nanoholes

5:15 - 5:25 Shastry, A. and Lal, R., I. I. T.- Bombay, India

A Low Voltage Electrical Microsystem to Move, Detect and Fractionate DNA 


\section{Tuesday Morning, September 23 \\ Kane Hall 110}

\section{Session D: Nanocatalysis (Don Baer, Chair)}

8:30 - 9:15 Pacchioni, G., Dipartimento di Scienza dei Materiali, Milan

Metal Atoms and Clusters on MgO Thin Films: Theory and Experiment

9:15 - 9:35 Apra, E. and Bylaska, E., PNNL

Use of the NWChem Computational Chemistry Software in Nanotechnology Research

9:35 - 9:55 Campbell, C. T., Chem/UW

Catalysis by Nanoparticles: State of the Art and Promises for the Future

9:55 - 10:15 Baer, D., PNNL

Characterization and Properties of Iron and Iron-Oxide Nanoparticles

10:15 - 11:00 McFarland, E., UC Santa Barbara

Big Reactions on Small Clusters

11:00 - 11:20 Chambers, S., PNNL

$\mathrm{MBE}$ Growth and Properties of Fe- $\mathrm{Cr}$ - and $\mathrm{Mn}$-Doped $\mathrm{TiO}_{2}$

11:20 - 11:30 Kaspar, T. C. and Rogers, B., UW/PNNL

Materials Characterization of Epitaxial $\mathrm{TiO}_{2}$ and $\mathrm{Cox}_{x} \mathrm{Ti}_{1-x} \mathrm{O}_{2-x}$ Deposited on $\mathrm{Si}(001)$ by Molecular Beam Epitaxy

11:30 - 11:40 Tait, S., Dohnalek, Z., Kay, B., and Campbell, C. T., UW/PNNL

Pd Nanoparticles on MgO(100): Model Catalysts to Probe Particle Size Effects in Alkane Activation

11:40 - 12:00 Saraf, L. V., PNNL

Correlation of Oxygen Diffusivity with Grain-Size and Its Impact on Ionic Transport

Properties in Nanocrystalline $\mathrm{CeO}_{2}$

12:00 - 12:20 Thevuthasan, S., PNNL

Influence of Multiple Interfaces on Oxygen Ionic Conductivity in Gadolinia-doped Ceria and Zirconia Nanofilms

\section{Tuesday Afternoon, September 23}

Kane Hall 110

Session E: Nanotechnology and Biology (Charles T. Campbell, Chair)

2:10 - 2:55 Vogel, V., BioE/UW

Engineering Principles of Biological Nanosystem

2:55 - 3:15 Sarikaya, M., MSE/UW

Molecular Biomimetics: Nanotechnology through Molecular Biology

3:15 - 3:35 Ackerman, E., PNNL

Immobilized Enzymes in Functionalized, Nanoporous Silica

3:35 - 3:55 Hess, H., BioE/UW

Nanodevices Based on Biomolecular Motors: Design and Applications

3:55 - 4:05 Liang, Y. and Palczewski, K., Ophthalmology/UW

Organization of the G Protein-Coupled Receptor Rhodopsin and Opsin in Native

Membranes by Atomic Force Microscopy

4:05 - 4:15 Veatch, S. and Kelly, S., Chem and Physics/UW 
Immiscibility in Model Lipid Membranes

4:15 - 4:25 Hull, J. and Castner, D., ChemE/UW

Investigation of the Binding Mechanism of the Bacterial Adhesin Scp to Fibronectin

4:25 - 4:45 Stedman, K., Portland State University

Extremophiles and their Viruses in Nanotechnology

4:45 - 4:55 Kohler, N. and Zhang, M., MSE/UW

Superparamagnetic Nanoparticles for Imaging

4:55 - 5:15 Kim, J., PNNL

Single Enzyme Nanoparticles Armored by a Nanoscale Organic/Inorganic Network

\section{Poster Session (12:20 - 2:10 PM, September 23)}

Kane Hall, Walker-Ames Room

Zheng, J. and Jiang, S., ChemE/UW

Non-Fouling Mechanism: A Molecular Simulation Study

Ngo, L. T., Tait, S. L., Yu, Q., Fain, S. and Campbell, C. T., Chem/Physics/UW

Sintering and Reactivity of Pd Nanoparticles on á-Al2O3(0001)-Supported Catalysts for Methane Combustion

Diaz, S., Smedh, M., Shamir, N. and Campbell, C. T., Chem/UW Adsorption Microcalorimetry on Thick Single Crystalline Samples

Schmidt, D. A., Ohta, T., Yu, Q., Chambers, S. A. and Olmstead, M. A., Physics/UW/PNNL Preparation of Lanthanum Aluminate (LaAlO3) Substrates for MBE Growth of TiO2

Ohta, T., Klust, A., Adams, J. A., Yu, Q., Olmstead, M. A. and Ohuchi, F. S., MSE/Physics/UW Heteroepitaxy of III-Se Materials for Their Applications to Nanoelectronics:

Compatibility to Si and Their Growth Studied by in-situ Scanning Probe Microscopy

Mao, D. and Dovichi, N., Chem/UW

Single Copy Detection of Gene Expression in Individual S. Cerevisiae Cells

Wickes, B. and Castner, D., ChemE/UW

Investigation of Pattern Fidelity and Self-Assembly of DNA-Thiol Patterns by ToF-SIMS Image Analysis

Li, N., Keenan, T. M. and Folch, A., BioE/UW

Neuronal Growth in Micro/Nanofluidic Devices

Chen, C. and Folch, A., BioE/UW

Grayscale Photolithography Using Microfluidic Photomasks

Hsu, C. H., Chen, C. and Folch, A. BioE/UW

"Microcanals" For Micropipette Access to Single Cells in Microfluidic Environments

Stucky, N., Kosar, T. F., Chen, C. and Folch, A., BioE/UW

3D PDMS-Based Arrays of Nanoholes for Cellular Analysis

Boggy, G., Keenan, T. M., Hsu, C. H. and Folch, A., BioE/UW

Microvalve Devices for Chemotaxis Studies

Tourovskaia, A. and Folch, A., BioE/UW

Synaptogenesis on a Microfludic Chip

Chen, Y. C., Yan, M., Wang, Z. and Prahl, S. A., Oregon Health \& Science University/PSU

Fluorescence Anisotropy Study of Molecularly Imprinted Polymers

Roberts, B., Pakhomov, A. B. and Krishnan, K. M., MSE/UW 
ZnO-Based Diluted Magnetic Semiconductors through Ion Beam and Magnetron Sputtering

Bao, Y., Beerman, M. and Krishnan, K. M., MSE/UW

Controlled Self-Assembly of Colloidal Cobalt Nanocrystals

Chou, T. P and Cao, G., MSE/UW

Ordered, Dye-Functionalized Titania Nanostructures for Photoelectrochemical Applications

Limmer, S. and Cao, G., MSE/UW

Sol Electrophoretic Growth of Oxide Nanostructures

Lin, Y., Liu, J. and Wang, J., PNNL/NMSU

Electrochemical Sensors and Biosensors Based on Conductive Nanomaterials

Liu, S., Jeffryes, C., Rorrer, G. L., Chang, C. and Wang, C., OSU/PNNL

Characterizations of Biogenic Silicon-Germanium Oxide Nanocomposites

Li, D. and Xia, Y., Chem/UW

Fabrication of Ceramic Oxide Nanofibers by Electrospinning

Wang, Y., Jiang, X. and Xia, Y., Chem/UW

Polyol-Mediate Approach to TiO2 and SnO2 Nanofibers under Mild Conditions

Sun, Y. G. and Xia, Y. Chem/UW

Synthesis and Characterization of Metal Nanostructures with Hollow Interiors

Ren, J. and Yan, M., Portland State University Polymer Thin Films Covalently Immobilized by Thermal and Photochemical Initiation

Harnish, B. and Yan, M., Portland State University

Polymer Ultrathin Films and Multilayers Generated by UV Irradiation

Moeck, P., Portland State University

Endotaxial Growth and Structural Transitions of Quantum Dots in Si Matrix

Moeck, P. and Pierz, K., Portland State University

Crystallographic Structure and Photoluminescence of Atomically Ordered (Cd,Mn, Zn)Se Quantum Dots in Matrix

Bryan, J. D. and Gamelin, D., Chem/UW

Colloidal Transition Metal Doped TiO2: Precursors to Spintronic Materials

Schwartz, D., Norberg, N., Nguyen, Q., Parker, J. and Gamelin, D., Chem/ UW Synthesis and Spectroscopy of Colloidal ZnO Diluted Magnetic Semiconductor Quantum Dots

Kittilstved, K., Schwartz, D., Joly, A. and Gamelin, D., Chem/UW/PNNL Classical and Dynamic Spectroscopy of Ni2 + in Nanoscale II-VI Semiconductors

Norberg, N., Radovanovic, P. V., Schwartz, D. S., Amonette, J. E. and Gamelin, D., Chem/UW Magneto-optical and Magnetic Studies of Diluted Magnetic Semiconductor Nanocrystals

Radu, I., Hanein, Y. and Cobden, D., Physics/UW

New Techniques for Controlling the Growth of Single-Walled Carbon Nanotubes

Patel, D. G., Benedict, J. B. and Frank, N., Chem/UW

Crystalline State Photoisomerization in a Novel Class of Photochromes

Gable, S. L. and Frank, N., Chem/UW

Role of Magnetic Nanoparticles in Signal Transduction Pathways: Magnetotactic

Bacteria

Wang, C. M., Zhang, Y., Shutthanandan, V., Thevuthasan, S., Baer, D. R. and Thomas, L. E., PNNL 
Precipitation of Au Nanoclusters in $\mathrm{TiO}_{2}$

Gutowski,1,2 M., Jaffe, J., 1 Yakovkin, I. N. 1,3 and Dupuis, M.1, PNNL

Theoretical Studies of Nanoscale Heterojunctions $\mathrm{Fe}_{2} \mathrm{O}_{3} / \mathrm{Cr}_{2} \mathrm{O}_{3}$ and $\mathrm{Si} / \mathrm{SrTiO}_{3}$

Bachorz, R., Haranczyk, M., Dabkowska, I., Miller, J., Dupuis, M. and Gutowski, M., PNNL Modeling of Damaged DNA at the Density of Functional Level of Theory

Gross, G. M., Synovec, R. E. and Grate, J. W., Chem/UW/PNNL

Fundamental Studies of Monolayer-Protected Nanoparticles by Gas Chromatography

Breneman, W., Advanced Silicon Materials, LLC

Synthesis and Properties of Nanosized Polysilicon

Doot, B., Clemmens, J., Hess, H., Matzke, C.1, Bachand, G.2, Bunker, B.2 and Vogel, V., BioE/UW

Biomolecular Motors in Hybrid NEMS and MEMS Devices 


\title{
Richland Nanotechnology Workshop: Relating Nanoscience to Problems
}

\author{
Exploiting Opportunities in Nanoscience and Nanotechnology: Information \\ Exchange and Project Development Workshop, Feb. 21, 2002
}

This workshop will begin the process of revising the focus of the JIN and the PNNL Nanoscience and Nanotechnology Initiative for FY '03.

February 21, 2002

Hanford House Red Lion

Richland, WA

The objective of this information sharing and project development workshop is to help identify collaborations and the formation of project teams that will enable novel science and provide a basis for technological advances in DOE mission areas.

Activities planned for the day include a poster session to provide a snapshot of current nanoscience and nanotechnology research at PNNL and the UW, oral presentations on science and technology opportunities in areas important to PNNL, and breakout sessions to help identify specific topics and teams that are interested specific research topics.

Although this meeting is built around current or potential activities of the PNNL Nanoscience and Nanotechnology Initiative (NNI) and the PNNL-University of Washington Joint Institute of Nanoscience (JIN), the participation of other potential collaborators is encouraged.

Poster session - Each program funded as part of the Nanoscience and Nanotechnology Initiative (NNI) will be represented, and other researchers (lab, industry or university) involved in other nano-related projects are encouraged to present a poster summary of their work and interests.

Project Development Workshops - The intent of the workshop is to identify the areas for scientific collaboration and project development. Talks of approximately half an hour will introduce issues in some obvious and less than obvious areas where nanoscience and technology may have a significant impact. One object is to facilitate the difficult job of bridging the gap between basic science and technology applications and to ensure that the NNI (and JIN) focus on seeding top-quality basic science to lay the foundations required to serve DOE missions in the future. Tentative topical areas include Nanoscale Biological Processes and Systems, Nanotechnology in Photonics, Physical and Chemical Sensors, Hydrogen Storage and Energy Systems, and Nanotechnology for Water Resources and Engineering. These are not yet final, and comments and suggestions for session leaders are welcome. We would like to identify at least one PNNL science, PNNL mission, and UW member on each workshop topic.

Exploiting Opportunities in Nanoscience and Nanotechnology

9:00 a.m. Setup of posters

9:45 - 10:15 am Welcome, Introduction and Schedule updates (Don Baer and Paul Burrows)

10:15 - 12:30 p.m. Information Fair - Poster Session 
11:30 - 12:30 p.m. Lunch

12:30 - 2:30 p.m. Workshop - Plenary Session (overview talks about workshop areas)

2:40 - 4:40 p.m. Workshop Breakout Sessions

4:40 - 5:10 p.m. Plenary Summaries of Breakout Sessions

Topical Group Leaders for Breakout Sessions and Plenary Speakers

Nanoscale Biological Processes and Systems

Viola Vogel (UW), Steve Colson (FSD) Glen Fryxell

Nanotechnology in Photonics

Greg Exarhos, Paul Burrows, Alex Jen (UW)

Physical and Chemical Sensors

John Hartman, Mike Foley (NSD), Gordon Dudder, Rob Synovec (UW)

Hydrogen Storage and Energy Systems

Jud Virden (ESD), Bruce Kay, Charlie Campbell (UW)

Nanotechnology for Water Resources and Engineering

Joe Devary, Richard Skaggs, Christopher Wend, Loni Peurrung, Don Baer

Objectives of Sessions

The overall objective of the plenary talks and breakout sessions is to identify links between the science that will have been presented in the poster session (and other science that will or can be done around the lab, UW, and at other locations) to some of the laboratory's more applied missions.

Questions to focus and stimulate discussion

1) What are the important and interesting new science opportunities/questions that will provide the fundamental nanoscience basis that can solve some DOE mission-area problems? What is the important science needed to understand or solve a DOE-applied mission problem?

2) Can we form interested, talented teams to create unique opportunities? What teams with the laboratory, involving the University of Washington or other outside people, will help us have a major impact? Clearly related to this identification of needs is a suggestion for important follow on actions.

3) Are there important technology or science drivers and related funding opportunities? What opportunities do we have to establish programs in the areas identified in 1)? Are there contacts or funding opportunities that we need or can follow up? 


\section{Appendix D}

\section{Syllabi for the Three Intensive Nanoscience Courses}




\title{
Appendix D: Syllabi for the Three Intensive Nanoscience Courses
}

\section{D.1 Nanoclusters, Nanomaterials, and Nanotechnologies}

\author{
Calendar for Phys. 581 - Nanoclusters, Nanomaterials, and Nanotechnologies
}

Spring 2003

May 19 - 30, $2003 \quad$ Lecture Location: PNNL, Richland, WA

First week: Lai-Sheng Wang (unless otherwise noted)

May 19 13:00 - 13:30 General Introduction and Remarks (Don Baer, Lai-Sheng Wang, Fumio Ohuchi)

Monday $\quad$ 13:40 - 14:30 Introduction to Nanotechnology (Paul Barrows)

May $20 \quad$ 09:00 - 09:50 Introduction to Clusters

Tuesday $\quad 10: 00-10: 50$ Nanocluster generation in the gas phase: molecular beam methods 11:00 - 11:50 Gas aggregation and laser vaporization 13:00 - 13:50 Mass spectrometry study of clusters: size distribution and magic numbers

14:00 - 14:50 Lab: laser vaporization, time-of-flight mass spectrometry, and photoelectron spectroscopy

May $21 \quad$ 09:00 - 09:50 Magic numbers in alkali clusters: the electron shell model

Wednesday 10:00-11:00 Photoionization of metal clusters: the metallic droplet model 11:00 - 11:50 Photoelectron spectroscopy and electronic structure of clusters 13:00 - 13:50 Photoelectron techniques and time-of-flight photoelectron analyzer 14:00 - 14:50 Molecular to bulk transition, nonmetal to metal transitions

May $22 \quad$ 09:00 - 09:50 Transition metal clusters and aluminum clusters

Thursday $\quad 10: 00-10: 50$ Oxide clusters 11:00 - 11:50 Novel clusters and molecules: from clusters to materials 13:00 - 13:50 Chemical reactivity of clusters and cluster surface analogy 14:00 - 14:50 Gold clusters, nano-particles, and special catalytic properties

May 23 09:00 - 09:50 Discovery of Buckyballs, and Properties of fullerenes and fullerites Friday 10:00 - 10:50 Carbon Nanotubes 11:00 - 11:50 Race to Catch a Buckyball: NOVA TV program on $\mathrm{C}_{60}$ 13:00 - 13:50 Synthesis and Properties of Nanowires (David McIlroy, U.I.) 14:00 - 14:50 Helical nanosprings (David McIlroy, U.I.)

\section{Second week:}

May $26 \quad$ 09:00 - 10:50 Magnetic nano-films and nanoparticles for use in information storage 
Monday

(Y. K. Hong, U. of Idaho)

11:00 - 11:50 Nanolithography and nanodevice transport (Chris Berven, U. I.)

13:00 - 14:50 Nanocluster-Assembled Materials: Synthesis, Magnetic Properties Applications (Y. Qiang, U. of Idaho)

15:20 - 17:00 Synthesis of Carbon Nanotubes and Nanowires (Lab: Hai-Feng Zhang)

May $27 \quad$ 09:00 - 09:50 Scanning electron mircoscopy (Jim Young)

Tuesday $\quad 10: 00-11: 50$ SEM of Nanotube samples (Jim Young)

13:00 - 13:50 Transmission electron microscopy (Chongmin Wang)

14:00 - 17:00 TEM of Nanotube samples (Chongmin Wang)

May $28 \quad$ 09:00 - 09:50 Molecular beam epitaxy (Scott Chambers)

Wednesday 10:00 - 10:50 MBE Lab (Scott Chamber)

11:00 - 11:50 X-ray photoelectron spectroscopy and application to materials

(Don Baer)

13:00 - 13:50 XPS Lab (Don Baer)

14:00 - 14:50 Optical Imaging (Holtom)

15:00 - 15:50 Single Molecule/imaging Lab (Holtom)

May $29 \quad$ 09:00 - 09:50 Unique optical properties of metallic nanoparticles (Peter

$\begin{array}{ll}\text { Thursday } \quad 10: 00-10: 50 & \text { Lu) } \\ \text { Scanning tunneling microscopy (Scott Lea) }\end{array}$

11:00-11:50 STM Lab (Scott Lea)

13:00 - 13:50 Nano-ice films (Jim Cowin)

14:00 - 14:50 Nano-ice film Lab (Jim Cowin)

May $30 \quad$ 09:00 - 09:50 Laser-Surface Interaction (Wayne Hess)

Friday $\quad 10: 00-10: 50 \quad$ Laser Surface Lab (Wayne Hess)

Class ends

\section{Grading:}

1. Assigned reading materials

2. Selected home works

3. A term paper to be turned in by end of summer: propose an experiment or idea relevant to nanomaterials and nanotechnology. Give background information, motivation, experimental design and proposed procedures, and expected outcomes. The paper can be an improvement or refinement of an existing idea or experiment from the literature. Total Length: 10-15 pages (12 point font, double space, 1-inch margin) for text, tables, figures/illustrations, and references.

Format:

1. Title, name 4. Background information

2. Abstract 5. experimental design and procedures

3. Objectives 6. expected outcomes and conclusions 


\section{D.2 Fabrication and Characterization of Nanomaterials}

\section{UW MSE 498/ MSE 599 (4 credits) \\ WSU}

January 5-23, 2004 (intensive short course)

In Richland, Washington

Coordinators: $\quad$ Prof. F. S. Ohuchi -UW, Dr. D. R. Baer -PNNL, Prof. L-S. Wang-WSU

Small projects for January nano-synthesis and characterization course. During week 1 of the course, three types of specimens will be synthesized. These will involve a nanofilm formed by $\mathrm{MBE}$, and oxide nanostructure, and a nanostructured solgel film. Each course participant will be directly involved with one of these synthesis activities. These activities will be lead by:

1) Nanofilm - Tim Droubay, Josh Williams

2) Oxide nanostructures - Theva Thevuthasan, Igor Lyubinetsky

3) SolGel Film, Lax Saraf.

The end of week 1 and week 2 will focus on characterization of the three nanostructures by five different methods. Each course participant will see each of the methods, but will focus on one. These teams will be led as follows:

1) Electron Spectroscopy - Mark Engelhard, Scott Lea, and Don Baer

2) Ion Beam methods - Theva Thevuthasan and Shutta Shutthanandan

3) X-ray Methods - Josh Williams and Dave McCready

4) TEM/SEM - Chongmin Wang and Jim Young

5) SPM Scott Lea and Igor Lyubinetsky.

The small project activity in week three will involve integration of the characterization methods to understand the nature of the synthesized materials. A series of synthesis or process questions will be posed at the start of the study as the objectives of the analyses. The students will prepare a report summarizing the results and make a short presentation on the final day of the course. 


\begin{tabular}{|c|c|}
\hline $1 \mathrm{pm}$ to $1: 50 \mathrm{pm}$ & $\begin{array}{l}\text { Day } 1 \text { January } 5 \text { (Monday) } \\
\text { Course introduction (Don Baer) }\end{array}$ \\
\hline $2 \mathrm{pm}$ to $2: 50 \mathrm{pm}$ & $\begin{array}{l}\text { Approaches, limitations \& Challenges to nanosystem formation (Don Baer and/or } \\
\text { Paul Burrows) }\end{array}$ \\
\hline $3 \mathrm{pm}$ to $4: 30 \mathrm{pm}$ & $\begin{array}{l}\text { Small-Project Descriptions and initial Reading Assignments } \\
\text { Synthesis Task leads: 1) Nanofilm - Tim Droubay, Josh Williams 2) Oxide } \\
\text { nanostructures - Theva Thevuthasan, Igor Lyubinetsky, 3) SolGel, Lax Saraf }\end{array}$ \\
\hline 7:pm to $8 \mathrm{pm}$ & $\begin{array}{l}\text { Nano Clusters Lecture I (L-S Wang) } \\
\text { Day } 2 \text { January } 6 \text { (Tuesday) }\end{array}$ \\
\hline 9:00 to $9: 30$ am & Quiz 1 \\
\hline $9: 40$ am to $10: 40 \mathrm{am}$ & Nano Clusters Lecture II (L-S Wang) \\
\hline 10:50 am 11:50 am & Lab visit - Nano Clusters \\
\hline $1 \mathrm{pm}$ to $1: 50 \mathrm{pm}$ & MBE Lecture I Films Chambers/Droubay \\
\hline $2 \mathrm{pm}$ to $2: 50 \mathrm{pm}$ & MBE lab tours \\
\hline $\begin{array}{l}3 \mathrm{pm} \text { to } 5: 00 \mathrm{pm} \\
7: \mathrm{pm} \text { to } 8 \mathrm{pm}\end{array}$ & $\begin{array}{l}\text { Film growth for small projects } \\
\text { MBE Nano-Films, MBE nanostructures, SolGel } \\
\text { MBE Lecture II - Nanostructures Thevuthasan/Lyubinetsky } \\
\text { Day } 3 \text { January } 7 \text { (Wednesday) }\end{array}$ \\
\hline 9:00 to $9: 30$ am & Quiz 2 \\
\hline $9: 40$ am to $10: 40 \mathrm{am}$ & Supramolecular Chemistry I Rafail Khairoutdinov \\
\hline 10:50 am 11:50 am & Supramolecular Chemistry II Rafail Khairoutdinov \\
\hline $1 \mathrm{pm}$ to $1: 50 \mathrm{pm}$ & XRD Lecture Josh Williams \\
\hline $2 \mathrm{pm}$ to $2: 50 \mathrm{pm}$ & XRD lab tour Dave McCready \\
\hline $3 \mathrm{pm}$ to $5: 00 \mathrm{pm}$ & $\begin{array}{l}\text { Synthesis activities and/or XRD analysis } \\
\text { Day } 4 \text { January } 8 \text { (Thursday) }\end{array}$ \\
\hline $\begin{array}{l}9: 00 \text { to } 9: 30 \text { am } \\
9: 40 \text { am to } 10: 40 \text { am }\end{array}$ & $\begin{array}{l}\text { quiz } 3 \\
\text { SEM Lecture Jim Young }\end{array}$ \\
\hline 10:50 am 11:50 am & TEM Lecture I Chongmin Wang \\
\hline $1 \mathrm{pm}$ to $1: 50 \mathrm{pm}$ & TEM Lecture II Chongmin Wang \\
\hline $2 \mathrm{pm}$ to $2: 50 \mathrm{pm}$ & Tour of SEM/TEM labs \\
\hline $3 \mathrm{pm}$ to $5: 00 \mathrm{pm}$ & XRD/Synthesis/Start TEM Cross section \\
\hline 7:pm to $8 \mathrm{pm}$ & $\begin{array}{l}\text { Scanning Probe Lecture } 1 \text { STM Lyubinetsky } \\
\text { Day } 5 \text { January } 9 \text { (Friday) }\end{array}$ \\
\hline $9: 00$ to $9: 30 \mathrm{am}$ & Quiz 4 \\
\hline $9: 40$ am to $10: 40 \mathrm{am}$ & Scanning Probe Lecture II Atomic Force Microscopy - Lea \\
\hline $10: 50$ am 11:50 am & SPM lab tours \\
\hline $1 \mathrm{pm}$ to $1: 50 \mathrm{pm}$ & Ion Beams I cluster formation - Thevusthasan and team \\
\hline $2 \mathrm{pm}$ to $2: 50 \mathrm{pm}$ & Ion Beam Analysis Shutta or Theva \\
\hline $3: 00 \mathrm{pm}$ to $4: 00 \mathrm{pm}$ & Accelerator Tour \\
\hline $4: 00 \mathrm{pm}$ & $\begin{array}{l}\text { Odds and ends - Sample prep/synthesis/XRD/TEM } \\
\text { Day } 6 \text { January } 12 \text { (Monday) }\end{array}$ \\
\hline 9:00 to $9: 30 \mathrm{am}$ & Quiz 5 \\
\hline $9: 40$ am to $10: 40 \mathrm{am}$ & XPS Don Baer and Mark Engelhard \\
\hline 10:50 am 11:50 am & AES - A. Scott Lea \\
\hline $1 \mathrm{pm}$ to $1: 50 \mathrm{pm}$ & XPS AES and SIMS lab tour \\
\hline & $\begin{array}{l}\text { Characterization Task/Project Activities Task Leads 1) XPS Mark and Don, 2) } \\
\text { RBS - Theva and Shutta, 3) XRD - Josh and Dave, 4) TEM/SEM - Chongmin and }\end{array}$ \\
\hline $2 \mathrm{pm}$ to $5: 00 \mathrm{pm}$ & Jim, 5) SPM Scott and Igor \\
\hline 7:pm to $8 \mathrm{pm}$ & AFM and SERS H. Peter Lu \\
\hline & Day 7 January 13 (Tuesday) \\
\hline $9: 00$ to $9: 30$ am & Quiz 6 \\
\hline $9: 40$ am to $10: 40 \mathrm{am}$ & CVD - Saraf or Aardahl \\
\hline
\end{tabular}




\begin{tabular}{|c|c|}
\hline 10:50 am 11:50 am & Carbon Nanotubes - Feng (Richard) Zheng \\
\hline $1 \mathrm{pm}$ to $1: 50 \mathrm{pm}$ & Self Assembly - SAMS Glen Fryxell \\
\hline $2 \mathrm{pm}$ to $2: 50 \mathrm{pm}$ & SAMMS Glen Fryxell and/colleagues \\
\hline $3 \mathrm{pm}$ to $5: 00 \mathrm{pm}$ & Characterization Activities \\
\hline 7:pm to $8 \mathrm{pm}$ & $\begin{array}{l}\text { Filaments, Nanosprings and Ribbons - Haifeng Zhang } \\
\text { Day } 8 \text { January } 14 \text { (Wednesday) }\end{array}$ \\
\hline $9: 00$ to $9: 30 \mathrm{am}$ & Quiz \\
\hline $9: 40$ am to $10: 40 \mathrm{am}$ & Single Enzyme Nanoparticles I JB KIM \\
\hline 10:50 am 11:50 am & Single Enzyme Nanoparticles II \\
\hline $1 \mathrm{pm}$ to $1: 50 \mathrm{pm}$ & Characterization Tasks - Coordinate with team leads \\
\hline & Day 9 January 15 (Thursday) \\
\hline 9:00 to $9: 30 \mathrm{am}$ & Quiz 7 \\
\hline $9: 40$ am to $10: 40 \mathrm{am}$ & Ballistic Deposition I - Kay or Dohnalak \\
\hline 10:50 am 11:50 am & Ballistic Deposition II \\
\hline $1 \mathrm{pm}$ to $1: 50 \mathrm{pm}$ & Ballistic Deposition Lab tour and Characterization Activities \\
\hline 7:pm to $8 \mathrm{pm}$ & Special Lecture? \\
\hline & Day 10 January 16 (Friday) \\
\hline $1 \mathrm{pm}$ to $1: 50 \mathrm{pm}$ & Visit UW nanotech center \\
\hline & Day 11 January 19 (Monday) \\
\hline $9: 00$ to $9: 30$ am & Quiz \\
\hline $9: 40$ am to $10: 40 \mathrm{am}$ & XAS measurements Pecher and Droubay \\
\hline 10:50 am 11:50 am & XAS II \\
\hline $1 \mathrm{pm}$ to $1: 50 \mathrm{pm}$ & Nano/Films Organic I Burrows \\
\hline $2 \mathrm{pm}$ to $2: 50 \mathrm{pm}$ & Nano Films Organic II \\
\hline $3 \mathrm{pm}$ to $4: 30 \mathrm{pm}$ & Particle Sizing and Counting - Pecher \\
\hline 7:pm to $8 \mathrm{pm}$ & Report preparation \\
\hline & Day 12 January 20 (Tuesday) \\
\hline $9: 40$ am to $10: 40 \mathrm{am}$ & Sol gel (Cao) \\
\hline 10:50 am 11:50 am & Electrochemical Etching - Lax Saraf \\
\hline $1 \mathrm{pm}$ to $1: 50 \mathrm{pm}$ & Sol gel (Cao) \\
\hline $2 \mathrm{pm}$ to $2: 50 \mathrm{pm}$ & Clean Room Visit? \\
\hline $3 \mathrm{pm}$ to $5: 00 \mathrm{pm}$ & Report and Presentation work \\
\hline 7:pm to $8 \mathrm{pm}$ & Report prep help session \\
\hline & Day 13 January 21 (Wednesday) \\
\hline $9: 00$ to $9: 30 \mathrm{am}$ & Quiz \\
\hline $9: 40$ am to $10: 40$ am & Particle Synthesis - Linehan \\
\hline 10:50 am 11:50 am & Nanoparticle Formation II \\
\hline $1 \mathrm{pm}$ to $1: 50 \mathrm{pm}$ & Project time \\
\hline & Day 14 January 22 (Thursday) \\
\hline $9: 40$ am to $10: 40 \mathrm{am}$ & NMR TBD \\
\hline 10:50 am 11:50 am & Magnetic Measurements Tim Droubay \\
\hline $1 \mathrm{pm}$ to $1: 50 \mathrm{pm}$ & Interface Defects, F. S. Ohuchi \\
\hline $2 \mathrm{pm}$ to $2: 50 \mathrm{pm}$ & Magnetic Nanoparticles I - You Qiang \\
\hline $3 \mathrm{pm}$ to $4: 30 \mathrm{pm}$ & Magnetic Nanoparticles II - You Qiang \\
\hline 7:pm to $8 \mathrm{pm}$ & Ohuchi's lecture (Interface Defects) discussion \\
\hline & Day 15 January 23 (Friday) \\
\hline $9: 00$ to $9: 30 \mathrm{am}$ & Final Report and Prep Preparation \\
\hline $10: 00$ to noon & Presentations on synthesis and characterization of three materi \\
\hline
\end{tabular}




\title{
D.3 Fabrication and Characterization of Nanomaterials
}

\author{
University of Washington-Pacific Northwest National \\ Laboratory-NSF Intensive Course in Nanoscience \\ September 16-20 Seattle WA \\ Several types of registration options
}

Title:

Theory and Modeling of Nanoscale Material Systems

Course Objective: To offer a theory perspective in areas related to the structure, stability, and functional characteristics of nanoscale materials, and the connection of this theory to physically based models and multiple scales (atomic, mesoscale, continuum). Primary emphasis will be on solid-state nanoscale materials such as quantum dots, self-assembled mono-layers, and thin films. The course will consist of lecture-type presentations on theoretical developments in the areas of synthesis, structure, and properties followed by guided hands-on investigation of specific application examples, culminating with an extensive individual project in one of the course topic areas.

Prerequisites: $\quad$ Exposure to basic statistical thermodynamics (e.g., PHYS 224, PHYS 328, PHYS 524, MSE 321, MSE 525, EE 539, Chem E 326, Chem E 525, ME 521, or CHEM 456) and introductory quantum mechanics (e.g., PHYS 225, Phys 315, PHYS 324, MSE 351, EE 482, MSE 565, EE 531, ME 522, or CHEM 455).

Instructor(s): $\quad$ Anter El-Azab (PNNL) \& Scott Dunham (UW)

Listing: UW EE 539N (Electrical Engineering, Topics in Solid State)

Location: UW campus, EE/CSE Building Room EE1 042

Time: 8:30am-5:30pm, Sept.16-20, plus follow-on project consultations, seminars.

Readings: $\quad$ Course packet with papers from literature plus course notes.

Student Evaluation: 4 short quizzes covering reading material and course content (20\%), 5 lab reports $(30 \%)$, project $(50 \%)$.

Registration: $\quad 3$ quarter credits, 2 semester credits (20 hours of lecture, 20 hours of lab/discussion plus consultations on project).

Lecture Content

- Important nanoscale systems and their novel properties (clusters, dots, films) (2 hours).

- Nucleation and growth: diffusion of atoms, nucleation theory, crystal growth (4 hours).

- Elastic (epitaxial and compositional) stresses and their distribution in model nanoscale systems; effects of stress on structure and properties of quantum dots and films (2 hours)

- Self-organization: morphological and compositional nanoscale pattern formation (2 hours).

- Atomic-scale theory of nanostructures (2hours).

- Computational modeling: structure and stability (molecular dynamics, multiscale approaches) (2 hours). 
- Mechanical, lattice dynamics, cluster properties (2 hours)

- Electronic/optical/magnetic properties of nanostructures (quantum effects) (4 hours)

Lab projects:

Lab \#1: Classical (continuum) nucleation and growth

Lab \#2: Formation of self-assembled arrays of III-V semiconductor quantum dots.

Lab \#3: Pattern formation in self-assembled alloy monolayers.

Lab \#4: Molecular dynamics simulations of material structure and properties.

Lab \#5: Quantum dots and Coulomb blockade devices.

Up to date and additional information can be found at www.nano.washington.edu/pnnl/courses.html while the registration site is http://www.engr.washington.edu/epp/nano/. 


\section{Appendix E}

\section{Joint Institute for Nanoscience Steering Committee and \\ Joint Institues Council of Fellows and Advisory Board}




\title{
Appendix E: JIN Organization
}

\author{
Joint Institute for Nanoscience Steering Committee: \\ From the University of Washington: \\ Charles Campbell (Co-Director) \\ Professor, Chemistry \\ Karl Bohringer \\ Associate Professor, Electrical Engineering \\ Samson Jenekhe \\ Professor, Chemical Engineering \\ Shaoyi Jiang (until fall 2003) \\ Associate Professor, Chemical Engineering \\ Younan Xia \\ Associate Professor, Chemistry \\ From Pacific Northwest National \\ Laboratory \\ Donald Baer (Co-Director) Fellow \\ Interfacial Chemistry and Engineering \\ Eric Ackerman, Staff Scientist \\ Protein Function \\ Paul Burrows, Fellow \\ Materials Chemistry and Surface Research \\ Bruce Kay, Fellow \\ Chemical Structure and Dynamics \\ H. Peter Lu, Senior Research Scientist \\ Chemical Structure and Dynamics
}

Miqin Zhang (starting fall 2003)

Assistant Professor, Materials Science and

Engineering

\section{Joint Institutes Council of Fellows (2001-2003):}

\section{University of Washington:}

Norman Dovichi

Professor of Chemistry

David Eaton

Associate Dean for Research, School of Public

Health and Community Medicine

Professor, Environmental and Occupational

Health Sciences

Edward Lazowska

Bill and Melinda Gates Chair, Computer

Science and Engineering

Viola Vogel

Director, Cente for Nanotechnology,

Bioengineering
PNNL:

Thomas Ackerman

Battelle Fellow, Atmospheric Chemistry

David Dixon

Battelle Fellow, Molecular Theory

Charles Peden

Laboratory Fellow, Heterogeneous Catalysis

Richard Smith

Battelle Fellow, Proteomics/Mass

Spectrometry 


\section{Joint Institutes Advisory Board Members (2001-2003)}

\section{University of Washington:}

Albert Berger

Associate Dean, Office of Research and

Graduate Education

Professor, Physiology and Biophysics

Denice Dee Denton

Dean, College of Engineering

Professor, Electrical Engineering

Craig Hogan

Vice Provost for Research, Office of the

Provost

Professor, Physics and Astronomy

Alvin Kwiram

Professor, Chemistry

Vice Provost for Research Emeritus

Marsha Landolt

Dean of Graduate School (deceased)
PNNL:

Walter Apley

Associate Laboratory Directory, Environmental Technology

Interim Laboratory Director (Dec 2002-April

2003)

John Bagley

Director of External Relations

Jean Futrell

Battelle Fellows, Chair PNNL Council of

Fellows

Michael Kluse

Associate Laboratory Director for National

Security

J.W. Rogers

Chief Research Officer and Director of EMSL 